Original Research Paper

\title{
Technical Buckling, Stress and Strain Simplified Analysis of Semi-Slender Thin-Walled Cylindrical Pinned Column
}

\author{
Krzysztof Murawski \\ Colleges and Universities, Independent Researcher, Poland
}

Article history

Received: 04-02-2021

Revised: 24-03-2021

Accepted: 13-04-2021

Email: k.murawski@interia.pl

\begin{abstract}
The stability of load-bearing members is a challenging issue for designers. The avoidance of possible stability troubles is a mandatory step of the overall design process. The paper presents and discusses two simplified methods based on the Technical Stability Theory (TSTh) of loss of stability of lateral buckling in elastic-plastic states of semi-slender columns axially compressed by force. It is assumed that in the critical elastic-plastic transverse cross-section there are the elastic and plastic parts of the area, keeping strength. To simplify the calculations, there are assumed the simplifications that the whole moment of inertia of a cross-section area is taken into account $J_{z}=J_{z}^{\text {all }}$, the plastic module equals compress module $E_{p l}=E_{c}$ taken from experimental researches and as the next bigger simplification, the plastic module equals compressing module $E_{p l}=0$. The graphs of functions of the curved axes, their slopes, deflections of the columns, stresses and strains in thin-walled columns and compressing critical stresses depending on the cross-section areas and slenderness ratios are presented as the theoretical examples of thin-walled cylindrical columns and compared to results obtained from experiments with columns made of steel St35.
\end{abstract}

Keywords: Stability, Buckling, Elastic-Plastic States, Semi-Slender, Column

\section{Introduction}

The problem of the stability was searched and analyzed with a focus on many other relevant aspects for various engineering applications.

Many research contributions were related to the stability issues of a multitude of load-bearing systems and members, including plates (Raheem et al., 2013; Hosseinpour et al., 2015; Hedayat et al., 2018; Than et al., 2018; Civalek and Avcar, 2020; Zhang et al., 2020) and bracing systems (Solazzi, 2010; Alencar et al., 2018; Mohabeddine et al., 2020), or Functionally Graded Material (FGM) structures (Sofiyev et al., 2008; Sofiyev and Avcar, 2010; Sofiyev et al., 2012; Nam et al., 2019; Cuong-Le et al., 2021), etc.

The buckling of beams was searched by (Maraveas et al., 2018; Wankhade and Bendine, 2017; Toufik et al., 2018; Mansour et al., 2019; Mondal and Chatterjee, 2021; Zaki, 2021) and microbeams (Demir and Civalek, 2017).

Single-layer graphene sheets have been examined in (), while polymer-confined concrete columns have been discussed in () and hyperelastic tubes are analyzed by ().

The buckling of structures composed of various constructional materials was searched by
(Broujerdian et al., 2018; Rostami and Kolahdooz, 2019; Esmaeili et al., 2020; Hassan and Al-Zaidee, 2020; Kilıç and Çinar, 2020; Taraghi et al., 2021).

In the case of very slender columns, this refers to the problem of stability in elastic states. The basic theory of slender columns losing stability in elastic states, as known, has been originally formulated by Euler (1744). He first introduced the concept of critical load $P_{c r}$ and presented, according to his theory, the differential equation of an elastic deflected central line. Later it was searched by many others like (Khalil, 2004; Noaman, 2011; Avcar, 2014; Melo and Barbosa, 2020; Selvaraj and Madhavan, 2021).

The stability phenomenon of semi slender columns in elastic-plastic states was researched too, by (Tetmajer, 1886; Jasiński, 1895; Engesser, 1889; Ostenfeld, 1898; Kármán, 1910; Shanley, 1947). This phenomenon was later researched by others.

Yiotis et al. (1982) presented a solution methodology for investigating the stability of rectangular box-shaped structures subjected to transverse uniformly distributed compressive loading. This investigation was concerned with the two-dimensional behavior of box-shaped structures of finite length which required an analysis of four interconnected plates. 
Nakashima et al. (1994) presented the results of a pilot test conducted for evaluating the energy dissipation behavior of shear panels made of low yield steel whose 0.2 per cent offset yield stress is $120 \mathrm{MPa}$. The six full-scale shear panels were tested with the loading condition, stiffener spacing and magnitude of axial force as test variables. The shear panels tested yielded by a shear force that was approximately $1 / 3$ of the yield shear force of equivalent shear panels made of common mild steel. Sufficient strain hardening was observed in the shear panels tested, with their energy dissipation capacity about 1.5 times larger than that of an equivalent linear-elastic and perfect-plastic system. Plate buckling did not lead the shear panels to immediate degradation in their energy dissipation capacity.

Brank et al. (1997) presented a large-deformation model for thin shells composed of elastic-plastic material. Formulation of the shell model, equivalent to the two-dimensional Cosserat continuum, was developed from the three-dimensional continuum by employing standard assumptions on the distribution of the displacement field in the shell body. An elastic-plastic constitutive model was developed based on the von Mises yield criterion and isotropic hardening.

Lepik (1999) considered a bifurcation of axially loaded elastic-plastic cylindrical shells in the case of an axisymmetric buckling. The effect of stress waves travelling along the shell was taken into account. It was assumed that the shell material had linear strain hardening. The analysis was carried out for both the deformation and for the flow theory of plasticity. The numerical examples were presented.

Papanastasiou and Durban (1999) presented a linear bifurcation analysis for pressure sensitive elastic-plastic hollow cylinders under radial surface loads. Material response was modeled by the flow and deformation theories of the Drucker-Prager solid accounting for arbitrary hardening. Sample calculations were given for cylinders that deformed in axially symmetric patterns under uniform radial pressure applied at the boundaries.

Dubina and Ungureanu (2000) dealt with the elasticplastic interactive buckling of thin-walled steel compression members. The interaction formula for local and overall buckling modes of Thin-Walled Steel Compression (TWSC) members, the effect of local buckling was introduced by means of the effective strength of short members.

Dabaon et al. (2001) presented the elastic stability analysis of a column with variable cross-section subjected to distributed and concentrated axial load.

Lilkova-Markova and Dzhupanov (2001) dealt with the dynamic stability of short continuous pipes conveying liquid and supported by elastic supports. The left end of the pipe was fixed. The pipe and the spring crossbars (supporting the pipe) were accomplished by homogeneous, isotropic and linearly elastic material. The liquid was non-compressible, inviscid and heavy. The Boundary Conditions (BC) on every one of the supports matched the elastica describing its continuity.

Milašinović et al. (2003) dealt with the buckling problem of steel columns using by Rheological-Dynamical Analogy (RDA).

Seyranian and Privalova (2003) dealt with the optimization and post-buckling behavior of columns elastically supported at both ends.

Alvarenga and Silveira (2006) presented a study about the necessary steps to qualify a second-order inelastic analysis as advanced one. A plastic-zone approach applied to steel plane frames (portals) and the numerical formulation was based on finite element model of a Bernoulli-Euler beam-column member called "slice technique". This element was set on a Lagrangian updated co-rotational system. The nonlinear problem was solved using Newton-Raphson iterative strategy and a new axial force iterative integration was shown.

D'Aniello et al. (2006) executed two full-scale experimental tests on the lateral load-displacement response of a Reinforced Concrete (RC) structure seismically retrofitted by buckling restrained braces. The results were compared to numerical modeling. The two tested buckling restrained braces differed for the lateral restraining system: One was made using two restraining rectangular tubes that were fully welded together; the second was detachable, made with two restraining rectangular tubes.

Lolov and Lilkova-Markova (2006) dealt with a dynamic stability of a curved pipe bent in the arc of a circle on the hinge supports at the ends. The authors investigated curved pipes conveying fluids. The methods of numerical solution of the dynamic stability of a pipe in its plane were developed. An example of a curved pipe was solved.

Fraldi et al. (2008) aimed at deriving assessment and design formulae for determining the elastic-plastic response and the ultimate compressive strength of circular concrete columns confined by the Fiber Reinforced Polymers (FRP). A constructive method for obtaining closed-form elastic and post-elastic solutions for Functionally Graded Material Cylinders (FGMCs), constituted by the isotropic central core and arbitrary cylindrically orthotropic hollow phases, was proposed.

Sanchez and Salas (2008) dealt with seismic ground motions causes large deformations of buried pipelines. They analyzed the steel straight pipes, for the purpose of clarifying the deformations of the pipes with internal pressure under large displacement and bending. The effect of internal pressure on the deformability of pipe was investigated both under load bending. Stress analysis using FEM was performed in order to simulate the large deformations of the pipes.

Voyiadjis and Woelke (2008) presented a finite element model for the elastic-plastic and damage 
analysis of thin and thick shells. Linear elastic, inelastic and softening behaviors caused by damage in structural shells, as well as large rotations were investigated. The presented formulation was developed primarily for large scale structural analyses. Special emphasis was therefore placed in computational efficiency.

Wahrhaftig et al. (2008) evaluated a buckling critical load of bars subjected to their self-weight. Wahrhaftig et al. (2016) executed a calculation of the natural frequency of vibration and the stability verification of a slender column including the reducing effects of stiffness both of the axial force and creep. Wahrhaftig et al. (2019) executed an analytical determination of the vibration frequencies and buckling loads of slender reinforced concrete towers. Wahrhaftig et al. (2020a) evaluated a limit state of stress and strain of free-fixed columns with variable geometry according to criteria from the Brazilian code for concrete structures. Wahrhaftig et al. (2020b) did an evaluation of mathematical solutions for the determination of buckling of columns under selfweight. Wahrhaftig (2020) did a time-dependent analysis of slender, tapered reinforced concrete columns. Wahrhaftig et al. (2021) made a stress assessment in reinforcement for columns with concrete creep and shrinkage through Brazilian technical normative.

Ismail (2011) provided an analysis of the dynamical behavior and stability of pipes conveying fluid. According to their dynamical similarity, pipes were divided into two main groups; conservative pipes including: Pinnedpinned, clamped-pinned and clamped-clamped pipes; and non-conservative pipes including: Cantilever, pinned-free and free-free pipes. The methods of solutions were checked either theoretically or experimentally by comparing their results with the available results in the literature. A new experimental method for estimating the critical velocity of buckling of conservative pipe was suggested.

Phungpaingam et al. (2011) presented an alternative model to analyze the postbuckling behavior of a hingedhinged column made from nonlinear material (i.e., Ludwick material). The continuous column was divided into several pieces of rigid segments connected with nonlinear spring joints. One end of the column was a hinged joint while the other end was placed on a roller support where an axial force was applied. The constitutive equation of nonlinear spring obeyed the law of the Ludwick's material involving a real number parameter $\mathrm{n}$ which defined the degree of nonlinearity.

Beylergil et al. (2012) studied the buckling and compressive failure of adhesively-bonded stepped-lap joints (with/without composite patches) composed of pultruded glass fiber-reinforced polymer. The composite laminates were investigated experimentally and numerically. Twocomponent epoxy adhesive was used for bonding purposes. Composite patches were woven glass-epoxy layer.

Abed et al. (2013) presented the Finite-Element (FE) study of the axial load capacity of pre-twisted steel bars of rectangular cross sections. The FE simulations were conducted using the software ABAQUS. The bar ends were gripped and embedded in cylindrical slips. Geometric imperfections as well as actual elastic-plastic behaviors had been implemented in nonlinear FE models. The column strengths, load-shortening curves as well as failure modes, were predicted. The FE model was initially verified by comparing the buckling capacity and mode of the simulated straight bars with the experiments and the AISC code.

Kambe et al. (2013) proposed a sandwich panel with plywood and steel members for a new structural member. They studied the compressive performance of that whole member and analyzed the buckling strength of thick plywood. They conducted compression tests with some slenderness ratio and experimental results were compared with some estimation methods like the Southwell-method, yield-strain-criterion, Euler's equation, yield-strain-criterion and Tetmajer-method.

Ananthi and Anbarasu (2015) studied a possibility of using built-up cold-formed steel columns composed of two lipped channels interconnected using a series of batten plates. Spacing between the channels was chosen such that moment of inertia around minor axis was twice the moment of inertia around major axis. They investigated on the compressive capacity of pin-ended cold-formed steel built-up sections using the finite element software ABAQUS. A nonlinear finite element model was developed and verified against theoretical and experimental results available in the literature. Ananthi et al. (2021) using the Finite Element Model (FEM) previously reported, a parametric study, comprising 132 models, described for stainless steel battened built-up columns. Two different grades of stainless steel, that is, austenitic EN1.4404 and ferritic EN1.4003 had been considered. The effects of slenderness, different cross-sectional geometries and batten depth were investigated.

Eissa et al. (2014) analyzed the work of a saturationbased active controller for vibration suppression of a four-degree-of-freedom rotor-AMB system.

Andreev and Tsybin (2015) gave the solution of the problem of the stability of a compressed rod with a variable cross-section.

Li et al. (2015) presented a novel scrimber composite. The attempts were made through theoretical analysis to predict the buckling stress of the column specimens under both elastic and inelastic buckling. In Fig. 9e they presented the graph of strains at midlength of a slender column and measured by strain gauges similarly like in Fig. $4 \mathrm{a}$ in the book (Murawski, 2011a; 2011b) and in Fig. 4 in the paper (Murawski and Kłos, 2007a-b) and in the doctor's thesis (Murawski, 1999) as well as in Rys.2 in the paper (Murawski, 1992).

Patel et al. (2015) dealt with High-strength thinwalled Concrete-Filled Steel Tubular (CFST) columns 
widely used in modern composite structures which might undergo local and global buckling. They presented accurate and robust numerical models for simulating the behavior of normal and high strength thin-walled CFST columns incorporating the important effects of local buckling and concrete confinement. It described the nonlinear analysis procedures and fundamental behavior of circular and rectangular CFST short and slender columns under various design actions.

Özbaşaran et al. (2015) presented an alternative design procedure for lateral-torsional buckling of the cantilever I-beams which aimed to simplify the calculation of critical loads and design moments. A closed-form equation was proposed to determine a critical lateral-torsional buckling load. The accuracy of the equation was validated through ABAQUS which. The tests were conducted on European IPE100 section cantilevers. The design procedure was presented for cantilever I-beams which considered elastic buckling, inelastic buckling and full plastic strength.

Al-Kamal (2016) presented the possible collapse mechanisms initiated by a precast flexural member dropping on a lower member. The analytical and numerical solutions were developed to solve three possible collapse scenarios: Perfectly plastic, inelastic and elastic. The analytical solution involves using Fourier series and the numerical solution involves a developed method of converting an initial velocity profile to an impulse load using SAP2000.

Jakab et al. (2016) focused on load-bearing glass columns and also on the design, the load-bearing capacity and the stability issues of fins. In Fig. 4 they presented the graph of strains set at mid-length of a slender glass column measured by strain gauges similarly like in Fig. 4a in the book Murawski (2011a; 2011b) and in Fig. 4 in the paper of Murawski and Kłos (2007a-b) and in the doctor's thesis Murawski (1999) as well as in Rys.2 in the paper Murawski (1992). They described this as: “... Fig. 4 indicates the loading force vs. strains on the glass surface. At the beginning both outer surface of the glass column is in compression after that, the compression starts to decrease at one outer glass surface and tensile stresses develop. The buckling process starts during this phenomenon", i.e., is according to the Technical Stability Theory (TSTh).

Kalamara et al. (2016) executed an experimental investigation for the structural performance assessment of square hollow glass columns.

Kukhar et al. (2016) formed gradient curve of temperature distribution of lengthwise of the billet by differentiated heating before profiling by buckling. They made an analysis of the main methods of forming control and differential heating of metal-forming processes. It is proved that impression-free methods of pre-profiling of billets for preliminary forming was rational to combine with their gradient heating that changed the plastic properties of the billet differently by the length.
Łukowicz et al. (2016) dealt with cold-formed steel sections as extensively affected the modern steel construction industry.

Megahed (2016) dealt with steel-concrete composite columns used in modern buildings. He investigated the behavior of pin-ended axially and eccentrically loaded concrete encased steel composite columns. The work was composed of structural design, experimental test and numerical analysis of concrete encased cold formed steel composite column composed of steel. The experimental program carried out on columns tested under uniaxial compression load. A total of thirteen specimens have been tested experimentally to failure.

Tarsha and Takla (2016) evaluated the ultimate load of composite columns "steel-concrete" having square or circular steel tubes filled hollow section with concrete. The reinforcing steel columns were subjected to a centrical load and exposed to the standard fire in accordance with ISO 834 from all sides. The thermal and mathematical analyses to evaluate the ultimate centrical load according to French National Annex of EN 1994-1-2 and comparing it with Euro code 4 Part 1.2 was the purpose of the research.

Abbas and Awazli (2017) developed a numerical model in a three-dimensional nonlinear finite element and then validated against experimental results reported in the literatures. They investigated the behavior of conventionally Reinforced Concrete (RC) columns subjected to axial load and lateral reversal cyclic loading. The numerical analysis was conducted by using finite element program ABAQUS/Explicit.

Abdel-Karim et al. (2017) proposed a model for the strength analysis of High-Strength Concrete (HSC) columns subjected to eccentric loading. The model was based on a stability analysis of pin-ended columns using the theoretical sinusoidal equation for the deflected shape of the column. The reduction in column stiffness as the axial load increases, representing the basic characteristic of the inelastic response of columns, was considered subject to equilibrium conditions, compatibility requirements and constitutive relationships for the concrete and reinforcement.

Ammash (2017) dealt with shape optimization of innovated cold-formed steel columns under uniaxial compressive loading.

Atteya et al. (2017) dealt with an axial load capacity and the stiffness of a rectangular Hollow Structural Section (HSS) of the steel tube. In Fig. 19 they presented the graphs of strains set at mid-length measured by strain gauge similarly like in Fig. 4a in the book Murawski (2011a; 2011b) and in Fig. 4 in the paper Murawski and Kłos (2007a-b) and in the doctor's thesis Murawski (1999) as well as in Rys.2 in the paper Murawski (1992). Those graphs showed the way of losing stability in accordance with the Technical Stability Theory.

Baru (2017) dealt with the buckling, as the most prominent failure mode of steel column stability as well as the structural stability of steel structures. 
Johnson et al. (2017) reported the results of a numerical and theoretical study of buckling phenomenon in elastic columns containing a line of holes.

Bedon and Amadio (2017) did a unified approach for the buckling verification of structural glass elements. In Bedon and Amadio (2018) they made a buckling analysis and design proposal for 2-side supported double Insulated Glass Units (IGUs) in compression.

Oliveira et al. (2017) studied the shear effect on the buckling of columns embedded in an elastic medium, evidencing the interaction of the column with the foundation.

Silvestre et al. (2018) studied the influence of the nature of the deformation mode (global, local and distortional) on the load carrying capacity of beams beyond the yield load. The five beams with different cross-sections, lengths, supports and loadings were analysed.

Słowiński and Piekarczyk (2017) dealt with a safe and economic design of steel cylindrical shells according to European Standard EN 1993-1-6 often requiring a nonlinear analysis. The plastic collapse load resulting from a materially nonlinear analysis was to be determined then in many cases. The authors used the modified Southwell plot and also the plot between the load factor increment and the arc length for an evaluation of the plastic collapse resistance of a steel cylindrical shell.

Abdulazeez et al. (2018) presented a numerical study on the behavior of Hollow-Core Fiber Reinforced Polymer-Concrete-Steel (HC-FCS) columns under combined axial compression and lateral loadings. The investigated HC-FCS columns consisted of an outer circular Fiber Reinforced Polymer (FRP) tube, an inner square steel tube and a concrete wall between them. Three-dimensional numerical models were developed and validated against experimental results. The presence of the concrete wall restrained by the outer FRP and inner steel tubes significantly affected the steel tube buckling.

Brasil and Wahrhaftig (2018) did an experimental evaluation of the effect of geometric nonlinearities on structural resonances.

Can et al. (2018) designed a novel crash box as a telescopic structure by joining coaxial tubes by using gradual bonding surface areas. The telescopic crash box was absorbed to impact energy by sequentially fracturing adhesive interfaces from the top tube to the back tubes. Frontal impact simulations were performed using Finite Element Method.

Isleem et al. (2018) dealt with experimental and analytical investigations of the stress-strain behavior of rectangular concrete columns externally confined with Carbon Fiber-Reinforced Polymer (CFRP) composites under axial compression loading. They presented the results of experimental tests on 28 larger-sized rectangular plain and Reinforced Concrete (RC) columns confined with CFRP wrap. An important finding of the study was that the internal longitudinal and hoop steel reinforcement influenced the shapes of the axial stressstrain envelope curves, the unloading and reloading paths and the plastic strain values.

Lilkova-Markova and Lolov (2018) investigated the problem of loss of stability of an axially compressed column. The column was fixed at one of its ends and on a transversal linear spring support at the other. The multi-segment integration technique has been applied for obtaining the critical force of the column. The results obtained showed the dependence of the critical force for the column on the rigidity of the spring support.

Massumi et al. (2018) matched the real behavior of the RC structures constructed based on the assumed specifications of the used materials. The lateral strength (plastic behaviors) and damage to twenty-five RC Moment-Resisting Frames (MRFs) were studied by applying the inelastic analysis. The obtained results indicated that there was a semi-linear relationship between the deviation in the strength of reinforcement and the changes in the lateral strength values of the MRFs.

Razdolsky (2018) focused on elastic stability analysis of battened columns and laced columns with crosswise, fir-shaped and serpentine lattices.

Saeed and Eissa (2018) analyzed bifurcations of periodic motion of a horizontally supported nonlinear Jeffcott-rotor system having a transversely cracked shaft. Saeed and Eissa (2019) did a bifurcation analysis of a transversely cracked nonlinear Jeffcott-rotor system at different resonance cases. Saeed (2019) did an analysis of vibration behavior and motion bifurcation of a nonlinear asymmetric rotating shaft. Next Saeed (2020) did an analysis of the steady-state forward and backward whirling motion of the asymmetric nonlinear rotor system and Saeed et al. (2020a) did a nonlinear dynamic analysis of the six-pole rotor-AMB system under two different control configurations. Later Saeed et al. (2020b) executed an analysis of radial versus Cartesian control strategies to stabilize the nonlinear whirling motion of the six-pole rotorAMBs and Saeed et al. (2020c) an analysis of periodic, quasi-periodic and chaotic motions diagnose a crack on a horizontally supported nonlinear rotor system. Next, Saeed et al. (2021a) made a sensitivity analysis and vibration control of asymmetric nonlinear rotating shaft system utilizing 4-pole AMBs as an actuator and Saeed et al. (2021b) did an analysis of the rub-impact forces between a controlled nonlinear rotating shaft system and the electromagnet pole legs.

Slimani et al. (2018) dealt with the concept of the effective length factor of columns representing an important parameter with regard to the elastic buckling analysis.

Thumrongvut and Tiwjantuk (2018) presented the experimental results on the strength and axial behavior of rectangular steel tube columns filled with Cellular Lightweight Concrete (CLC) under axial compression. A total of 24 specimens, including 6 Reinforced Cellular Lightweight Concrete (RCLC) columns and 18 cellular 
Lightweight Concrete-Filled Steel Tube (CLCFT) columns were investigated. The behavior of the columns was nonlinear due to the crushing of the concrete core and local wall buckling of the steel hollow tube.

Anuntasena et al. (2019) presented the 3D Finite Element (FE) analysis of the Concrete-Encased Steel (CES) columns subjected to concentric or eccentric loadings. A new simplified technique of FE modelling that incorporates the concrete confinement behavior of the composite columns was proposed. This technique eliminated the need of predefining zones and constitutive properties of the confined concrete.

Ivanov (2019) studied small vibrations of a cylindrical shaft caused by inertial excitation. The shaft was vertically situated. It was supported by a spherical and a cylindrical joint.

Krishan et al. (2019) presented a theoretical study of the structural resistance of compressed short concrete elements in a glass-fiber reinforced shell. The methodology was based on a nonlinear strain model of how this element reacts to incremental load in. The lateral pressure kept increasing due to changes in the concrete-core and glass fiber-reinforced shell lateralstrain coefficients, causing greater stress in the material.

Kudryavtsev (2019) presented the study of behavior of axially loaded columns that consisted of two flanges and a thin triangularly corrugated web, connected by automatic welding.

Nazarimofrad and Shokrgozar (2019) dealt with a Buckling-Restrained Braced frame (BRB) as the seismic force-resisting systems used in buildings. Nonlinear time history and incremental dynamic analysis techniques were applied to investigate the behavior of the two frames with different stories under different ground motion records.

Qi et al. (2019) dealt with the innovative pultruded Fiber Reinforced Polymer (FRP). Axial compression tests with both ends pinned were employed to investigate the columns under concentric load. Strain responses on specimens with different slenderness ratios were consistent with the observed failure modes. The courses of the values of the longitudinal strains in Fig. 10 correspond to the graph in Fig. 4 in the paper Murawski and Kłos (2007a-b) and in Fig. 4a Murawski (2011a; 2011b) - what confirm qualitatively the correctness of the Technical Stability Theory.

Roy et al. (2019) dealt with a built-up box section popular for column members in Cold-Formed Steel (CFS). The authors presented an experimental investigation on an axial capacity. Tests were conducted for different values of slenderness.

Simão et al. (2019) presented a study on the buckling behavior of slender steel columns under fire conditions, which depended on two main factors: The thermal elongation of the column and the degradation of the steel mechanical properties due to temperature rise. The column's mechanical behavior was based on a total potential energy formulation, considering an elastic-plastic law for steel and the member's kinematic description was performed by means of the Generalized Beam Theory.

Virgens et al. (2019) presented the experimental study of eccentrically loaded reinforced concrete columns with an added $35 \mathrm{~mm}$ self-compacting concrete jacket attached to the column's most compressed faces using wedge bolts. Nine columns with a $2000 \mathrm{~mm}$ height were tested under compression and one-way bending until failure.

Zhou et al. (2019) introduced the effective length factor and imperfection factor to the current stability factor formula to calculate the ultimate load of the lattice boom accurately.

Zucco et al. (2019) tested a $750 \times 640 \times 240 \mathrm{~mm}$ variablestiffness unitized integrated-stiffener out-of-autoclave thermoplastic composite wing-box for a combined shearbending-torsion induced buckling load. The experimental test results of the wing-box were also compared with the predictions made by a numerical study performed.

Abedini et al. (2020) focused on investigating blast load parameters to design of Reinforced Concrete (RC) columns to withstand blast detonation. The numerical model was based on finite element analysis using LSDYNA. The couples of simulations were performed with changing blast parameters to study the effects of various scaled distances on the nonlinear behavior of RC columns.

Ahiwale et al. (2020) dealt with a Concrete-Filled Tubular (CFT) structure consisted of high strength, favorable ductility, fire resistance and energy absorption. The twelve CFT columns had been tested under axial compression and they behavior had been studied in terms of axial load-carrying capacity, deflection and buckling effects.

Alomarah et al. (2020) dealt with auxetic structures exhibit Negative Poisson's Ratio (NPR). They presented a combined experimental and numerical investigation of the out-of-plane and in-plane performances of a Reentrant Chiral Auxetic (RCA), under quasi-static uniaxial compression. Deformation mode, stress-strain curves and energy absorption of the three types of structure were studied and compared.

Avci-Karatas (2020) dealt with a construction in areas of high earthquake intensity, extreme climates and blast loading. Considering the need for suitable analysis and design of mid-rise Reinforced Concrete (RC) buildings in hilly regions, the present deals with the evaluation of the response of a $\mathrm{G}+3$ building on a hilly area subjected to earthquake and wind.

Doan et al. (2020) dealt with a design of thin-walled composite columns. They provided an investigation based on a numerical study of the effects of the section dimensions, thickness ratio and slenderness ratio on the critical buckling load of a thin-walled composite strut under uniaxial compression. The linear and postbuckling behavior analysis was performed to verify the results of the numerical model with the obtained buckling load from the experiment. 
Goroshko et al. (2020) proposed a method of preventing the loss of Euler stability by thin rods.

Kiss (2020a) investigated the planar stability of fixedfixed shallow circular arches and Kiss (2020b) aimed to find the buckling loads for pinned-rotationally restrained shallow circular arches in terms of the rotational end stiffness, geometry and material distribution.

Naseri et al. (2020) presented an experimental study into the buckling behavior of Glass Fabric-Reinforced Polymer (GFRP) cylindrical shells subjected to axial compression load. The tests were conducted on six cylindrical shells with different height-to-radius ratios. It was concluded that the GFRP cylindrical shells showed the full-buckling strength and had local buckling failure mode.

Pinarbasi et al. (2020) dealt with the Turkish Building Code for Steel Structures replaced with a more rational Specification of Design and Construction of Steel Structures (SDCSS), which was prepared based on the American steel design specification (AISC 360-16). European steel design specification (EC3) was also widely used in Turkey. For various steel grades, member lengths and 153 different European I/H sections, design buckling resistances and design compressive strengths were computed and compared.

Qays and Al-Zuhairi (2020) discussed the idea of using slender Reinforced Concrete (RC) columns with a cross-shaped (+-shaped) instead of columns with squareshaped. The study explored the structural response of slender +-shaped columns experimentally and numerically by nonlinear finite element analysis using Abaqus simulation tools.

Rajkannu and Sanjeevi (2020) presented the details of an experimental and numerical study on the effect of warping on the Flexural-Torsional Buckling (FTB) behavior of axially loaded cold-formed steel lipped channel members.

Saberi et al. (2020) studied the cooperation of steel and concrete in composite columns.

Saingam et al. (2020) dealt with a seismically retrofitting Reinforced Concrete ( $\mathrm{RC}$ ) building with a combination of Buckling-Restrained Braces (BRBs) and elastic steel frames provided additional lateral stiffness and energy dissipation capacity. Numerical models considering the detailed composite behavior were developed and calibrated against quasi-static cyclic loading tests and a simplified evaluation method was proposed.

Terazawa et al. (2020) dealt with a grid-purlin system composed of RHS members known to be effective to prevent buckling of the welded beams. The lattice dome composed of radial beams and welded grid purlins (Grid purlin shell dome) were studied. The linear, elastic and elastic-plastic buckling strength of Grid purlin shell domes were analyzed using FEM analyses. Their results were compared with the shell theory with continuum analogy and easy design approaches were investigated.
Viana et al. (2020) addressed a corotational Lagrangian formulation for nonlinear dynamic analysis of steel planar frames. This formulation employed the Plastic Zone Method and is capable of considering second-order effects, initial geometric imperfections and residual stresses. The integration of stresses over the cross-section area was executed based on elasticperfectly plastic stress-strain curve.

Mehrabi et al. (2021) studied dynamic response and mechanical performance of fiber-reinforced concrete columns using hybrid numerical algorithms. Whereas test data had nonlinearity, an Artificial Intelligence (AI) algorithm had been incorporated with different metaheuristic algorithms. Adaptive Neuro-Fuzzy Inference System (ANFIS) was carried out as an AI beside the combination of Particle Swarm Optimization (PSO) and Genetic Algorithm (GA).

Besides, there was done the literature review of semi-slender, thin-walled column stability (Murawski, 2008a-e; 2020a-c).

\section{Stability Experimental Research of Semi-Slender, Thin-Walled Column}

There were executed the experimental researches of the columns made of steel (Murawski, 2011a; 2011b; 2017a; 2020a; 2020b) compressed by ball-and-socket joints with friction (Fig. 1).

Figure 2 presents the curve $\sigma(\varepsilon)$ and Fig. 3 the graphs of the curved axis $y(x)$ and its slope $d y / d x$ of the cylindrical thin-walled specimen $\phi 45 \times 1 \times 545$ with dimensions $R=22 \mathrm{~mm}, t=1 \mathrm{~mm}, L=545 \mathrm{~mm}$ and the slenderness ratio $\lambda=35$, made of steel St 35 , compressed through ball-and-socket joints with friction.

\section{Stability Analysis}

The author assumed in his own analysis of very slender column TSTh (Murawski, 1992; 1999; 2002a-b; 2003a-d; 2004a-f; 2005; 2007a-b; 2011a-c; 2017b; 2018; 2019) that the loss of the stability occurs already at a minimum load and the loss of carrying capacity follows the exit of the force line from the critical cross-section.

Consistently according to this Technical Stability Theory (TSTh) the state of stresses in the critical crosssection, after the loss of stability and before the loss of carrying capacity, results of the superimposition of pure compression and bending as well as the external shear forces are not present. In this theory is assumed that internal shear forces appearing as the reaction to bending of the column may be missed. Consistently the shear stresses are missed too (Fig. 4 and 5).

Hence, in the elastic states, the surely loss of stability, as the conservative assumption in an engineering practice, follows the entry of the resultant neutral layer in the critical transverse section, however here is assumed the loss of carrying capacity following the exit of the force line from 
the critical cross-section. Therefore, the normal strain $\varepsilon_{n}$ of any fibre at the distance $y$ from the central layer of very slender columns in elastic states is (Murawski, 2004b; 2004d; 2011a; 2011b; 2017b; 2018; 2019):

$\varepsilon_{n}=\frac{ \pm(\rho+y) \cdot \theta-\rho \cdot \theta}{\rho \cdot \theta}= \pm \frac{y}{\rho}$,

Where:

$\rho$ : Denotes the radius of the curved central line

$\theta$. The angle of the central line slope, in relation to the force line

The normal stress in this fibre equals:

$\varepsilon_{n}=\sigma_{g}-\sigma_{c}= \pm \frac{y}{\rho} \cdot E-\frac{P}{A}$,

Where:

$E$ : Denotes the Young's modulus of elasticity of a column

$\varepsilon_{n}$ : Represents the normal stress

$\sigma_{g}$ : The bending stress

$\sigma_{c}$ : The compressive stress

$P$ : The imposed axial force

$A$ : The area of the critical cross-section

Assuming, unlike Euler, that the displacement of the column axis is determined by the small deformation theory and due to the forces equilibrium (Murawski, 2003d; 2004b; 2004d; 2011a; 2011b; 2017b; 2018; 2019), that is:

$$
\frac{1}{\rho} \cong \frac{d^{2} y}{d x^{2}}, d P=\left(\sigma_{g}+\sigma_{c}\right) \cdot d A=\left( \pm \frac{y}{\rho} \cdot E-\frac{P}{A}\right) \cdot d A .
$$

After integrating were obtained the differential equation of the elastic line in the elastic states and in the elastic-plastic states.

On the assumption that the state of strains is the result of a superposition of bending and pure compression the state of strains is as follows:

$$
\begin{aligned}
& \varepsilon_{n} \cdot E=\sigma_{n}=\sigma_{g}+\sigma_{c}= \pm \frac{y}{\rho} \cdot E-\frac{P}{A} \\
& =E \cdot\left( \pm \frac{y}{\rho}-\frac{\Delta L}{L}\right)=E \cdot\left( \pm \varepsilon_{g}-\varepsilon_{c}\right)=>
\end{aligned}
$$

with:

$=>\varepsilon_{n}= \pm \varepsilon_{g}-\varepsilon_{c}$.

Where:

$\varepsilon_{g}$ : Denotes the bending strain

$\varepsilon_{c}$ : The compressive strain

From the equilibrium of the moments for symmetric transverse cross-section profiles, the formulas of the normal stress in the elastic state $\sigma_{n}^{e l}(x, y)$ (Murawski, 2018) and in the elastic-plastic states $\sigma_{n}{ }^{e l-p l}(x, y)$ were obtained.

The formulas of $\varepsilon_{n}^{e l}, \sigma_{y}^{e l}$ and $\varepsilon_{y}^{e l}$ in the elastic state are as follows:

$$
\begin{aligned}
& \varepsilon_{n}^{e l}(x, y)=\frac{\sigma_{n}^{e l}(x, y)}{E}, \\
& \sigma_{n}^{e l}(x, y)=-\sigma_{n}^{e l}(x, y) \cdot v, \\
& \varepsilon_{y}^{e l}(x, y)=-\varepsilon_{n}^{e l}(x, y) \cdot v
\end{aligned}
$$

Where:

$\sigma_{y}$ : Denotes the orthogonal stress

$\varepsilon_{y}$ : The orthogonal strain

For columns axially compressed by ball-and-socket joints (Fig. 4 and 5) without friction, with the boundary conditions: $d y / d x=0$ when $x=L / 2$ and $y=0$ when $x=$ 0 , the equations of the slope in the elastic state $(d y / d x)^{e l}$ (Murawski, 2011a; 2011b; 2018) and in the elastic-plastic states $(d y / d x)^{e l-p l}$ as well as the elastic line in the elastic state $y(x)^{e l}$ (Murawski, 2011a; 2011b) and in the elastic-plastic states $y(x)^{e l-p l}$ after integrating were obtained.

For the column pinned at both ends, the equations of the maximal deflection, in the critical cross-section $x=L / 2$, in the elastic state $y(P)^{e l}{ }_{x=L / 2}$ (Murawski $2011 \mathrm{a} ; 2011 \mathrm{~b} ; 2018)$ as well as in the elastic-plastic states $y(P)^{e l-p l}{ }_{x=L / 2}$ were obtained.

Figure 6a shows the curve, stress $\sigma$ - strain $\varepsilon$, obtained from the tensile test with determined Young's modulus $E$, secant modulus $E_{s}$ and tangent modulus $E_{t}$.

When the position of the force line determines (Fig. $6 \mathrm{~b})$ the middle radius of the thin-walled column $R$ and angle $\omega$ - the coordinate of this line equals:

$y_{P}(\omega)=R \cdot \cos \omega$.

When the position of the plastic zone determines (Fig. 6b) the middle radius of the thin-walled column $R$ and angle $\alpha$ - the coordinate of the plastic zone border is:

$y_{p l}(\omega)=R \cdot \cos \alpha$.

For the cylindrical thin-walled column, according to Fig. $6 \mathrm{~b}$ the plastic and elastic areas, static moments and moments of inertia of elastic and plastic areas of the critical transverse cross-section in dependence on the angle $\alpha$ were determined.

Figure 7 shows how various with a slenderness ratio $\lambda$ the curves, stress $\sigma$ - strain $\varepsilon$ obtained from the compressive tests, with determined compress modulus $E_{c}$ and secant compress modulus $E_{s c}$ for thin-walled columns in elasticplastic states. It was assumed that in the elastic transverse cross-section area $A^{e l}$, with the static moment $S_{z}^{e l}$, there is 
the elastic Young's module $E>0$ and in the plastic transverse cross-section area $A^{p l}$, with the static moment $S_{z}^{p l}$, the plastic module equals compressing module $E_{p l}=E_{c}$.

On the assumption that in the critical elastic-plastic transverse cross-section area, strength keep both parts, i.e., elastic and plastic and by simplifications that whole moment of inertia of a cross-section area is taken into account $J_{z}=J_{z}^{\text {all }}$, the equation of the elastic lines $y(x)^{e l}$, elastic slopes $(d y / d x)^{e l}$ (Fig. 8) and function of maximal deflection $y_{L / 2}(P)^{e l}$ in the elastic state (Fig. 9), for the cylindrical column in the elastic states with both pinned ends, according to Murawski (2018), were determined.

On the assumption that the loss of carrying capacity occurs when the line of forces gets into the plastic zone (what is the simplification and what would be true for $E_{p l}$ $=0$, Fig. 6b):

$\alpha=\alpha_{c r} \Leftrightarrow \alpha=\omega$

for a critical situation (when $\alpha=\omega=\alpha_{c r}$ ) the equation of the central elastic-plastic line $y(x)_{c r}{ }^{e l-p l}$, its elastic-plastic slopes $(d y / d x)_{c r}{ }^{e l-p l}$ (Fig. 8) and equation of maximal elasticplastic deflection $y_{L / 2}(P)^{e l-p l}$ (Fig. 9) of the central line for the cylindrical column in the elastic-plastic states with both pinned ends at the critical situation were determined.

Figures 8 and 9 present the stability analysis: the elastic line $y(x)$, its slope $d y / d x$ and dependence $y_{L / 2}(P)$ with $E_{p l}=E_{c}$ of the cylindrical column made of St35 with $R=22 \mathrm{~mm}, t=1 \mathrm{~mm}, L=545 \mathrm{~mm}$ compressed by ball-and-socket joints without friction $(E=202768,28$ $\mathrm{MPa}$ was assumed). On the base of the assumption that the angle of the plastic zone depends directly proportionally on the slenderness ratio:

$$
\alpha_{c r}=\frac{\lambda_{e l_{-} l t}-\lambda}{\lambda_{e l_{-} l t}} \cdot \frac{\pi}{2}
$$

The moments of inertia of those plastic areas of the critical transverse cross-section were neglected, what was the simplification. Figure 10 presents the surface functions of the cylindrical thin-walled half-column as the theoretical example.

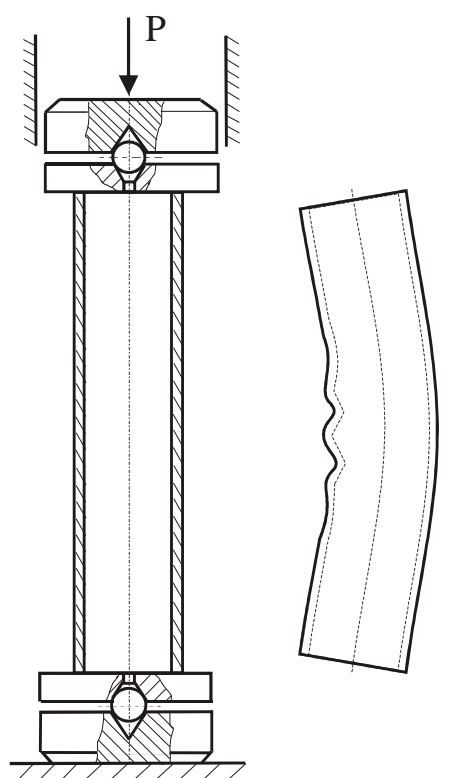

Fig. 1: Guidance and the fixing of the specimen during the compression through ball-and-socket joints with friction and the characteristic form of lateral buckling of the semi-slender cylindrical column in elastic-plastic states (Murawski, 2011a; 2011b; 2020)

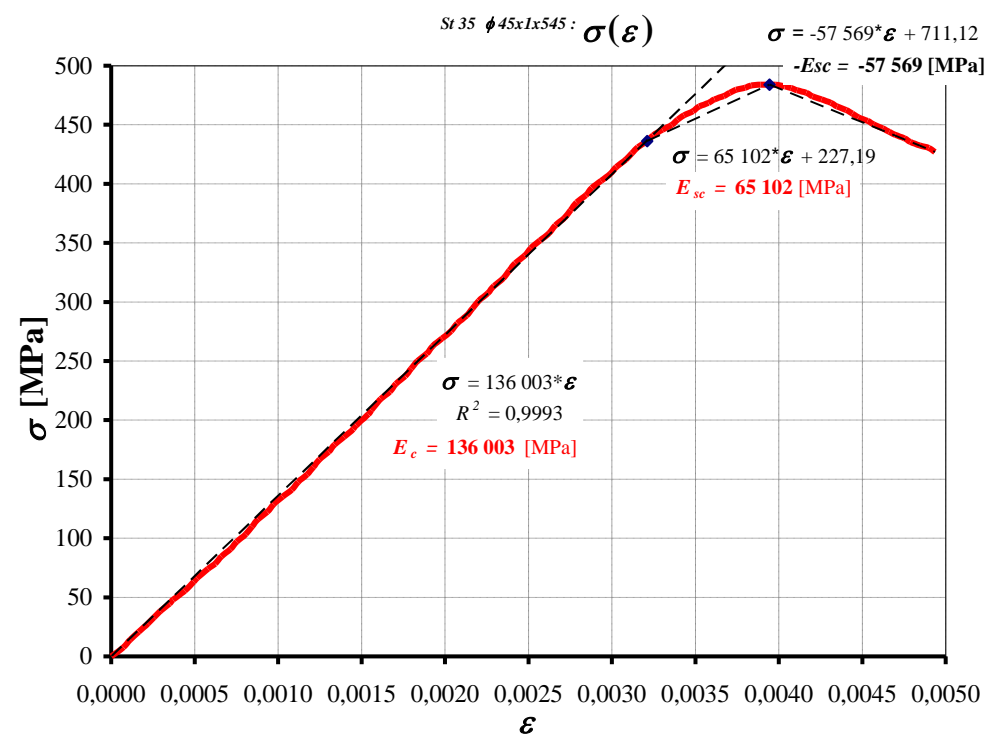

Fig. 2: Curve $\sigma(\varepsilon)$ of the specimen with dimensions $\phi 45 \times 1 \times 545$ and the slenderness ratio $\lambda=35$, made of steel St 35 , compressed through ball-and-socket joints with friction 

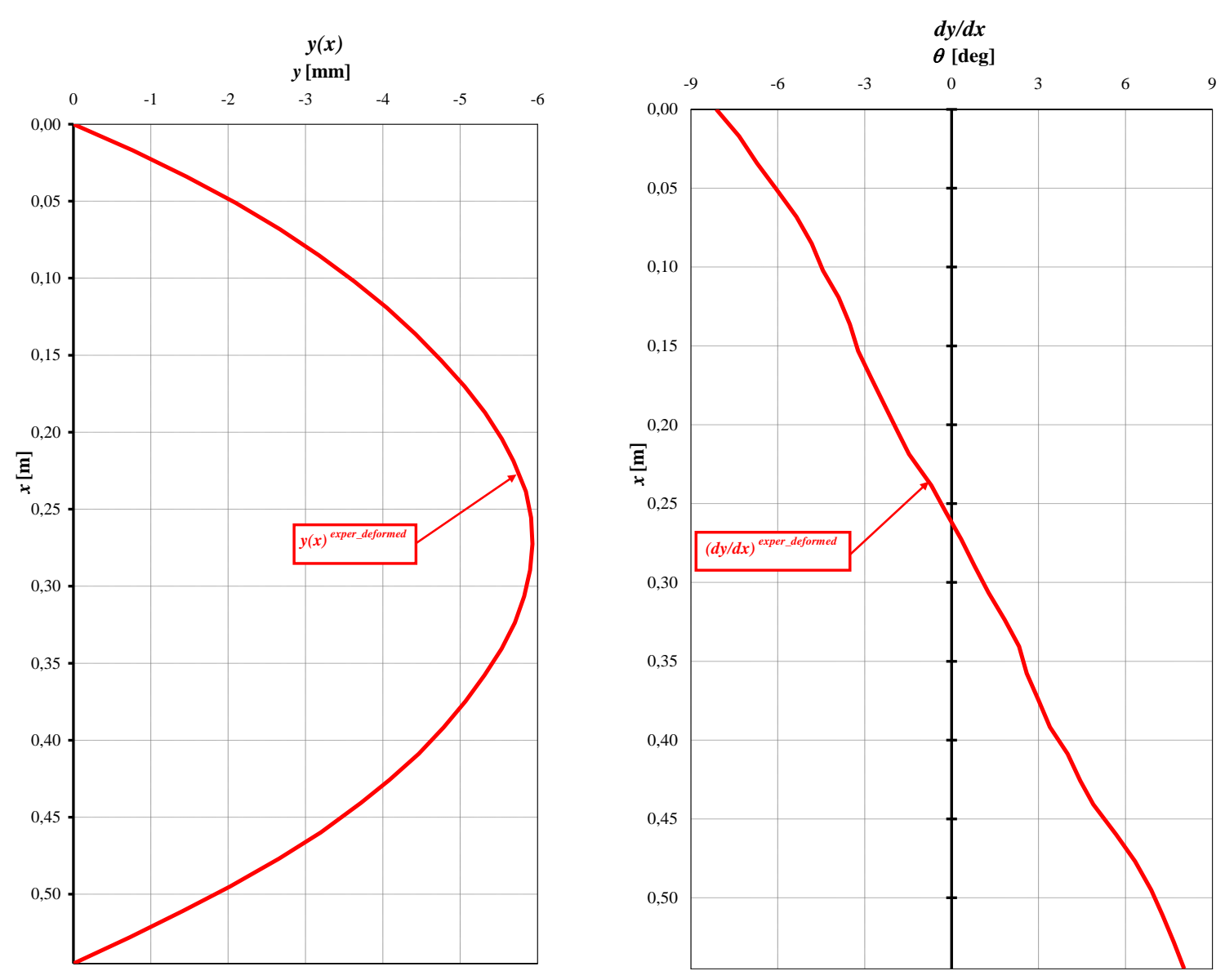

Fig. 3: Experimental graphs of the: (a) Curved axis $y(x)$ and (b) its slope $d y / d x$ of the cylindrical column made of St 35 with $R=22$ $\mathrm{mm}, t=1 \mathrm{~mm}, L=545 \mathrm{~mm}$ compressed by ball-and-socket joints without friction.
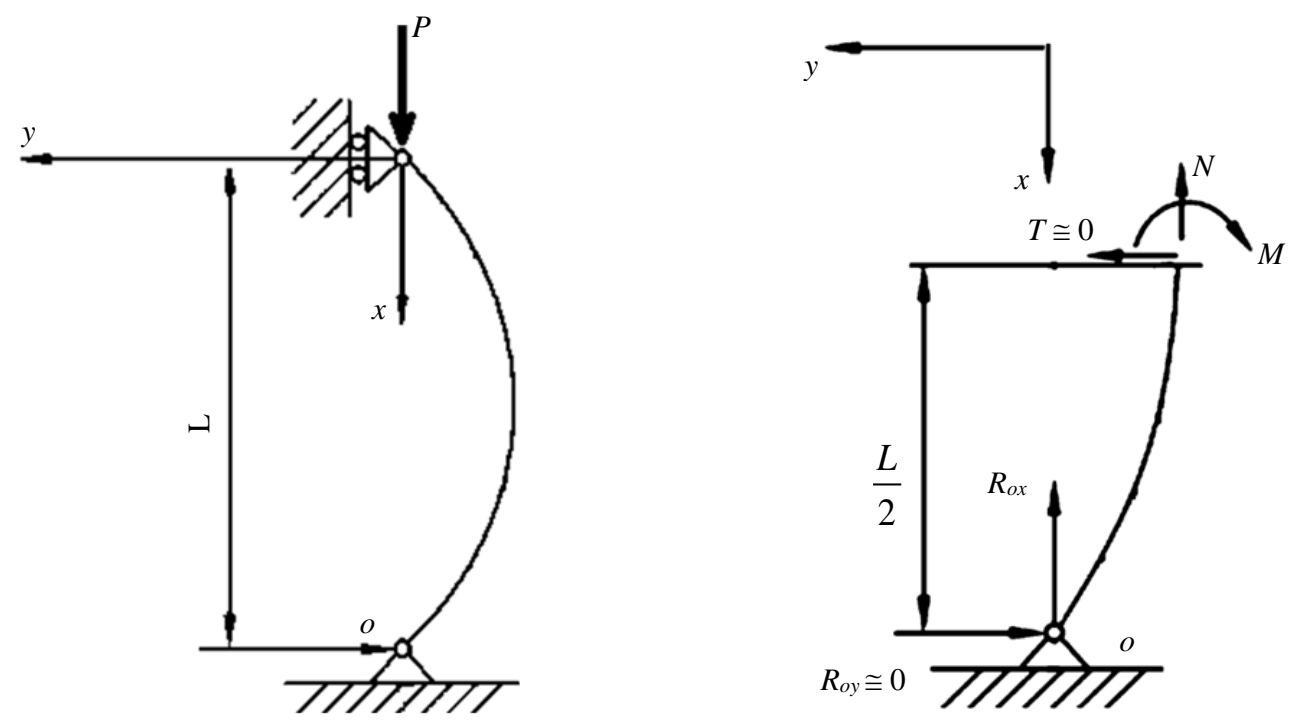

Fig. 4: Schematic figure (a) and the scheme of forces (b) in the critical transverse cross-section for a pinned slender column 


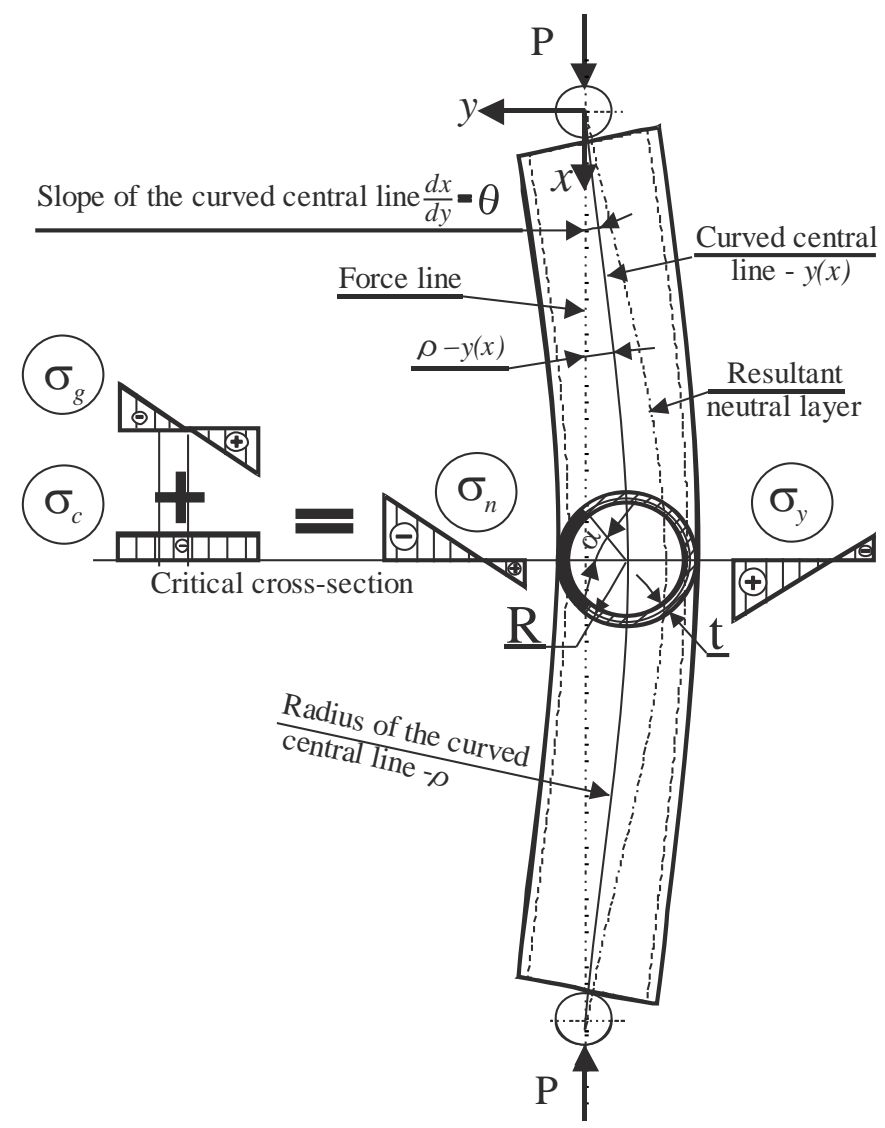

Fig. 5: Stresses in the critical transverse section of a pinned cylindrical column axially compressed after the loss of stability, according to the TSTh (Murawski, 2003c; 2004b)

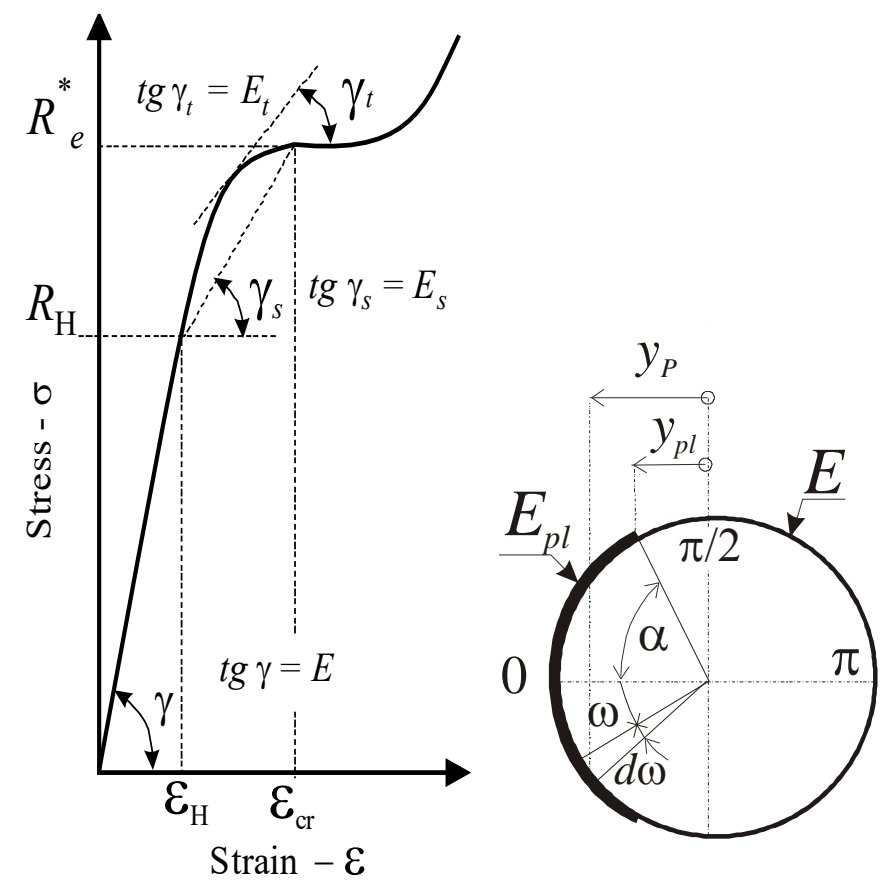

Fig. 6: Young's modulus $E$, tangent modulus $E_{t}$ and secant modulus $E_{s}$ during tension (a) (Murawski, 1992; 1999; 2002a; 2002b; 2003a) and the critical cross-section at the moment of the loss of stability of a cylindrical column in elastic-plastic states (b) 


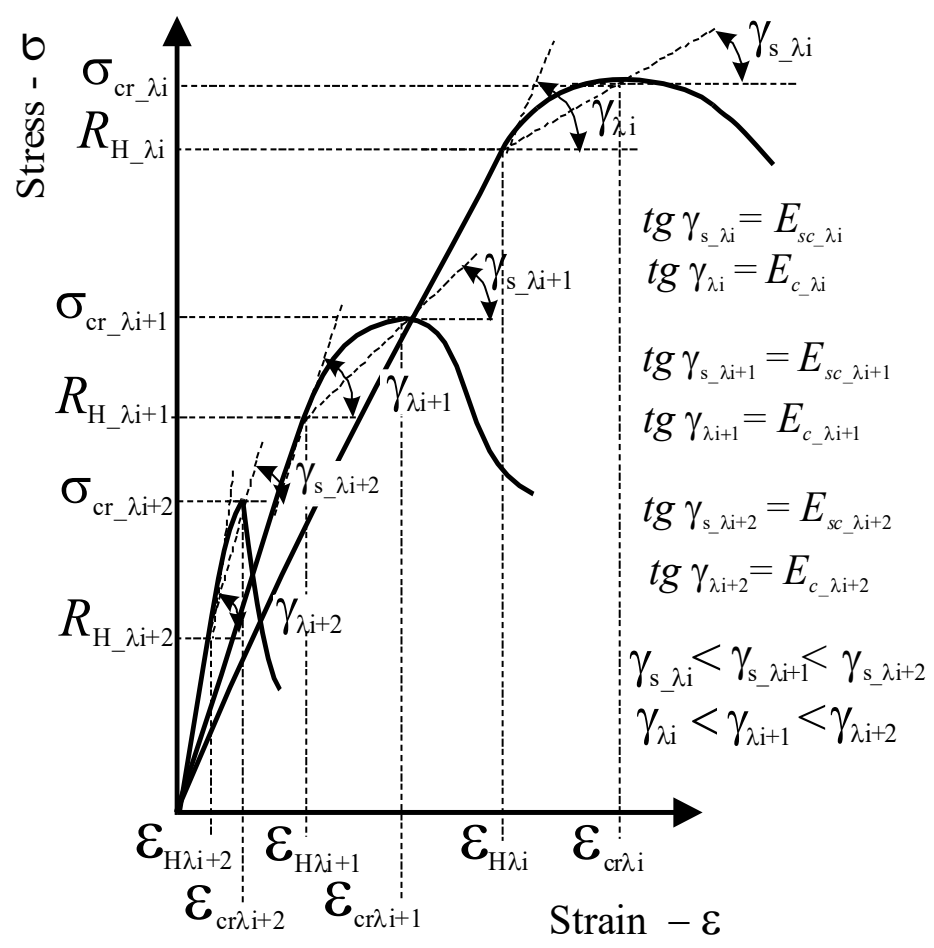

Fig. 7: Compress modulus $E_{c}$ and secant compress modulus $E_{s c}$ for thin-walled columns in elastic-plastic states (Murawski, 2020b, Fig. 25)
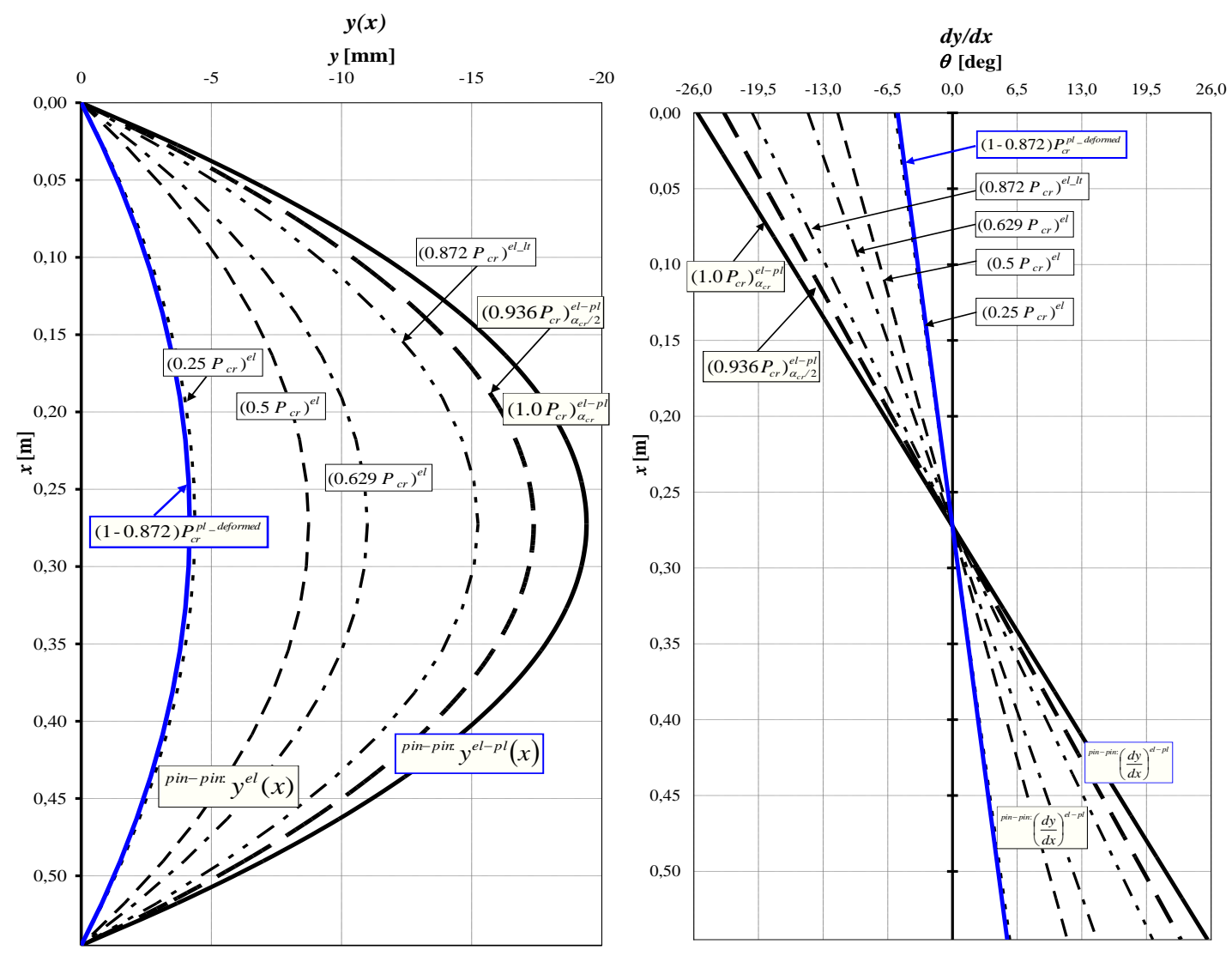

Fig. 8: Graphs of the: (a) Curved axis $y(x)$ and (b) its slope $d y / d x$ with $E p l=E_{c}$ of the cylindrical column made of St 35 with $\mathrm{R}=22$ $\mathrm{mm}, \mathrm{t}=1 \mathrm{~mm}, \mathrm{~L}=545 \mathrm{~mm}$ compressed by ball-and-socket joints without friction 


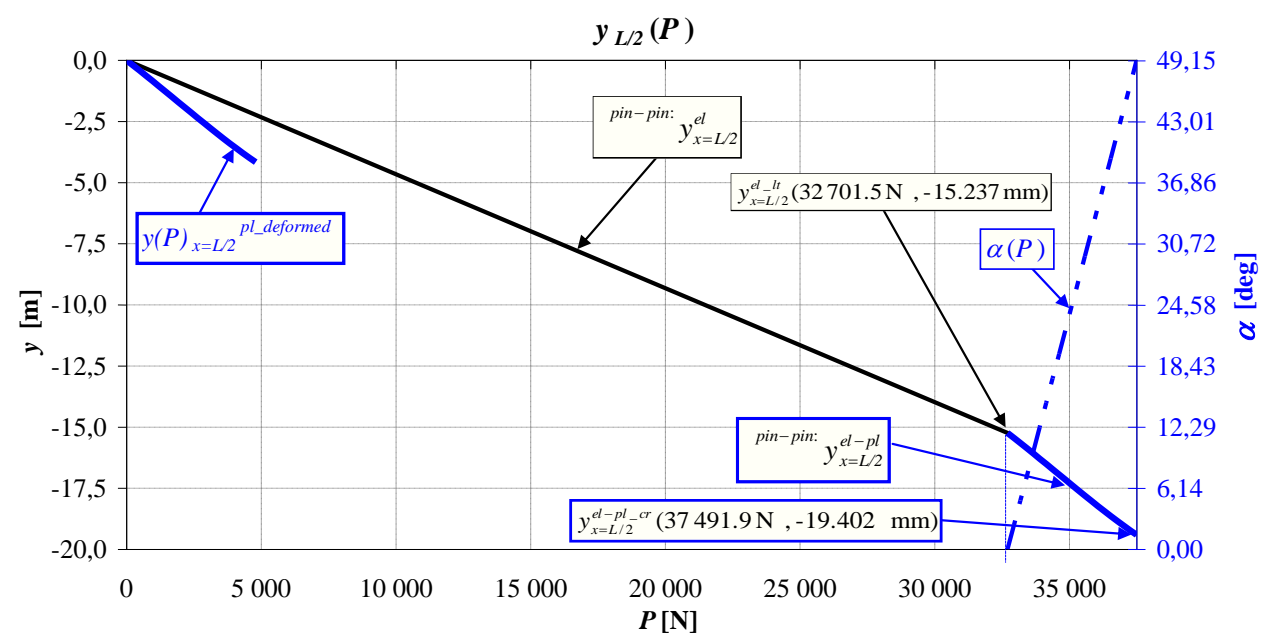

Fig. 9: Graph of the function $y L / 2(P)$ with $E p l=E_{c}$ of the cylindrical column made of steel St 35 with $\mathrm{R}=22 \mathrm{~mm}, \mathrm{t}=1 \mathrm{~mm}, \mathrm{~L}=545$ $\mathrm{mm}$ compressed by ball-and-socket joints without friction

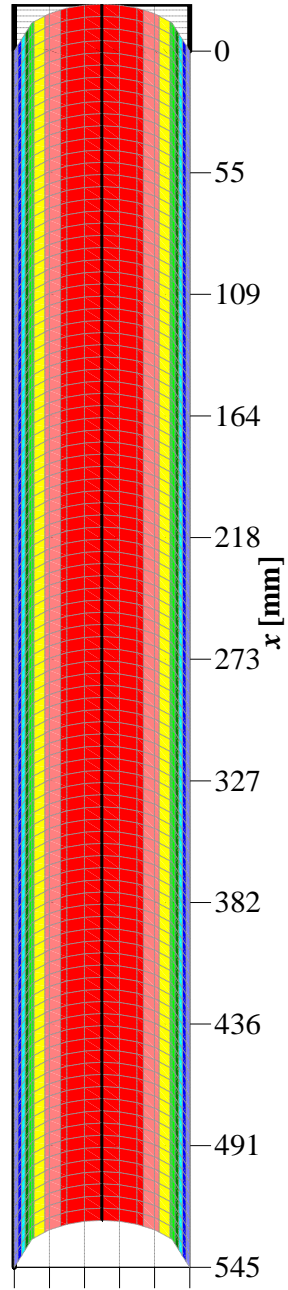

$-22-13-4 \quad 41322$

$y[\mathrm{~mm}]$

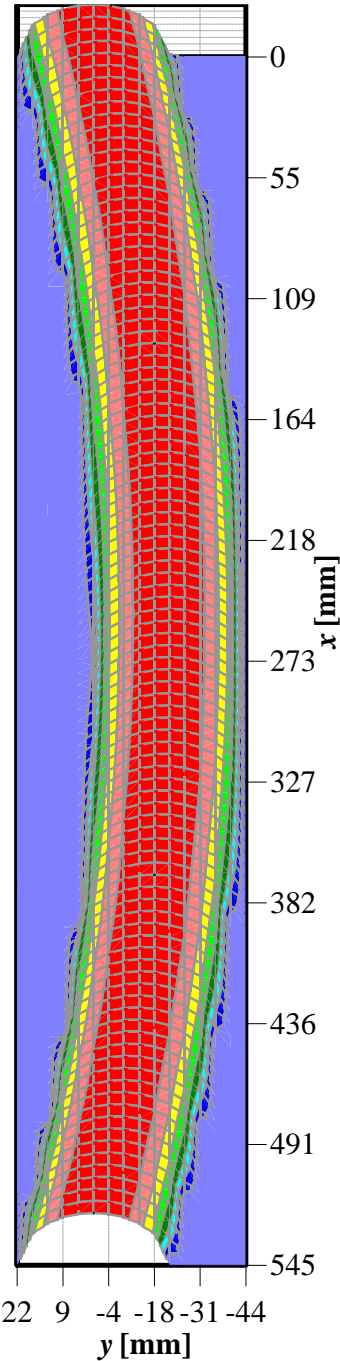

273

382

36

91

45 $\boldsymbol{y}[\mathrm{mm}]$

Fig. 10: Surface functions of the pinned cylindrical thin-walled half-column: (a) straight, (b) buckled 


\section{Stress and Strain Analysis}

Like in the stress analysis, the author assumed the state of strains as the result of the superposition of bending and of pure compression-Fig. 11 (Murawski, 2003d; 2004b; 2004d; 2011a; 2011b; 2017b; 2018; 2019). From the equilibrium of moments, the normal shell stresses $\sigma_{n}^{e l}(x, y)$ in the thin-walled cylindrical column pinned at both ends, without friction in the elastic state, depending on $x$ and $y$, were taken from (Murawski, 2018) and, taking into account the conditions of the elastic-plastic states, the normal shell stresses $\sigma_{n}^{\text {el-pl }}(x, y)$ depending on the plastic angle $\alpha$ were determined, too.

From the assumption that the limit of the elastic state follows the exit the force line from the elastic zone in the critical transverse cross-section, the compressing elastic limited stress in the elastic state $\sigma_{l t}^{e l}$ was determined.

On the assumption that the critical situation follows the entrance of the force line into the plastic zone, where the normal stress equals the yield stress $\left(\sigma_{n}=R_{e}^{*}\right.$ - determined like in Murawski, 2020c, Fig. 16), the compressive critical stress $\sigma(\alpha)_{c r}{ }^{e l-p l}$ in the elastic-plastic states for the cylindrical column, with the plastic zone determined by the middle radius of the thin-walled column $R$ and angle $\alpha$ in the critical cross-section, was determined with a simplification that in a critical transverse cross-section, the coordinate of line of forces equals the coordinate of the plastic zone border $\alpha=\omega=\alpha_{c r}\left(\right.$ true for $\left.E_{p l}=0\right)$ :

$$
y_{c r}(\alpha)=R \cdot \cos \alpha_{c r},
$$

Where:

$\alpha_{c r}$ : Denotes the angle coordinate of a plastic zone boundary, while

$\omega$ : Angle coordinate of an external force line, like in Eq. (9)

On the base of the assumption that the angle of the plastic zone $\alpha$ depends directly proportionally on the slenderness ratio-Eq. (12), the normal shell stresses $\sigma_{n}^{c r}(x, y)$ in the thin-walled cylindrical column pinned without friction at both ends, in the critical state, depending on the coordinates $x$ and $y$ and slenderness ratio, were determined, as well as the critical compressing stress $\sigma(\lambda)_{c r}{ }^{e l-p l}$, when in the plastic zone the normal stress got the yield stress $\left(\sigma_{n}=R_{e}^{*}\right)$.

On the assumption that in the critical elastic-plastic transverse cross-section area keep a resistance both parts, i.e., elastic and plastic (in the elastic transverse crosssection area $A^{e l}$, with the static moment $S_{z}^{e l}$, there is the elastic Young's module $E>0$ and in the plastic transverse cross-section area $A^{p l}$, with the static moment $S_{z}^{p l}$, the plastic module equals compressing module $E_{p l}=E_{c}$ ), with simplification that in elastic-plastic states the moment of inertia is taken of whole transverse critical cross-section $J_{z}=J_{z}^{\text {all }}$, the graphs of the stresses $\sigma_{n}$, $\sigma_{y}(x, y)$, strains $\varepsilon_{n}, \varepsilon_{y}(x, y)$ and extensions $\Delta L, \Delta 2 t(x, y)$ with $E_{p l}=E_{c}=118115,5 \mathrm{MPa}$ and $J_{z}=J_{z}{ }^{a l l}$ for $x=0 \div L$ and $y$ $= \pm 0.2 \div 1.0 R$ in the pinned cylindrical column made of steel St35 with dimensions: $R=22 \mathrm{~mm}, t=1 \mathrm{~mm}, L=545$ $\mathrm{mm}$ compressed for the column with both pinned ends in the elastic-plastic states, are presented in Fig. $12 \div 23$ as the theoretical example.

From Fig. 12a and 12c for the analyzed case of compression with $P=0.25 \cdot P_{c r}=9373.0 \mathrm{~N}$ and bending, computed with $E_{p l}=E_{c}$, results that the courses of the normal stresses $\sigma_{n}(x, y)$, strains $\varepsilon_{n}(x, y)$ and extensions $\Delta L(x, y)$ are symmetrical in relation to the layer with geometrical axis, in which the stresses are equal to the pure compressive stresses $(R=0)$, but their values are bigger on the concave side. The values of the transverse strains $\varepsilon_{n}$ are analogous to the course of normal stresses $\sigma_{n}$, but with values decreased by the inverse $1 / E$ - of Young's modulus. All values have the minus signs (are negative), i.e., all fibers are compressed and shortened.

From Fig. 12b and 12d results that the courses of the transverse stresses $\sigma_{y}(x, y)$, strains $\varepsilon_{y}(x, y)$ and extensions $\Delta 2 t(x, y)$, orthogonal to the normal stresses, strains and extensions, are also symmetrical in relation to the layer with geometrical axis $(R=0)$ with values bigger on the concave side but with the plus signs (are positive), what proves the existence of the tension in the transverse direction, orthogonal to the longitudinal axis. The values of the transverse stresses $\sigma_{y}$ are decreased by Poisson's ratio $\lambda$. The values of the strains $\varepsilon_{y}$ are decreased by Poisson's ratio $-v$.

From Fig. 13a, 13c for the analyzed case of compression with $P=0.5 \cdot P_{c r}=18745.9 \mathrm{~N}$ and bending, computed with $E_{p l}=E_{c}$, results that the courses of the normal stresses $\sigma_{n}(x, y)$, strains $\varepsilon_{n}(x, y)$ and extensions $\Delta L(x, y)$ are symmetrical in relation to the layer with geometrical axis, in which the stresses are equal to the pure compressive stresses $(R=0)$, but their values are bigger on the concave side. The values of the transverse strains $\sigma_{n}$ are analogous to the course of normal stresses $\varepsilon_{n}$. All values have the minus signs (are negative), i.e., all fibers are compressed and shortened.

From Fig. 13b and 13d results that the courses of the transverse stresses $\sigma_{y}(x, y)$, strains $\varepsilon_{y}(x, y)$ and extensions $\Delta 2 t(x, y)$, orthogonal to the normal stresses, strains and extensions, are also symmetrical in relation to the layer with geometrical axis $(R=0)$ with values bigger on the concave side but with the plus signs (are positive), what proves the existence of the tension in the transverse direction, orthogonal to the longitudinal axis.

From Fig. 14a and $14 \mathrm{c}$ for the analyzed case of compression with $P=0.629 \cdot P_{c r}=23595.5 \mathrm{~N}$ and bending, computed with $E_{p l}=E_{c}$, results that the courses 
of the normal stresses $\sigma_{y}(x, y)$, strains $\varepsilon_{y}(x, y)$ and extensions $\Delta L(x, y)$ are symmetrical in relation to the layer with geometrical axis, in which the stresses are equal to the pure compressive stresses $(R=0)$, but their values are bigger on the concave side. All values, except the edge fibre on the convex side, have the minus signs (are negative), i.e., all fibers are compressed and shortened, except the edge fibre, which is unloaded and unextended.

From Fig. $14 \mathrm{~b}$ and $14 \mathrm{~d}$ results that the courses of the transverse stresses $\sigma_{y}(x, y)$, strains $\varepsilon_{y}(x, y)$ and extensions $\Delta 2 t(x, y)$, orthogonal to the normal stresses, strains and extensions, are also symmetrical in relation to the layer with geometrical axis $(R=0)$ with values bigger on the concave side but with the plus signs. The edge fibre also is unloaded and unextended.

From Fig. $15 \mathrm{a}$ and $15 \mathrm{c}$ for the analyzed case of compression with $P=0.872 \cdot P c r=32701.53 \mathrm{~N}$ and bending, computed with $E p l=E c$, results that the courses of the normal stresses $\sigma n(x, y)$, strains $\varepsilon n(x, y)$ and extensions $\Delta L(x, y)$ are symmetrical in relation to the layer with geometrical axis $(R=0)$, in which the stresses are equal to the pure compressive stresses, but their values are bigger on the concave side. The values have the minus signs (are negative) in the internal fibers on the concave side-i.e., fibers are compressed and shortened and the plus signs are (positive) on the opposite convex side-fibers are tensed and extended. All fibers are in the elastic state yet.

From Fig. $15 \mathrm{~b}$ and $15 \mathrm{~d}$ results that the courses of the transverse stresses $\sigma y(x, y)$, strains $\varepsilon y(x, y)$ and extensions $\Delta 2 t(x, y)$, orthogonal to the normal stresses, strains and extensions, are also symmetrical in relation to the layer with geometrical axis $(R=0)$ with values bigger on the concave side but with the plus signs (are positive) of the tension in the transverse direction. The values have the plus signs (are positive) in the transverse internal fibers on the concave side - i.e., fibers are tensed and extended and the minus signs (are negative) on the opposite convex side-fibers are compressed and shortened. All fibers are in the elastic state yet.

From Fig. 16a and 16c for the analyzed case of compression with $P=0.936 \cdot P_{c r}=35096.7 \mathrm{~N}$ and bending, computed with $E_{p l}=E_{c}$, results that the courses of the normal stresses $\sigma_{n}(x, y)$, strains $\varepsilon_{n}(x, y)$ and extensions $\Delta L(x, y)$ are symmetrical in relation to the layer with geometrical axis $(R=0)$, in which the stresses are equal to the pure compressive stresses, but their values are bigger on the concave side. The values have the minus signs (are negative) in the internal fibers on the concave side -i.e., fibers are compressed and shortened and the plus signs are (positive) on the opposite convex side-fibers are tensed and extended. A part of fibers are in the plastic state. The angle of plastic area is $\alpha=\alpha_{c r} / 2=24.60 \mathrm{deg}$.
From Fig. 16b and 16d results that the courses of the transverse stresses $\sigma_{y}(x, y)$, strains $\varepsilon_{y}(x, y)$ and extensions $\Delta 2 t(x, y)$, orthogonal to the normal stresses, strains and extensions, are also symmetrical in relation to the layer with geometrical axis $(R=0)$ with values bigger on the concave side but with the plus signs (are positive) of the tension in the transverse direction. The values have the plus signs (are positive) in the transverse internal fibers on the concave side-i.e., fibers are tensed and extended and the minus signs (are negative) on the opposite convex side-fibers are compressed and shortened. A part of fibers are in the plastic state. The angle of plastic area is $\alpha=\alpha_{c r} / 2=24.60 \mathrm{deg}$.

From Fig. $17 \mathrm{a}$ and $17 \mathrm{c}$ for the analyzed case of compression with $P=1.0 \cdot P_{c r}=37491.88 \mathrm{~N}$ and bending results, computed with $E_{p l}=E_{c}$, that the courses of the normal stresses $\sigma_{n}(x, y)$, strains $\varepsilon_{n}(x, y)$ and extensions $\Delta L(x, y)$ are symmetrical in relation to the layer with geometrical axis $(R=0)$, in which the stresses are equal to the pure compressive stresses, but their values are bigger on the concave side. The values have the minus signs (are negative) in the internal fibers on the concave side-i.e., fibers are compressed and shortened and the plus signs are (positive) on the opposite convex side-fibers are tensed and extended. A part of fibers are in the plastic state. The angle of plastic area is $\alpha=\alpha_{c r}=49.20 \mathrm{deg}$.

From Fig. $17 \mathrm{~b}$ and $17 \mathrm{~d}$ results that the courses of the transverse stresses $\sigma_{y}(x, y)$, strains $\varepsilon_{y}(x, y)$ and extensions $\Delta 2 t(x, y)$, orthogonal to the normal stresses, strains and extensions, are also symmetrical in relation to the layer with geometrical axis $(R=0)$ with values bigger on the concave side but with the plus signs (are positive) of the tension in the transverse direction. The values have the plus signs (are positive) in the transverse internal fibers on the concave side-i.e., fibers are tensed and extended and the minus signs (are negative) on the opposite convex side-fibers are compressed and shortened. A part of fibers are in the plastic state. The angle of plastic area is $\alpha=\alpha_{c r}=49.20 \mathrm{deg}$.

Figure 18 and 19 show the surface functions of the normal stresses $\sigma_{n}(x, y)$ in the cylindrical pinned column made of steel St35 with dimensions: $R=22 \mathrm{~mm}, t=1$ $\mathrm{mm}, L=545 \mathrm{~mm}$ loaded with the force $P_{c r}=37491.88 \mathrm{~N}$ and computed with $E_{p l}=E_{c}$.

Figure 20 shows the surface functions of the normal stresses $\sigma_{n}(x, y) \quad[\mathrm{MPa}]$, strains $\varepsilon_{n}$ and extensions $\Delta L$ [mm], related to the straight and Fig. 21 -related to the buckled, cylindrical column, loaded with the force $P_{c r}=$ $37491.88 \mathrm{~N}$ and computed with $E_{p l}=E_{c}$.

Figure 22 shows the surface functions of the transverse stresses $\sigma_{y}[\mathrm{MPa}]$, strains $\varepsilon_{y}$ and extensions $\Delta 2 t[\mathrm{~mm}]$ related to the straight and Fig. 23 -related to the buckled, cylindrical column, loaded with the force $P_{c r}$ $=37491.88 \mathrm{~N}$ and computed with $E_{p l}=E_{c}$. 


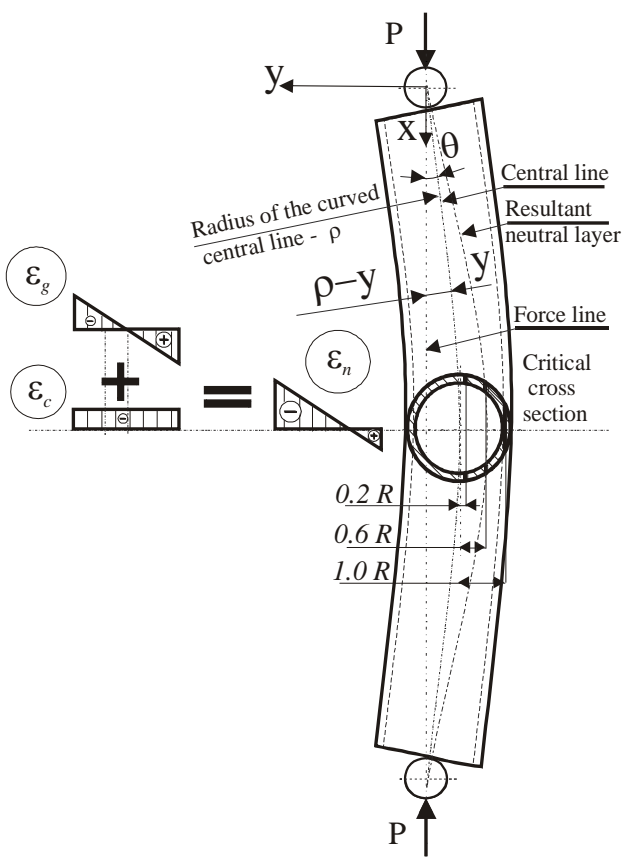

Fig. 11: Strains in the critical transverse section of a cylindrical column axially compressed by ball-and-socket joints, after the loss of stability and before the loss of carrying capacity, according to the author's own hypothesis (Murawski, 2003d; 2004b)

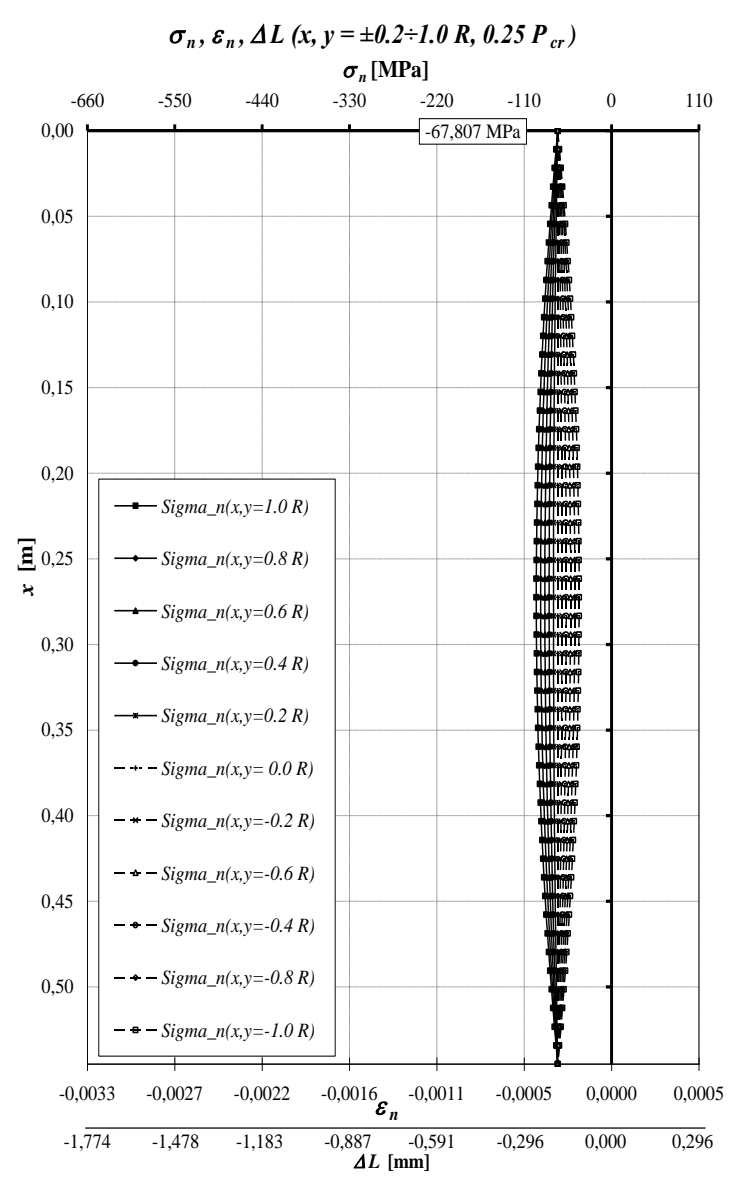

(a)

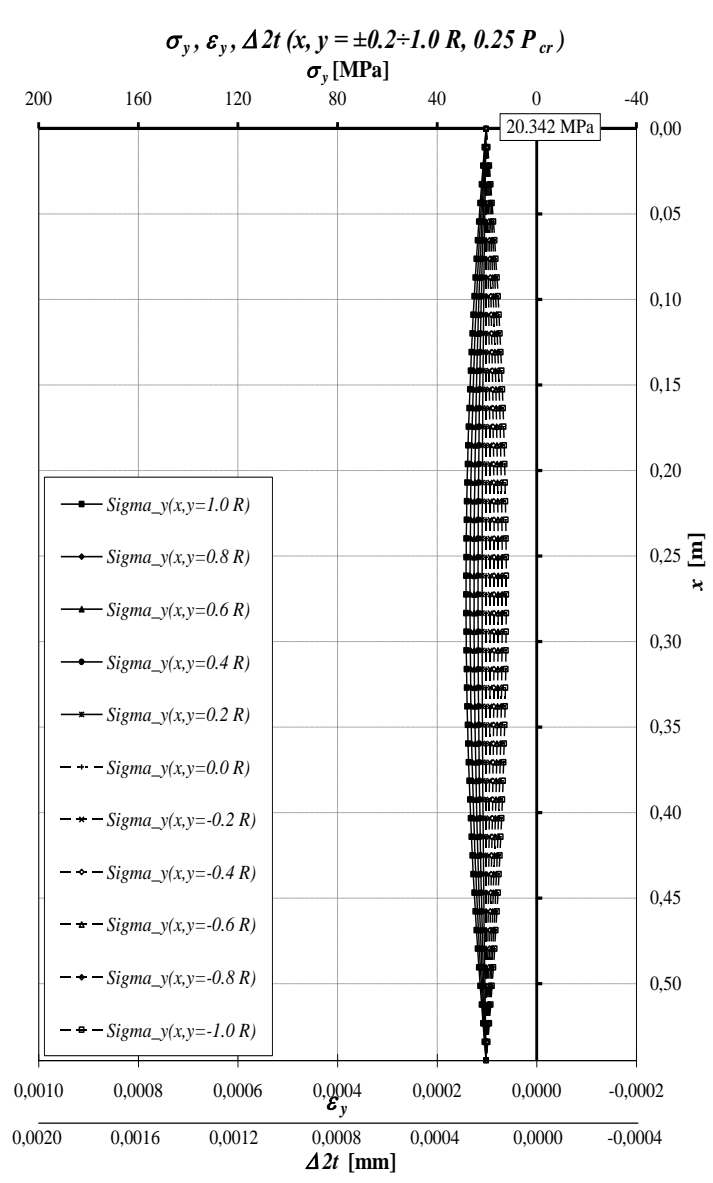

(b) 
Krzysztof Murawski / International Journal of Structural Glass and Advanced Materials Research 2021, Volume 5: 134.194 DOI: 10.3844/sgamrsp.2021.134.194

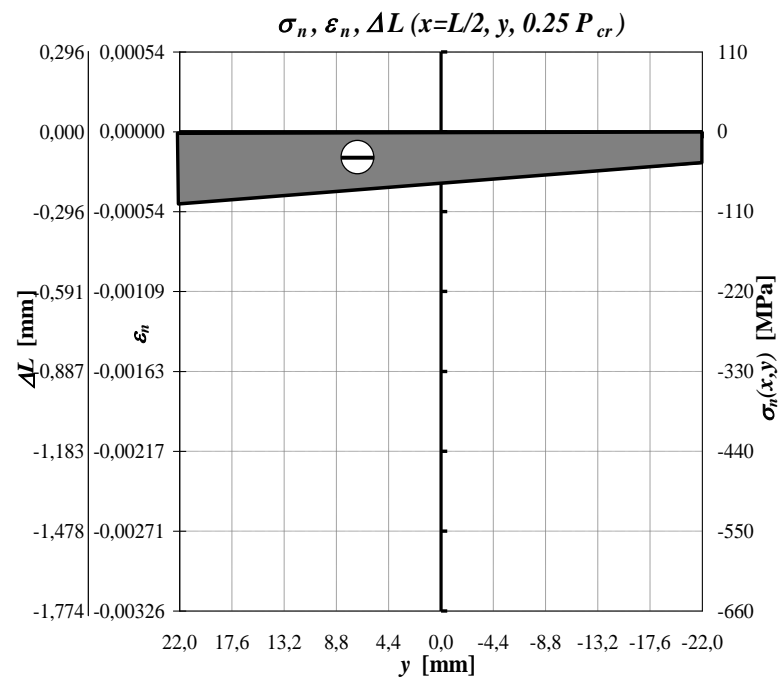

(c)

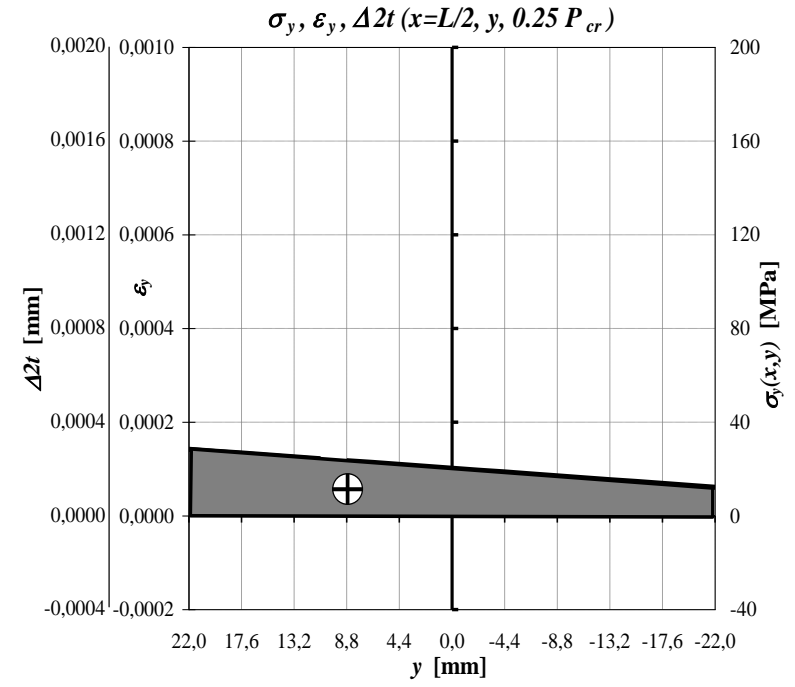

(d)

Fig. 12: Values of the stresses $\sigma_{n}, \varepsilon_{y}(x, y)$, strains $\sigma_{n}, \varepsilon_{y}(x, y)$ and extensions $\Delta L, \Delta 2 t(x, y)$ with $E p l=E_{c}$ and $J_{z}=J_{z}$ all for $x=0 \div \mathrm{L}$ and $y$ $= \pm 0.2 \div 1.0 \mathrm{R}$ in the pinned cylindrical column made of steel $\mathrm{St} 35$ with dimensions: $\mathrm{R}=22 \mathrm{~mm}, \mathrm{t}=1 \mathrm{~mm}, \mathrm{~L}=545 \mathrm{~mm}$ compressed with the force $P=0.25 \cdot P_{c r}=9373.0 \mathrm{~N}$ in the longitudinal $(\mathrm{a}, \mathrm{b})$ and transverse cross-section $(\mathrm{c}, \mathrm{d})$ for $x=\mathrm{L} / 2=272.5 \mathrm{~mm}$

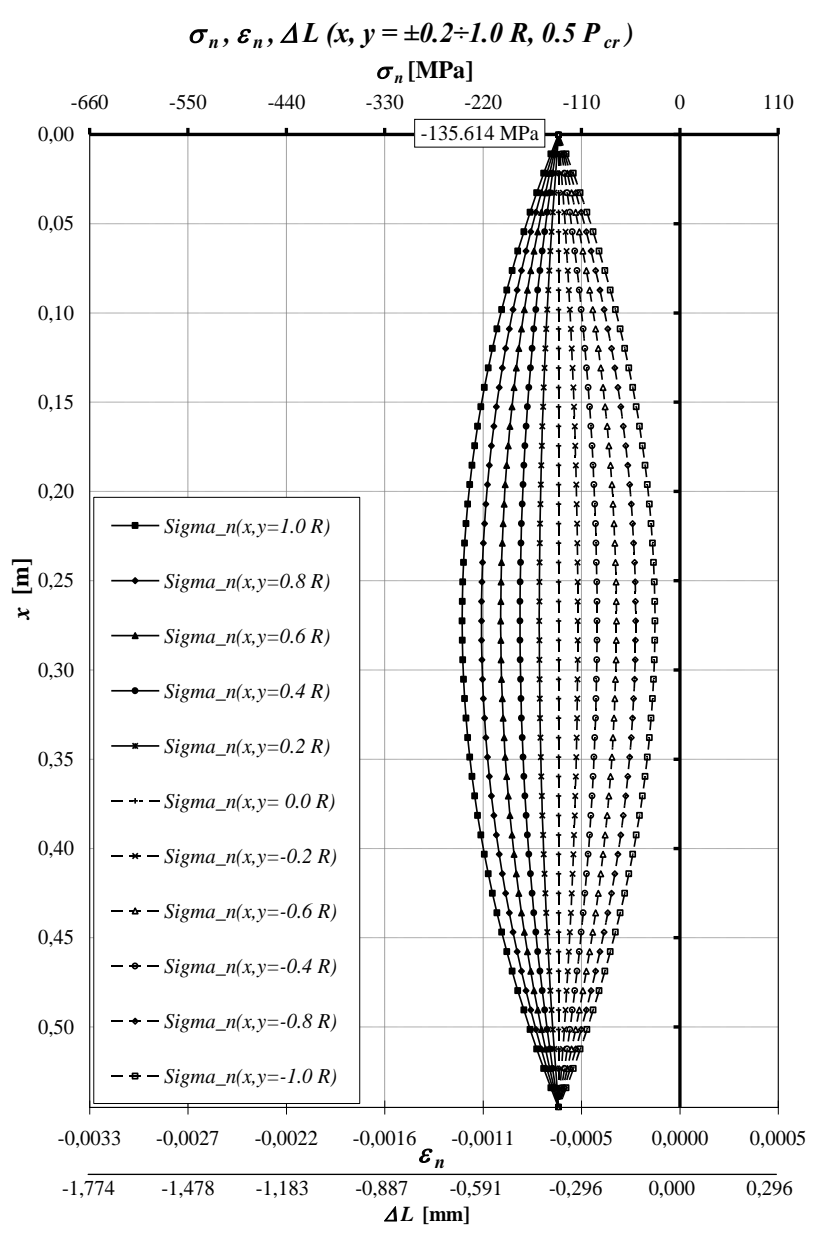

(a)

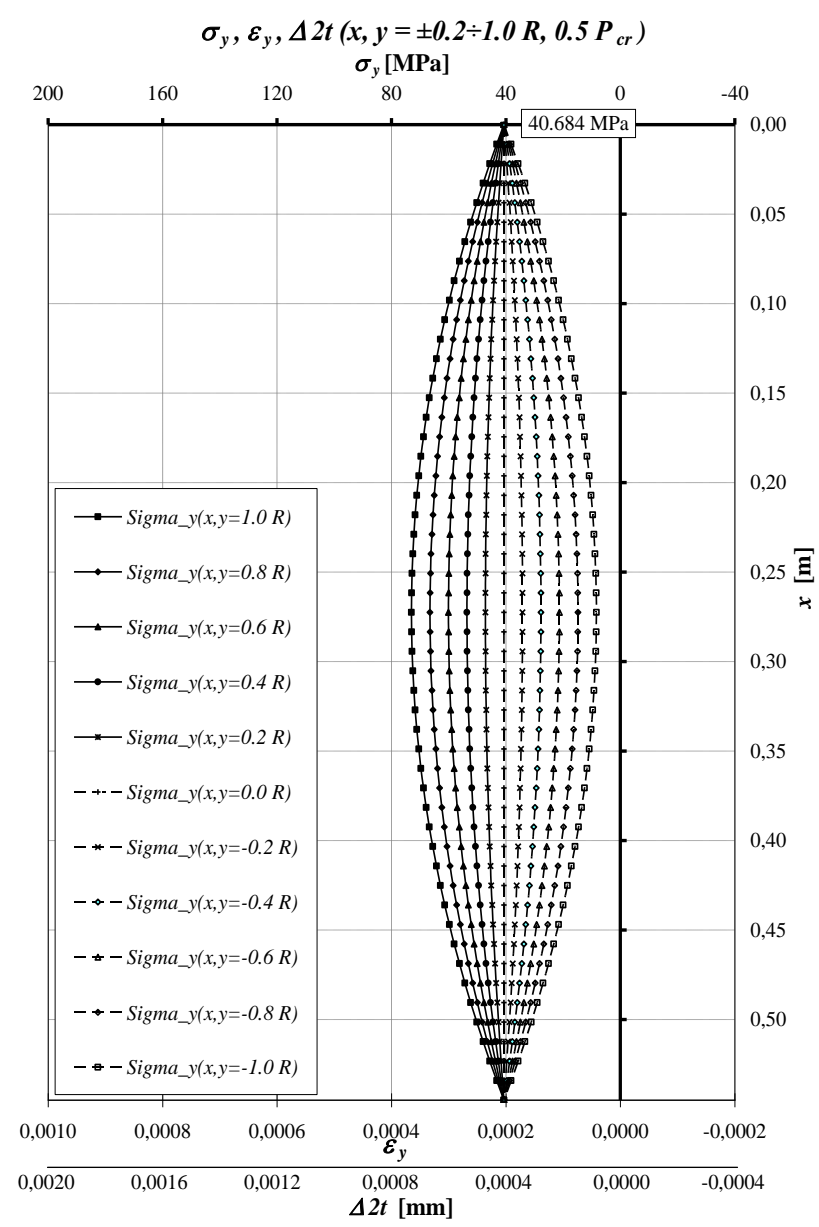

(b) 


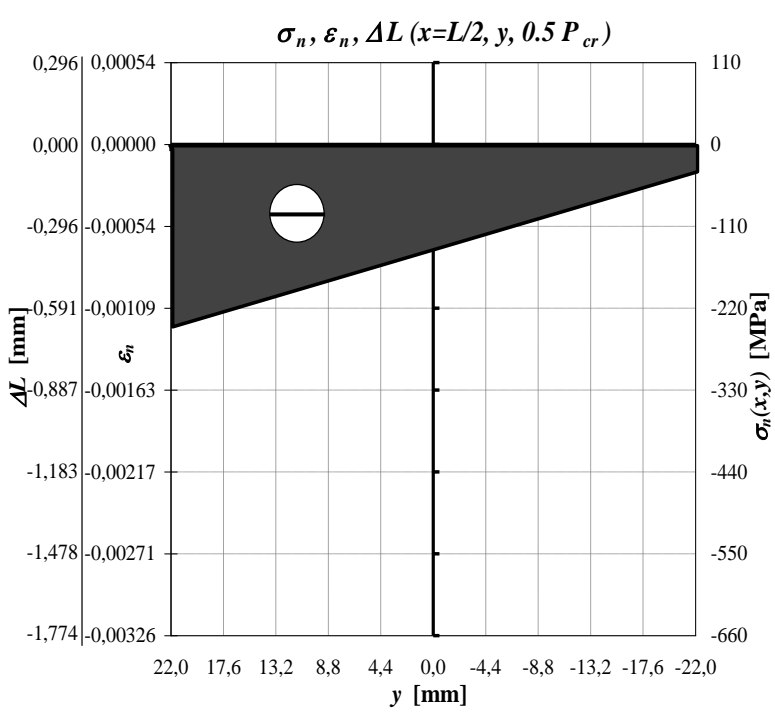

(c)

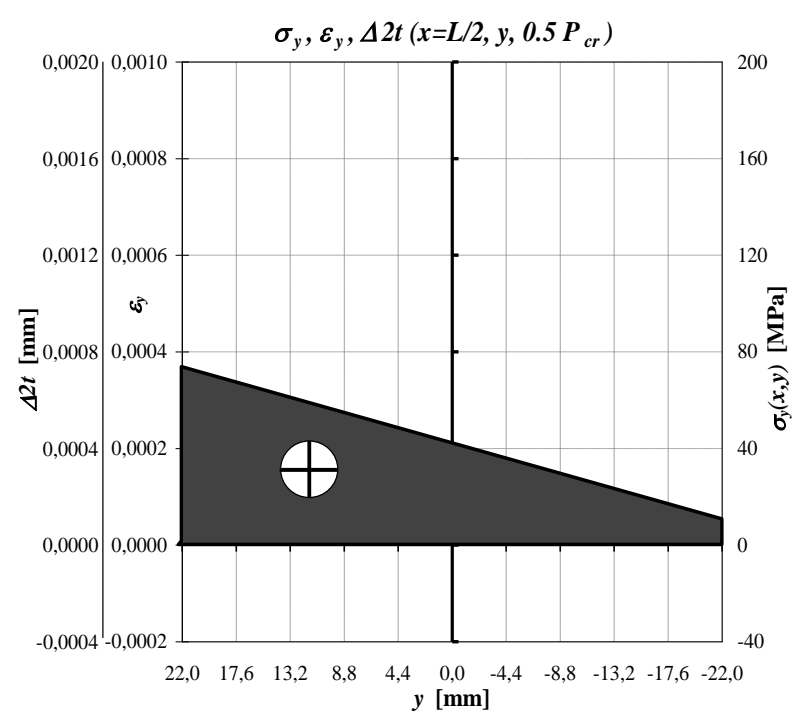

(d)

Fig. 13: Values of the stresses $\sigma_{n}, \varepsilon_{y}(x, y)$, strains $\sigma_{n}, \varepsilon_{y}(x, y)$ and extensions $\Delta L, \Delta 2 t(x, y)$ with $E p l=E_{c}$ and $J_{z}=J_{z}$ all for $x=0 \div \mathrm{L}$ and $y= \pm$ $0.2 \div 1.0 \mathrm{R}$ in the pinned cylindrical column made of steel St 35 with dimensions: $\mathrm{R}=22 \mathrm{~mm}, \mathrm{t}=1 \mathrm{~mm}, \mathrm{~L}=545 \mathrm{~mm}$ compressed with the force $\mathrm{P}=0.5 \cdot P_{c r}=18745.9 \mathrm{~N}$ in the longitudinal $(\mathrm{a}, \mathrm{b})$ and transverse cross section $(\mathrm{c}, \mathrm{d})$ for $\mathrm{x}=\mathrm{L} / 2=272.5 \mathrm{~mm}$

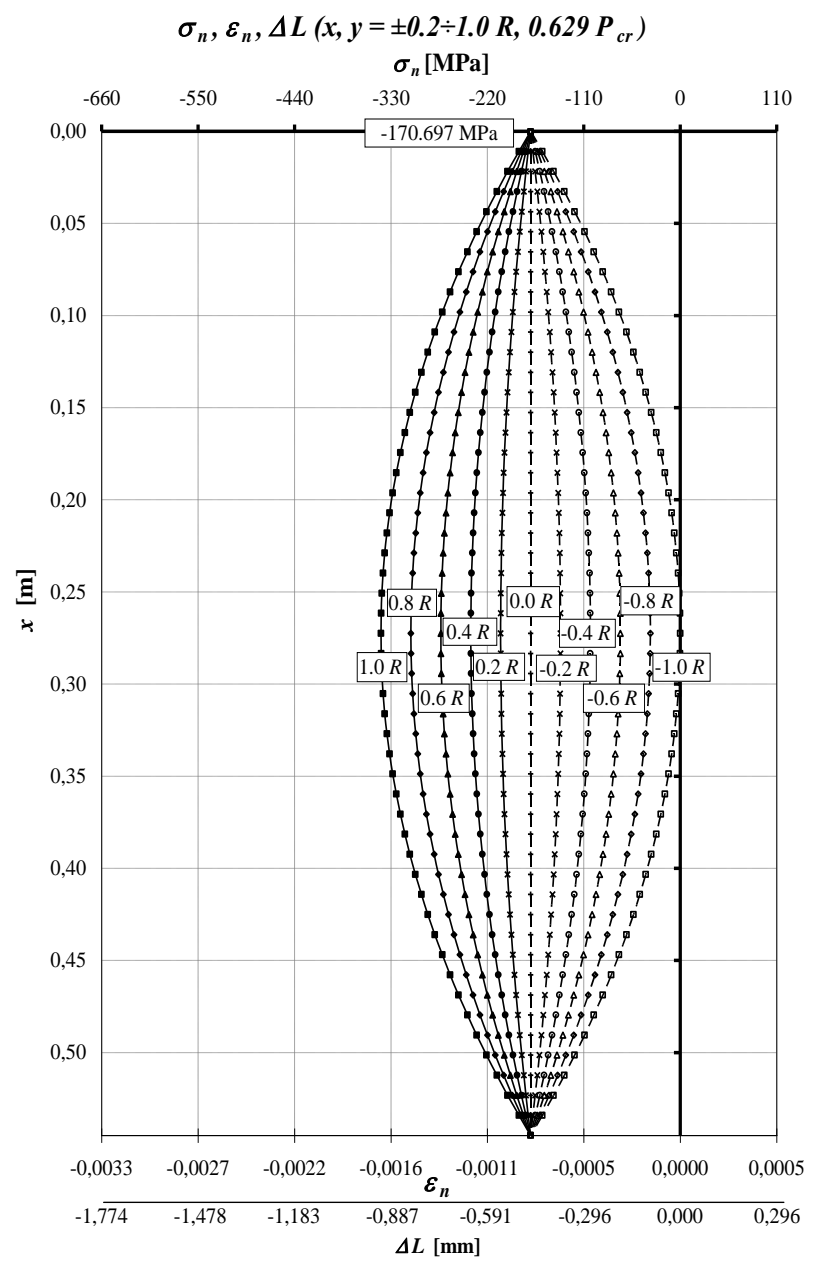

(a)

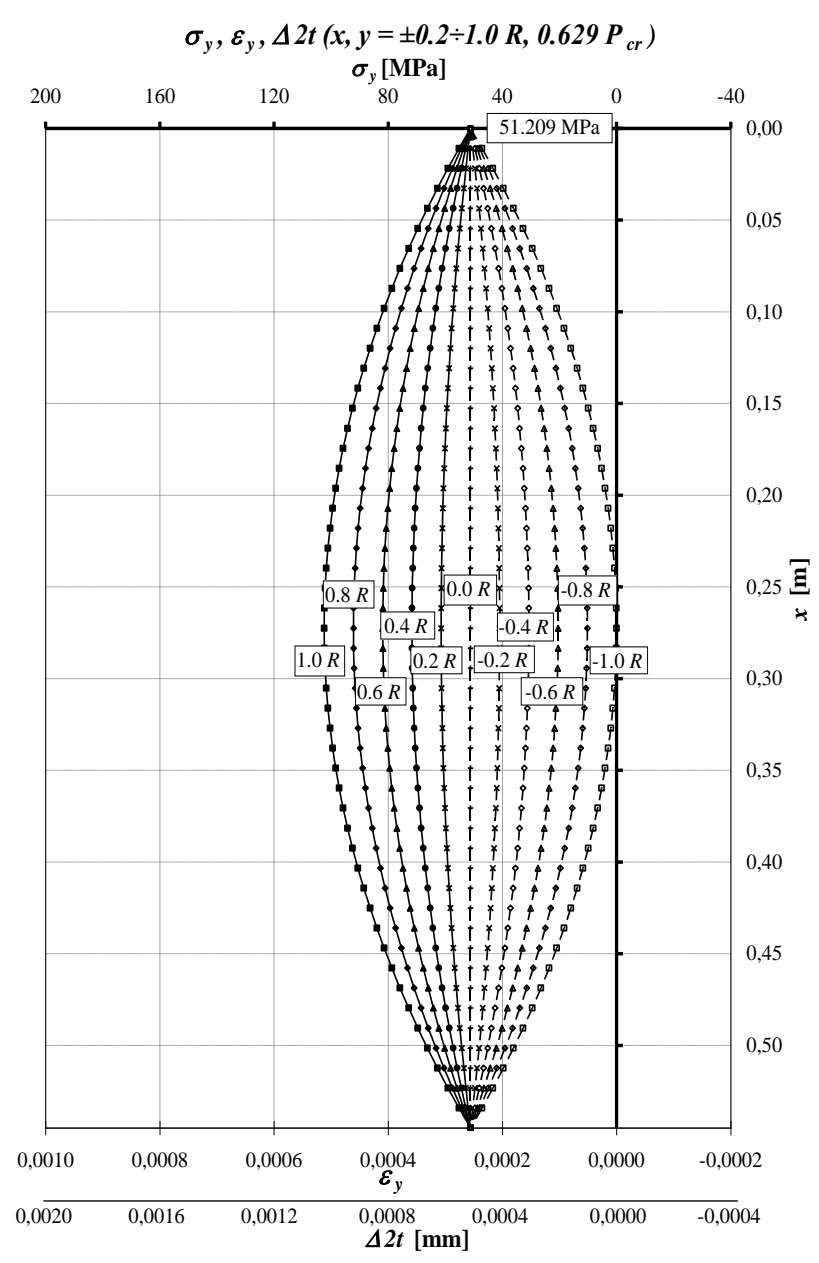

(b) 


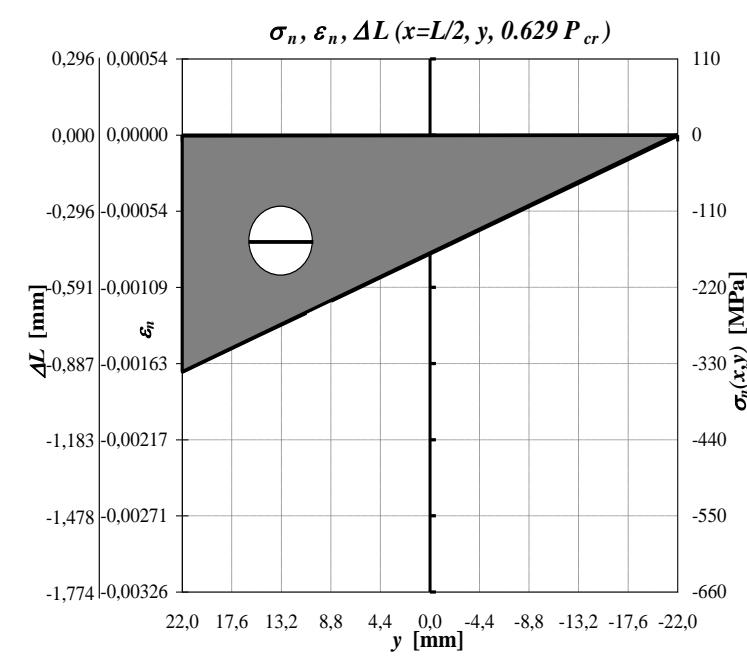

(c)

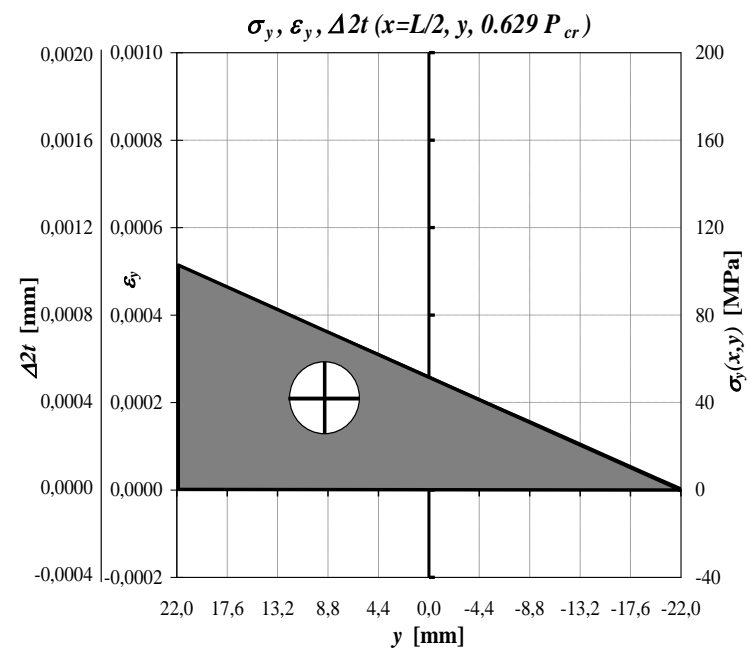

(d)

Fig. 14: Values of the stresses $\sigma_{n}, \varepsilon_{y}(x, y)$, strains $\sigma_{n}, \varepsilon_{y}(x, y)$ and extensions $\Delta L, \Delta 2 t(x, y)$ with $E p l=E_{c}$ and $J_{z}=J_{z}$ all for $x=0 \div \mathrm{L}$ and $y= \pm$ $0.2 \div 1.0 R$ in the pinned cylindrical column made of steel St35 with dimensions: $\mathrm{R}=22 \mathrm{~mm}, \mathrm{t}=1 \mathrm{~mm}, \mathrm{~L}=545 \mathrm{~mm}$ compressed with the force $P=0.629 \cdot P_{c r}=23595.5 \mathrm{~N}$ in the longitudinal $(\mathrm{a}, \mathrm{b})$ and transverse cross section $(\mathrm{c}, \mathrm{d})$ for $x=\mathrm{L} / 2=272.5 \mathrm{~mm}$

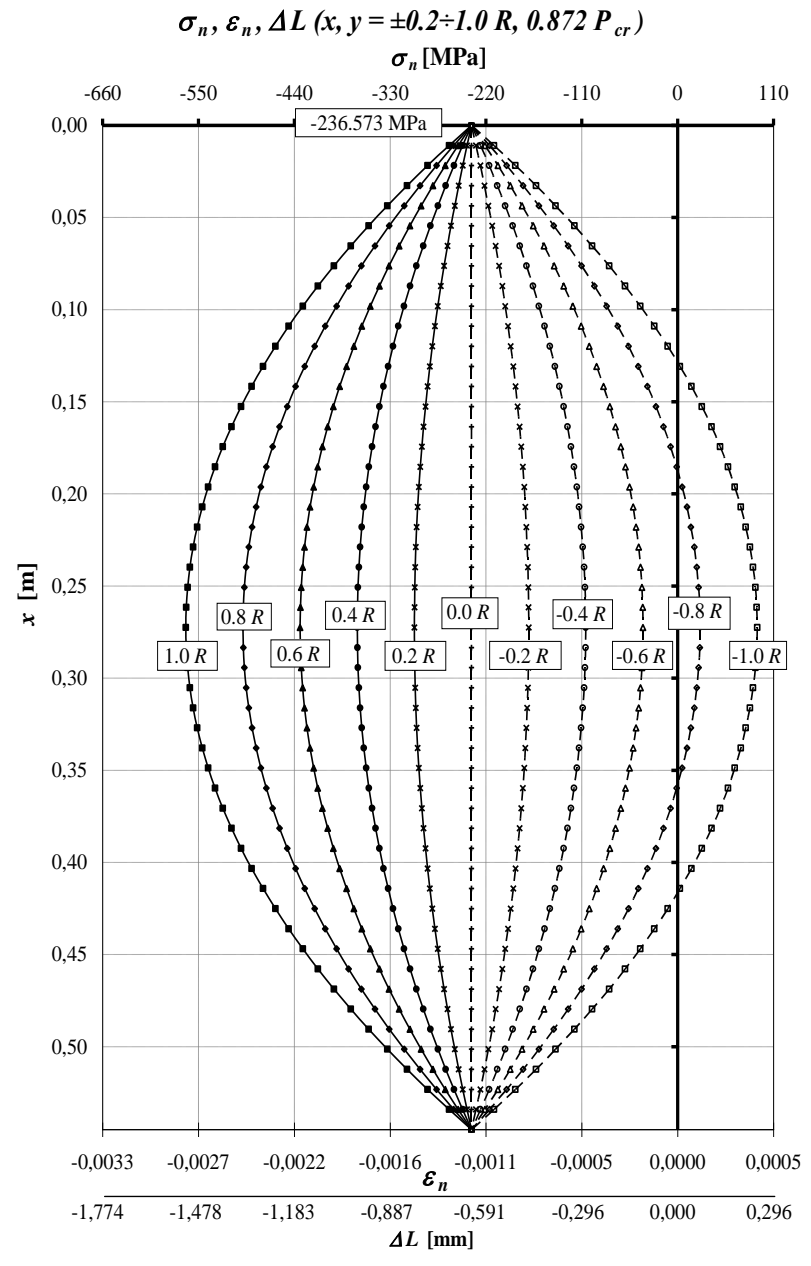

(a)

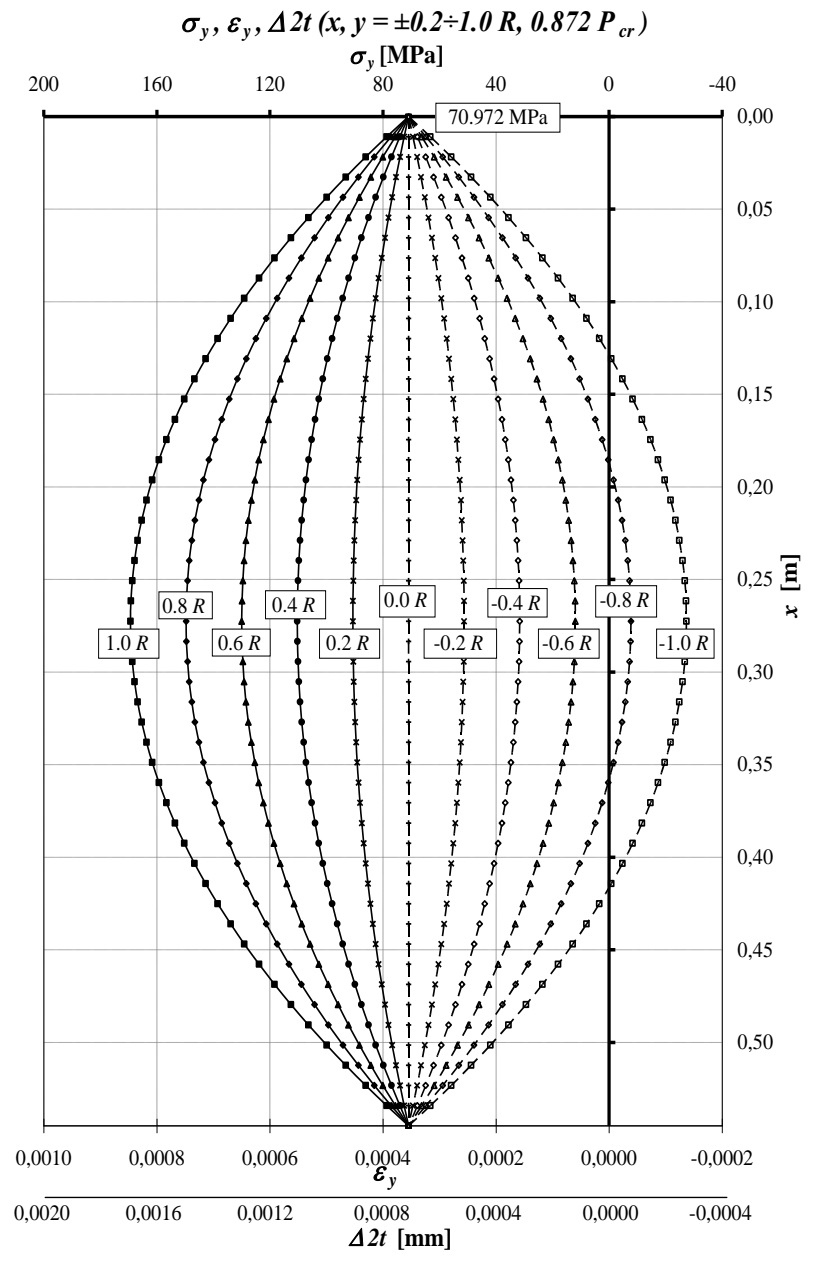

(b) 


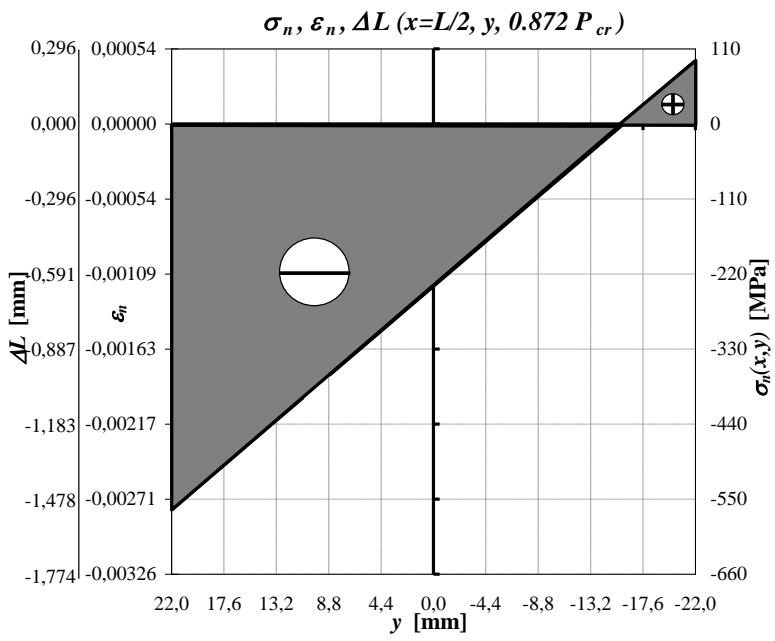

(a)

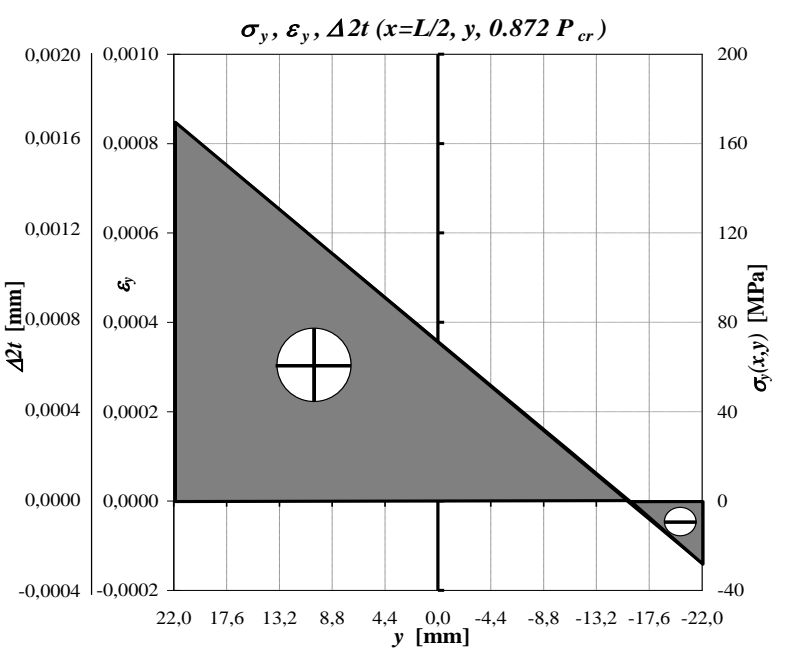

(b)

Fig. 15: Values of the stresses $\sigma_{n}, \varepsilon_{y}(x, y)$, strains $\sigma_{n}, \varepsilon_{y}(x, y)$ and extensions $\Delta L, \Delta 2 t(x, y)$ with $E p l=E_{c}$ and $J_{z}=J_{z}$ all for $x=0 \div \mathrm{L}$ and $\mathrm{y}= \pm$ $0.2 \div 1.0 \mathrm{R}$ in the pinned cylindrical column made of steel St 35 with dimensions: $\mathrm{R}=22 \mathrm{~mm}, \mathrm{t}=1 \mathrm{~mm}, \mathrm{~L}=545 \mathrm{~mm}$ compressed with the force $P=0.872 \cdot P_{c r}=32701.53 \mathrm{~N}$ in the longitudinal $(\mathrm{a}, \mathrm{b})$ and transverse cross section $(\mathrm{c}, \mathrm{d})$ for $x=\mathrm{L} / 2=272.5 \mathrm{~mm}$

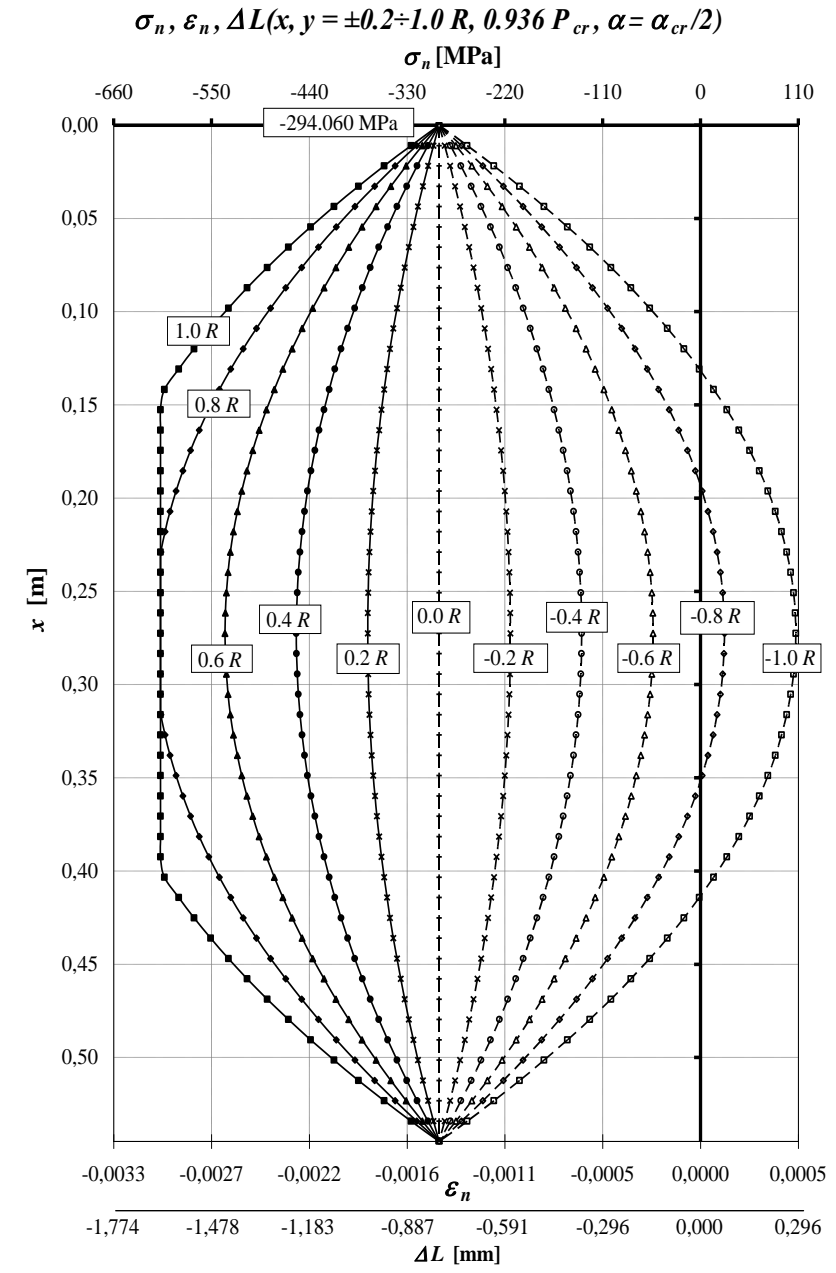

(a)

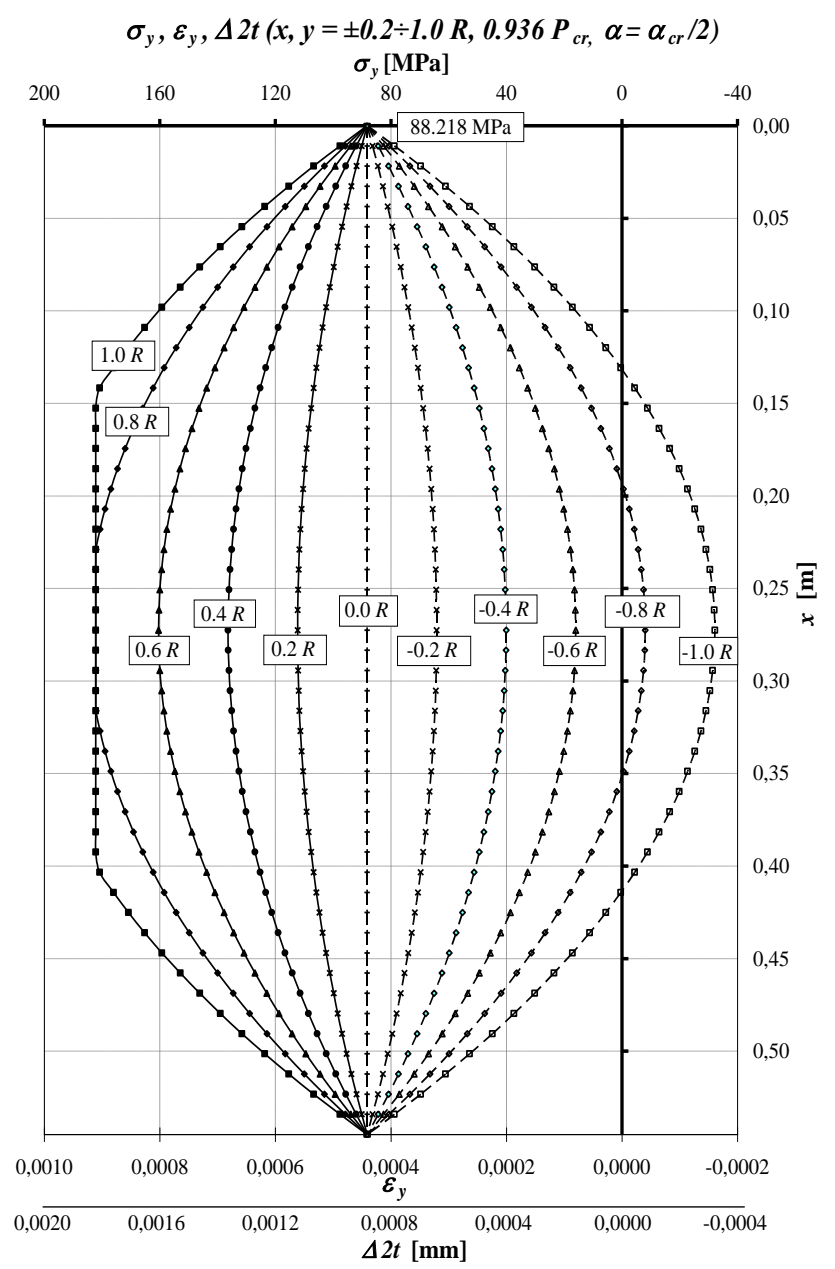

(b) 


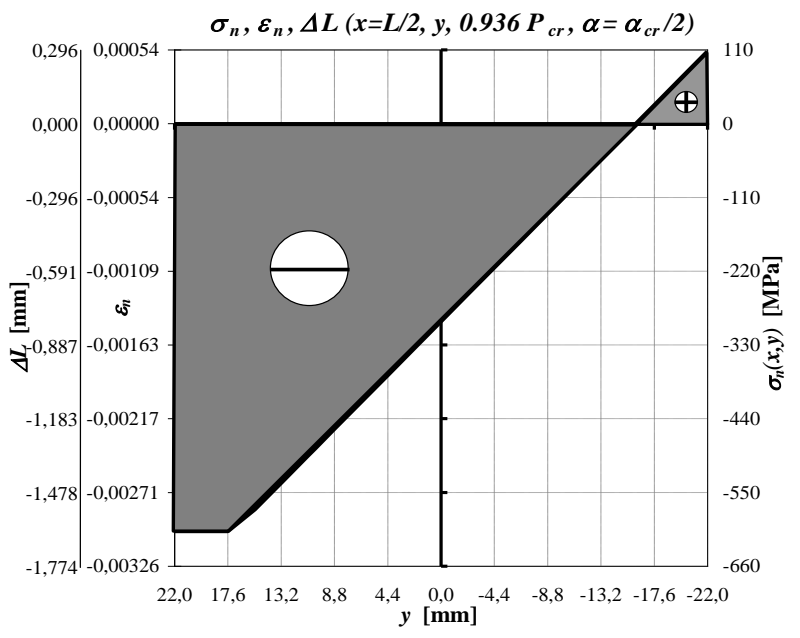

(c)

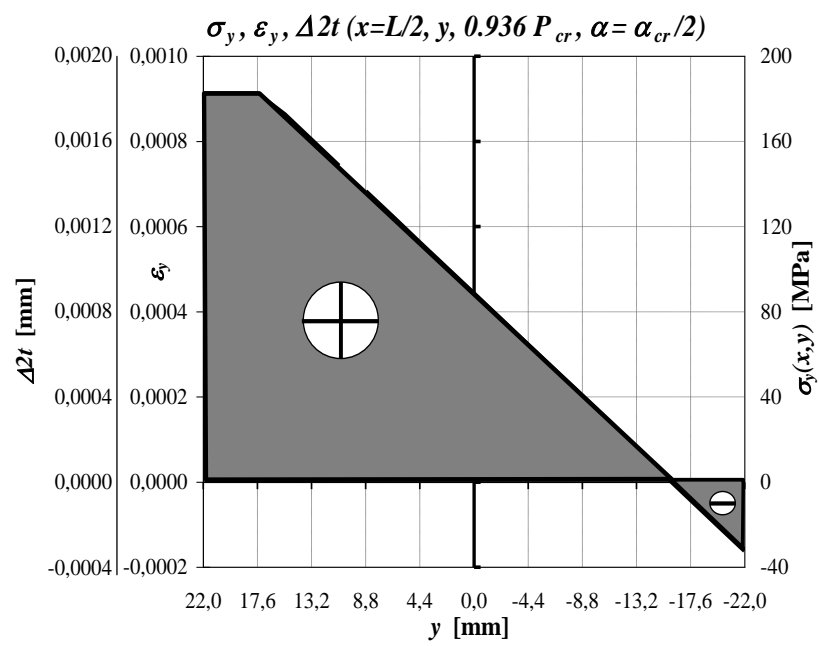

(d)

Fig. 16: Values of the stresses $\sigma_{n}, \varepsilon_{y}(x, y)$, strains $\sigma_{n}, \varepsilon_{y}(x, y)$ and extensions $\Delta L, \Delta 2 t(x, y)$ with $E p l=E c$ and $J z=J z$ all for $\mathrm{x}=0 \div \mathrm{L}$ and $\mathrm{y}= \pm 0.2 \div 1.0 \mathrm{R}$ in the pinned cylindrical column made of steel St35 with dimensions: $\mathrm{R}=22 \mathrm{~mm}, \mathrm{t}=1 \mathrm{~mm}, \mathrm{~L}=545 \mathrm{~mm}$ compressed with the force $\mathrm{P}=0.936 \cdot \mathrm{Pcr}=35096.7 \mathrm{~N}$ by $\alpha=\alpha_{c r} / 2=24.60 \mathrm{deg}$ in the longitudinal $(\mathrm{a}, \mathrm{b})$ and transverse cross section $(\mathrm{c}, \mathrm{d})$ for $\mathrm{x}=\mathrm{L} / 2=272.5 \mathrm{~mm}$

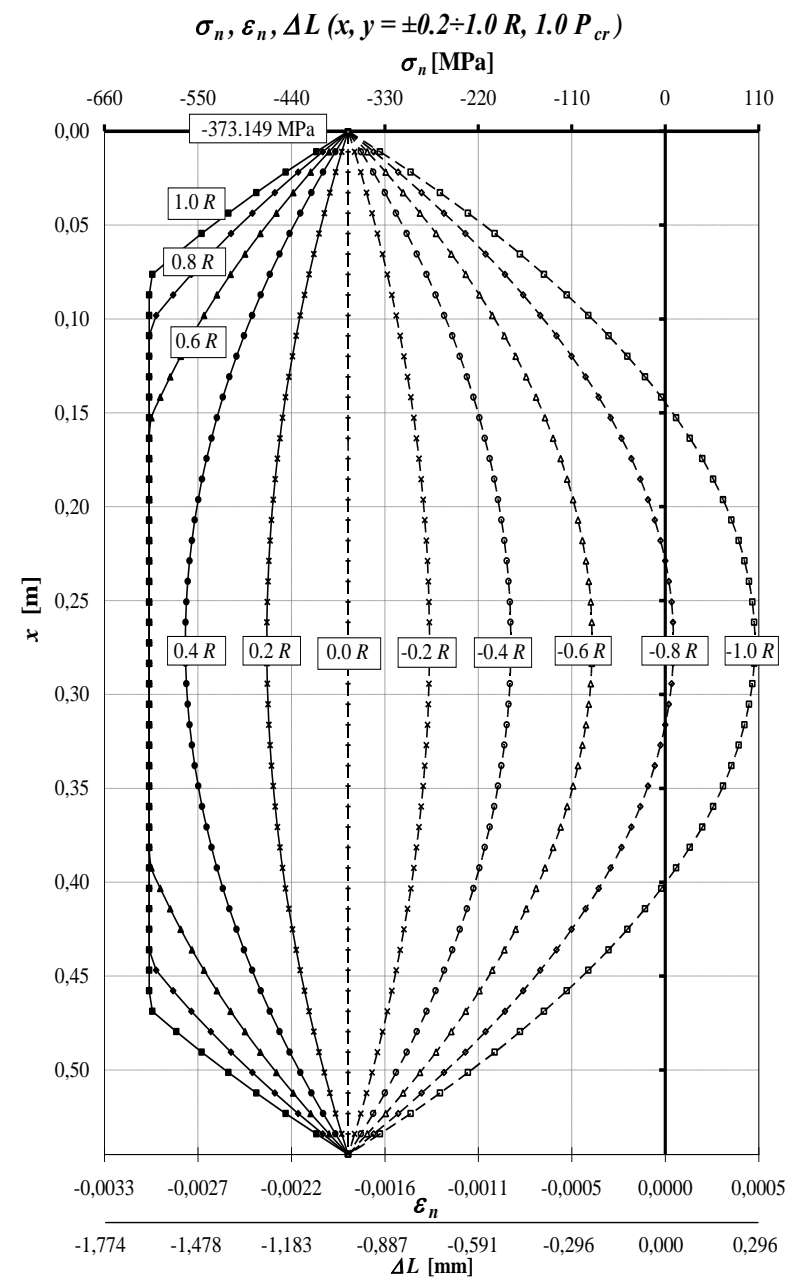

(a)

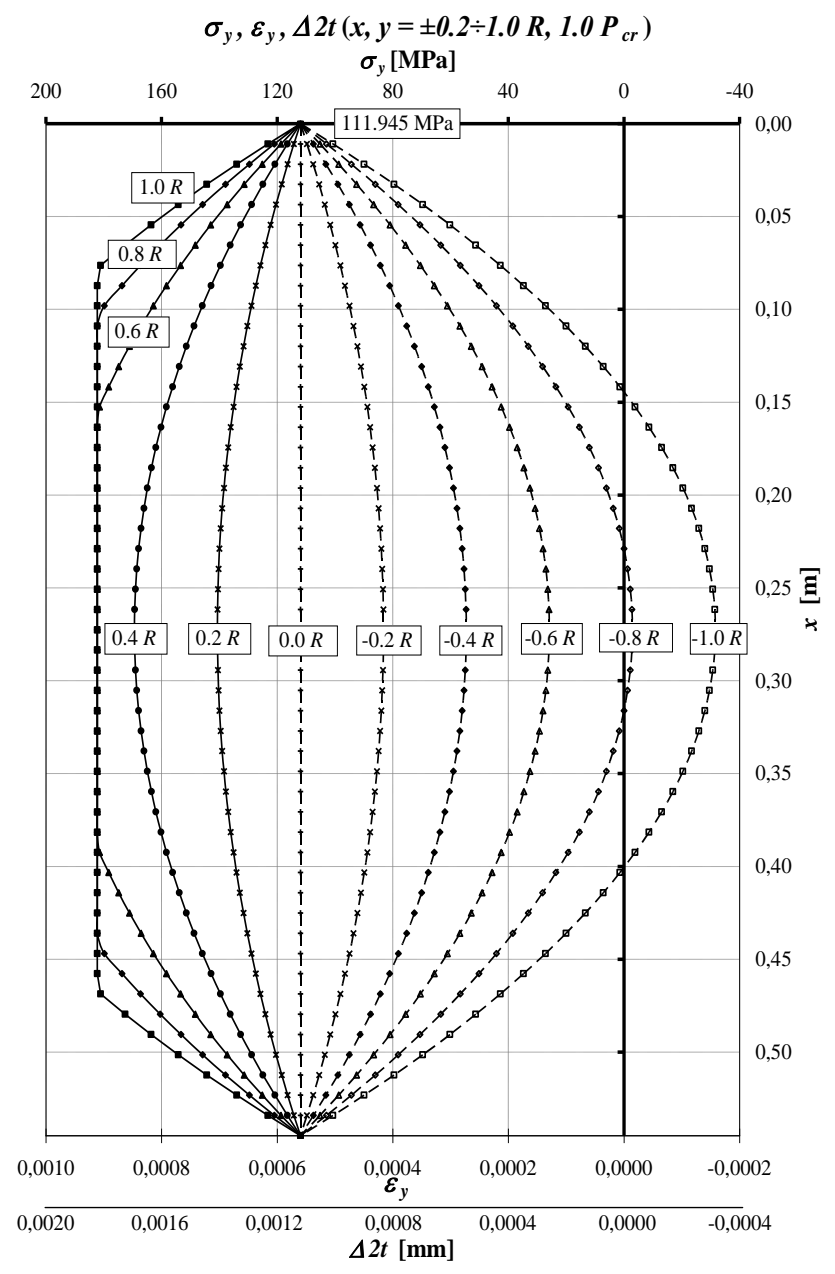

(b) 


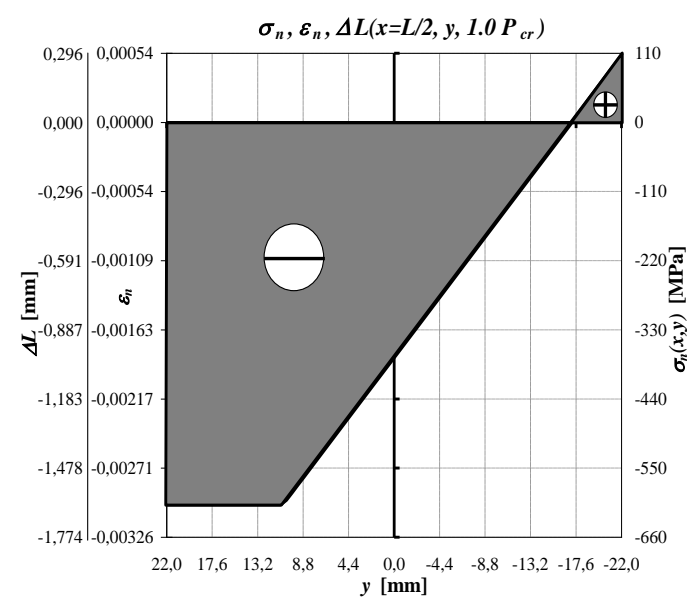

(c)

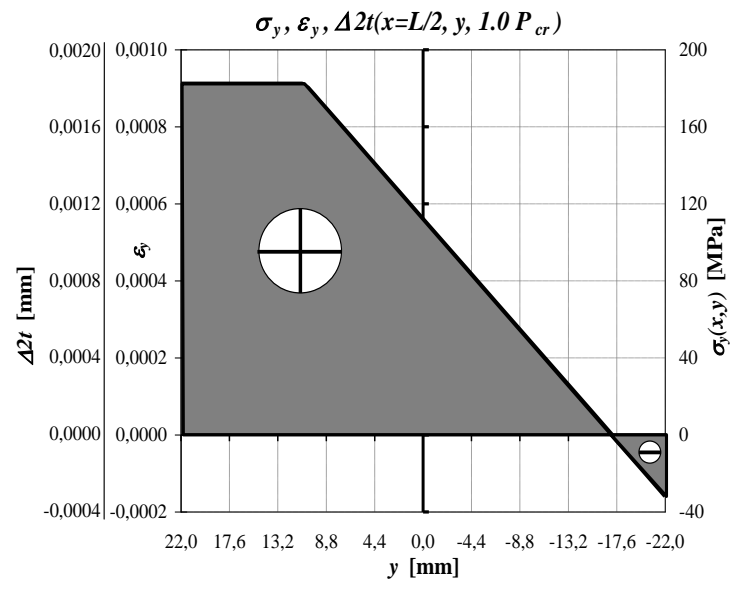

(d)

Fig. 17: Values of the stresses $\sigma_{n}, \sigma_{y}(x, y)$, strains $\varepsilon_{n}, \varepsilon_{y}(x, y)$ and extensions $\Delta L, \Delta 2 t(x, y)$ with $E_{p l}=E_{c}$ and $J_{z}=J_{z}^{\text {all }}$ for $x=0 \div L$ and $y= \pm 0.2 \div 1.0 R$ in the pinned cylindrical column made of steel St35 with dimensions: $R=22 \mathrm{~mm}, t=1 \mathrm{~mm}, L=545 \mathrm{~mm}$ compressed with the force $P$ $=1.0 \cdot P_{c r}=37491.88 \mathrm{~N}$ in the longitudinal $(\mathrm{a}, \mathrm{b})$ and transverse cross section $(\mathrm{c}, \mathrm{d})$ for $x=L / 2=272.5 \mathrm{~mm}$

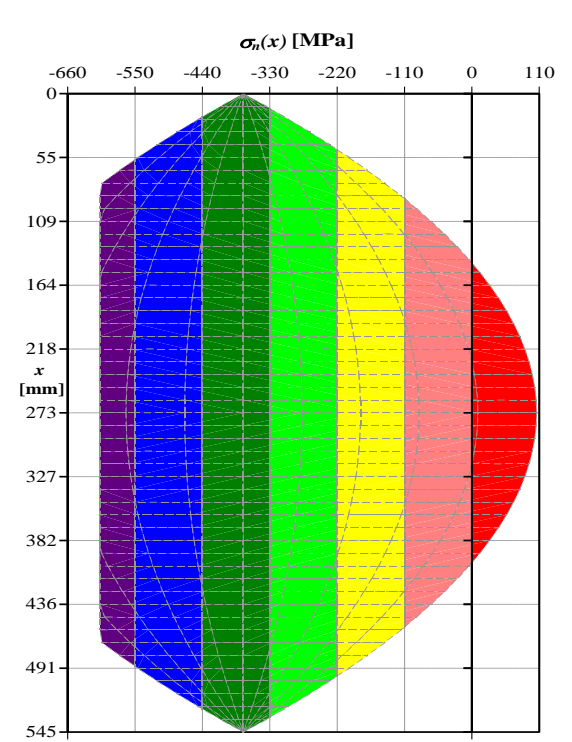

(a) $\sigma_{n}(x, y)$

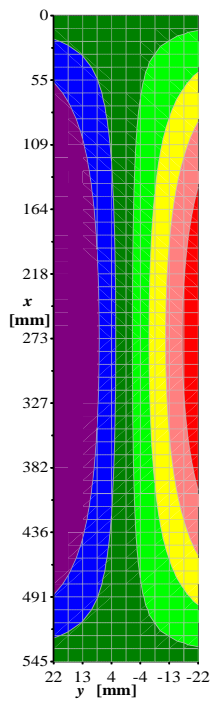

(b)

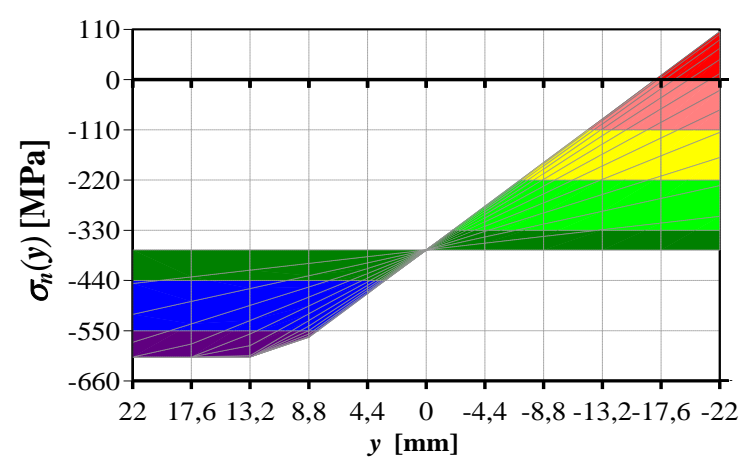

(c)

Fig. 18: Values of the stresses $\sigma_{n}(x, y)$ with $E p l=E c$ and $J_{z}=J_{z}$ all in the axially loaded with the force $P_{c r}$ cylindrical pinned column made of steel $\mathrm{St} 35$ with dimensions: $\mathrm{R}=22 \mathrm{~mm}, \mathrm{t}=1 \mathrm{~mm}, \mathrm{~L}=545 \mathrm{~mm}$ 

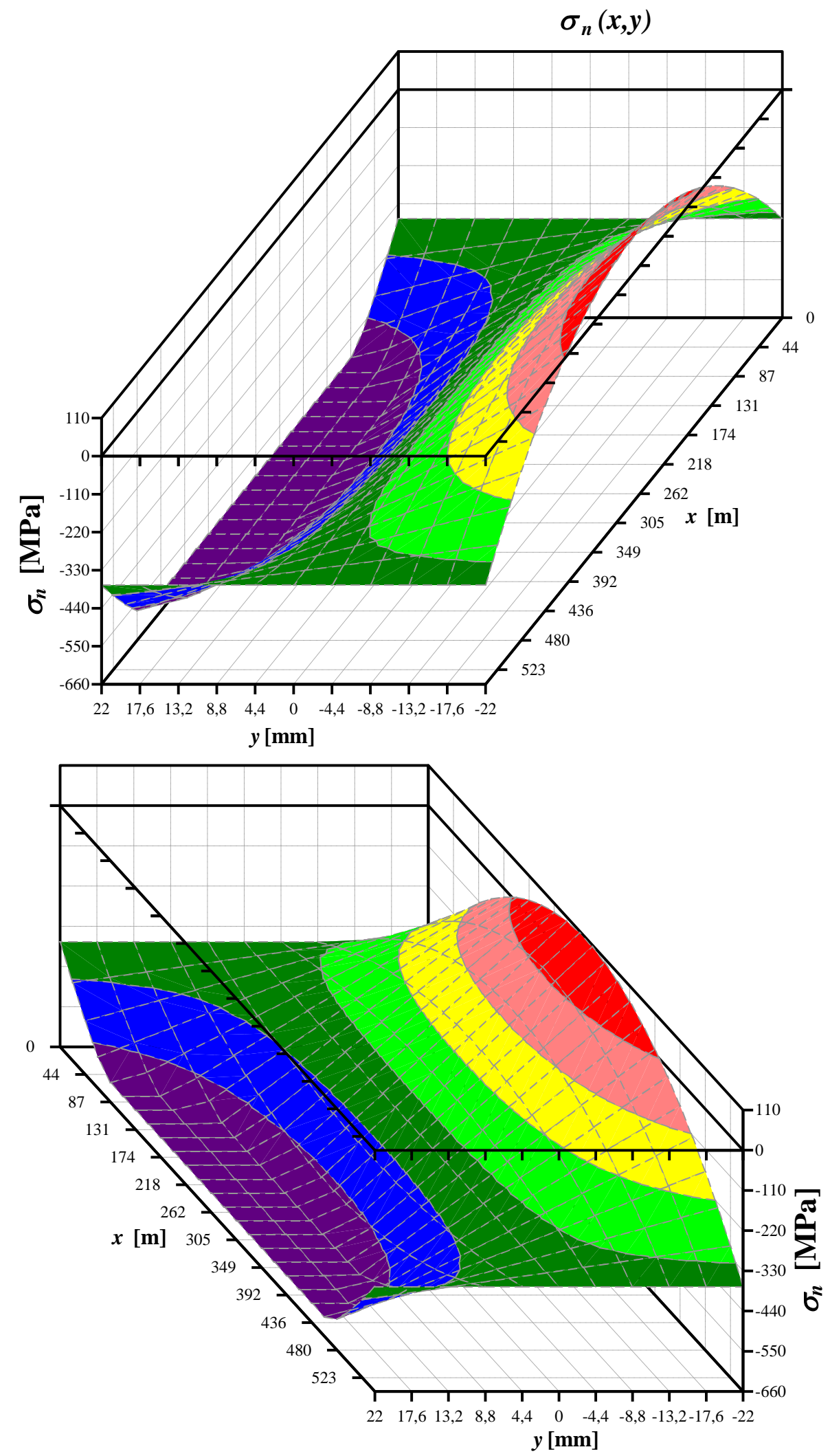

Fig. 19: Values of the stresses $\sigma_{n}(x, y)$ with $E_{p l}=E_{c}$ and $J_{z}=J_{z}{ }_{z}$ ll in the axially loaded with the force $P_{c r}$ cylindrical pinned column made of steel St35 with dimensions: $R=22 \mathrm{~mm}, t=1 \mathrm{~mm}, L=545 \mathrm{~mm}$ 


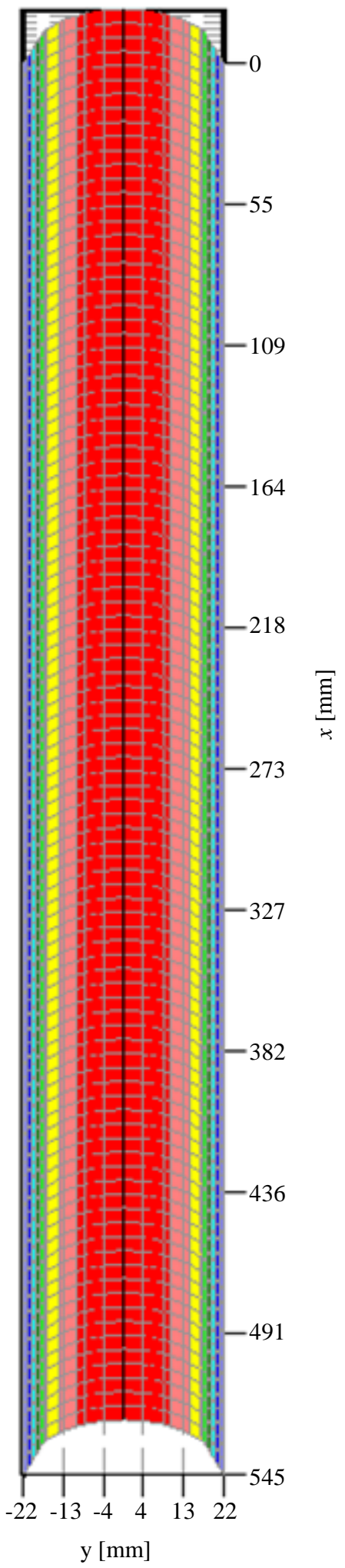

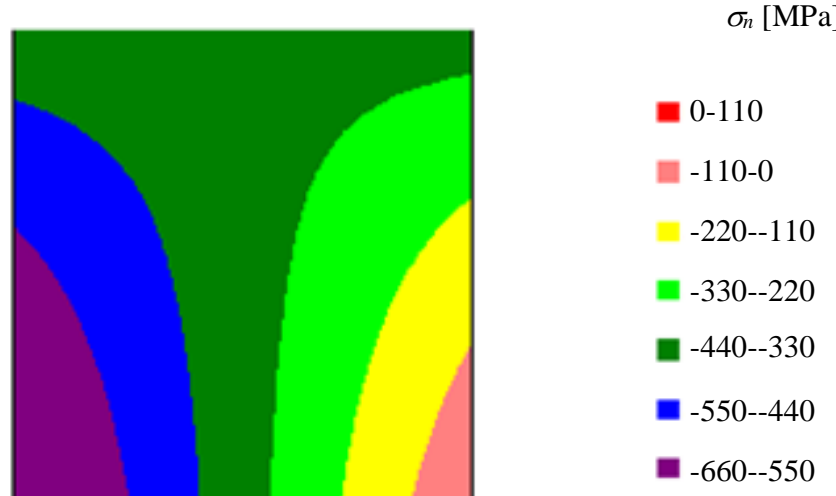

$\varepsilon_{n}$

- 0,0000-0,0005

$-0,0005-0,0000$

$-0,0011--0,0005$

$-0,0016--0,0011$

$-0,0022-0,0016$

$-0,0027--0,0022$

$-0,0033--0,0027$

$\Delta L[\mathrm{~mm}]$

0,000-0,296

- $-0,296-0,000$

-0,591--0,296

[-0,887--0,591

$-1,183--0,887$

$-1,478--1,183$

$-1,774--1,478$

Fig. 20: Surface functions of the normal stresses $\sigma_{n}[\mathrm{MPa}]$, strains $\varepsilon_{n}$ and extensions $\Delta L[\mathrm{~mm}]$ with $E_{p l}=E_{c}$ and $J_{z}=J_{z}^{\text {all }}$ related to the buckled pinned cylindrical column, compressed with the force $\mathrm{Pcr}$ 


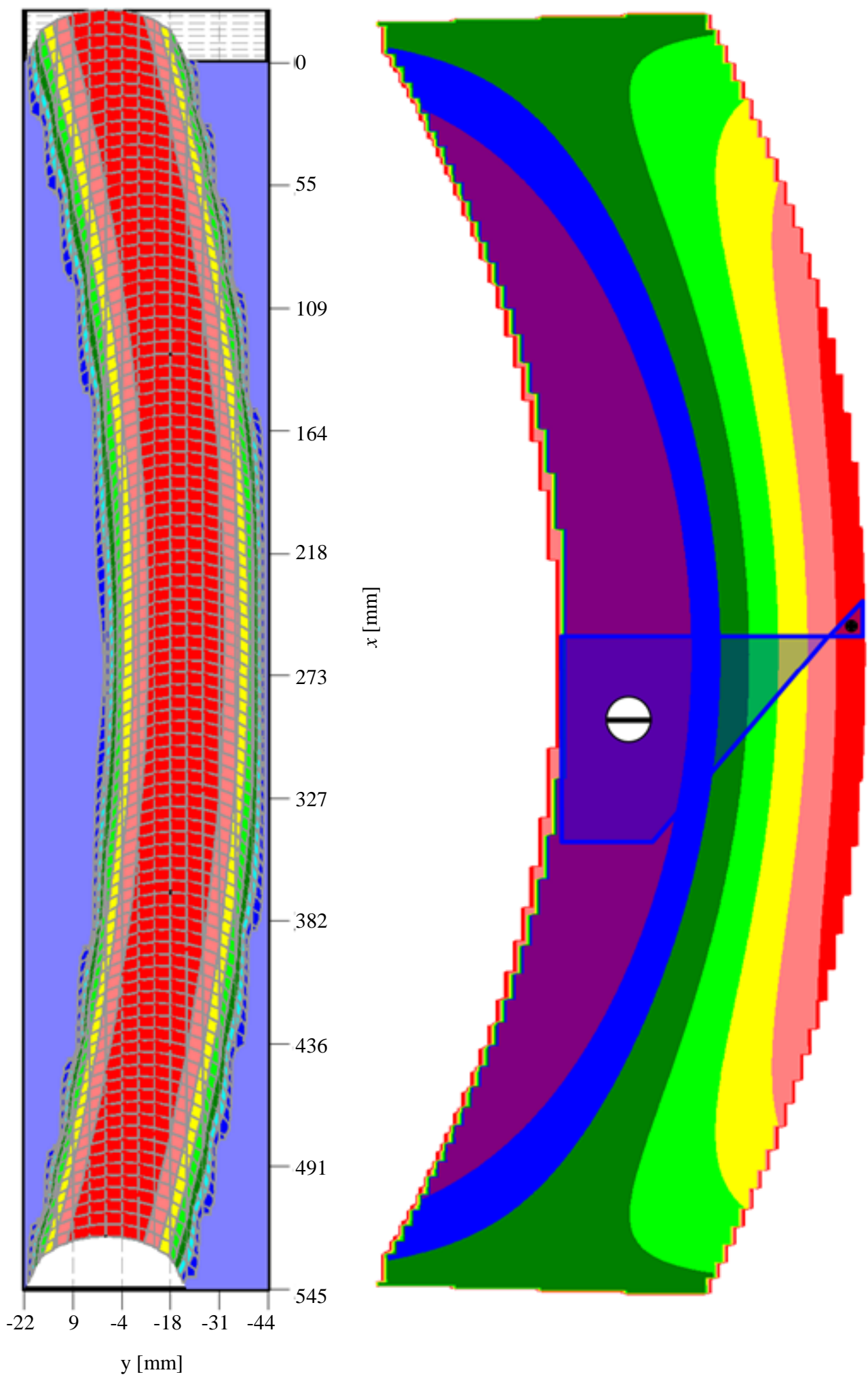

$\sigma_{n}[\mathrm{MPa}]$

- 0-110

$-110-0$

$-220--110$

- $-330--220$

- $-440--330$

$-550--440$

$-660--550$

$\varepsilon n$

0,0000-0,0005

$-0,0005-0,0000$

$-0,0011--0,0005$

$-0,0016--0,0011$

$-0,0022-0,0016$

$-0,0027--0,0022$

$-0,0033--0,0027$

$\Delta L[\mathrm{~mm}]$

- 0,000-0,296

$-0,296-0,000$

$-0,591--0,296$

$-0,887--0,591$

$-1,183--0,887$

$-1,478--1,183$

$-1,774--1,478$

Fig. 21: Surface functions of the normal stresses $s_{n}[\mathrm{MPa}]$, strains $e_{n}$ and extensions $D L[\mathrm{~mm}]$ with $E_{p l}=E_{c}$ and $J_{z}=J_{z}{ }^{a l l}$ related to the buckled pinned cylindrical column, compressed with the force $P_{c r}$ 


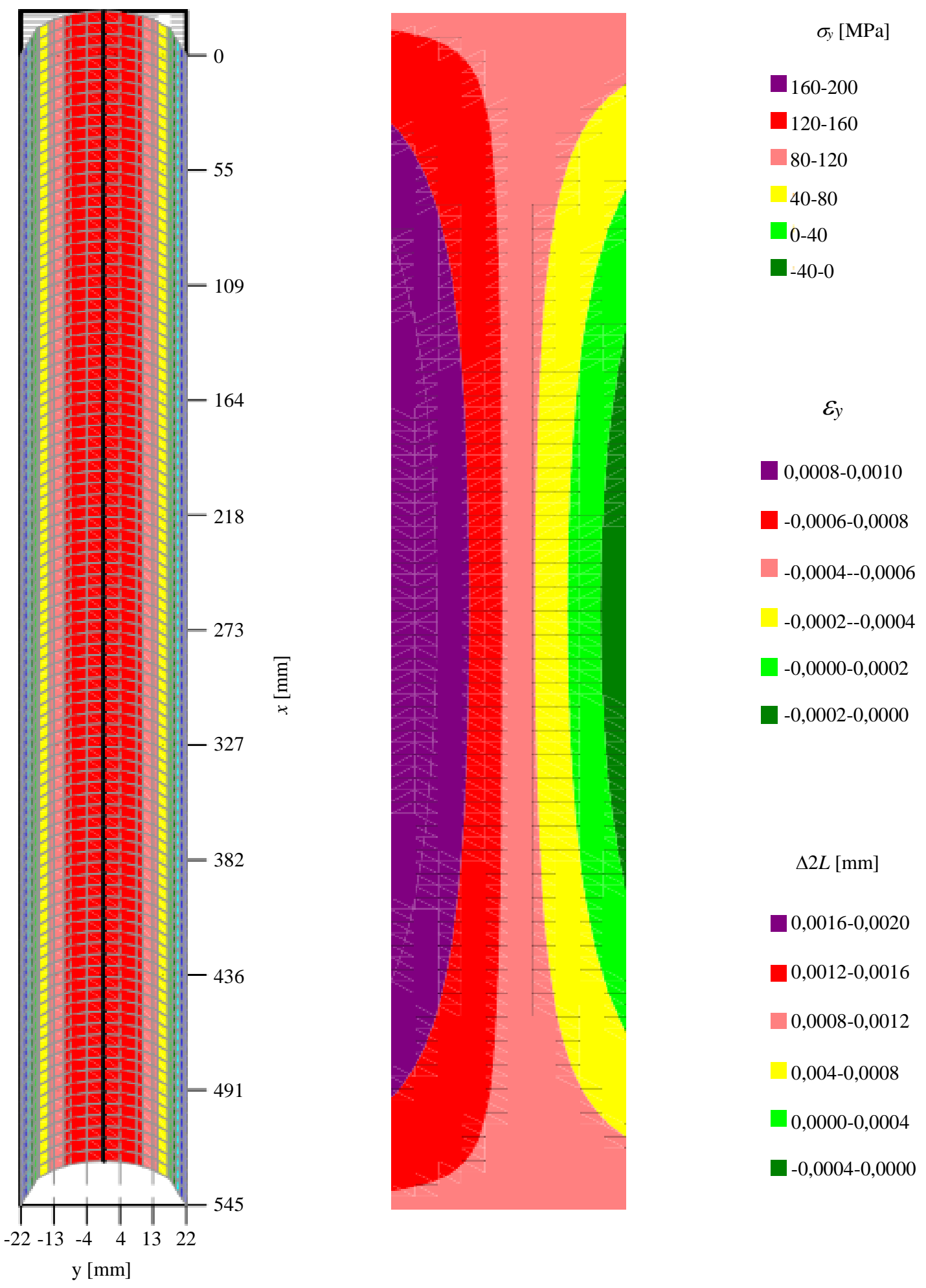

Fig. 22: Surface functions of the transverse stresses $\sigma_{y}[\mathrm{MPa}]$, strains $\varepsilon_{y}$ and extensions $\Delta 2 t[\mathrm{~mm}]$ with $E p_{l}=E_{c}$ and $J_{z}=$ $J_{z}$ all related to the straight, pinned cylindrical column, compressed with the force $P_{c r}$ 


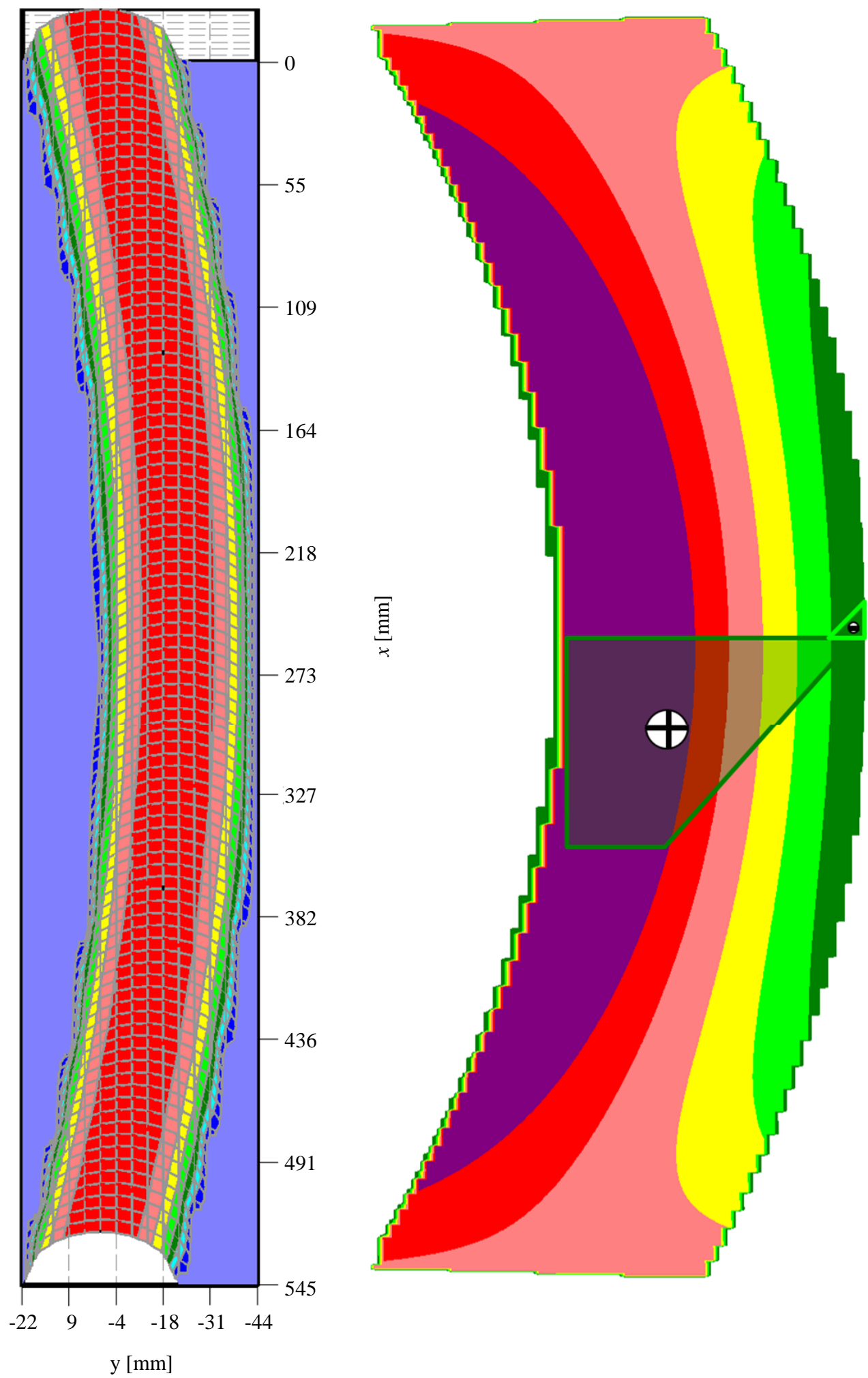

$\sigma_{y}[\mathrm{MPa}]$

- 160-200

120-160

80-120

40-80

0-40

$-40-0$

$\mathcal{E}_{y}$

$0,0008-0,0010$

$-0,0006-0,0008$

$-0,0004--0,0006$

$-0,0002--0,0004$

$-0,0000-0,0002$

$-0,0002-0,0000$

$\Delta L[\mathrm{~mm}]$

0,0016-0,0020

$0,0012-0,0016$

0,0008-0,0012

0,004-0,0008

0,0000-0,0004

$-0,0004-0,0000$

Fig. 23: Surface functions of the transverse stresses $\sigma_{y}[\mathrm{MPa}]$, strains $\varepsilon_{y}$ and extensions $\Delta 2 t[\mathrm{~mm}]$ with $E_{p l}=E_{c}$ and $J_{z}=J_{z}$ all related to the buckled cylindrical pinned column, compressed with the force $P_{c r}$ 
Figure 24 presents the values of the coordinate $y \sigma_{n=0,}$ $x=L / 2(P)$ with $E_{p l}=E_{c}=118115,5 \mathrm{MPa}$ and $J_{z}=J_{z}^{\text {all }}$ of the null normal stress $\sigma_{n}=0$ (the resultant neutral layer) in the critical cross-section $(x=L / 2)$ depending on the force $P$ compressing the pinned cylindrical column made of steel St35 with $R=22 \mathrm{~mm}, t=1 \mathrm{~mm}, L=545 \mathrm{~mm}$ as the theoretical example computed with $E_{p l}=E_{c}$.

Figure 25 presents the values of the extensions $\Delta L_{x=L / 2, y=0, \pm R}(P)$ with $E_{p l}=E_{c}=118115.5 \mathrm{MPa}$ and $J_{z}=J_{z}^{\text {all }}$ on the two opposite and one central generating lines $(y=0, \pm R)$ in the critical (middle) cross-section ( $x=L / 2$ ) depending on the force $P$ compressing the pinned cylindrical column made of steel St35 with $R=$ $22 \mathrm{~mm}, t=1 \mathrm{~mm}, L=545 \mathrm{~mm}$.
For computing were assumed the values of the steel St35 parameters (as the average for tubes $\phi 26 x 1$ and ф45xl, Murawski, 2020a): $E^{*}=198272.52 \mathrm{MPa}, R_{e}{ }^{*}=$ $603.68 \mathrm{MPa}, v=0.3, \lambda_{\text {ell } l l}=78.86$.

On the assumption that $\sigma_{n}(x=L / 2, y=R \cos \alpha)=R_{e}{ }^{*}$ was determined the critical compressive stress $\sigma_{c r}^{\text {elpl- TSTh }}$. Figure 26 shows the graphs of the theoretical functions calculated like pinned without friction: $\sigma_{c r}(\lambda)^{T S T h \_E p l=E c}$, for the columns made of steel St35: $\sigma 45 \times 1 \quad\left(E^{*}=\right.$ $\left.202768.28 \mathrm{MPa}, R_{e}{ }^{*}=607.35 \mathrm{MPa}, \lambda_{\text {ltd }}=77.194\right)$ and $\sigma 26 \times 1\left(E^{*}=193776.75 \mathrm{MPa}, R_{e}{ }^{*}=600.01 \mathrm{MPa}, \Delta_{l t d}=\right.$ $80.528)$ as well as the surface function $\sigma_{c r}{ }^{e l-p l}(\lambda$, $A)^{T S T L_{-} E p l=0}$ of cylindrical columns made of steel St35 with $E_{p l}=E_{c}=118115.5 \mathrm{MPa}$ and $J_{z}=J_{z}^{\text {all }}$.

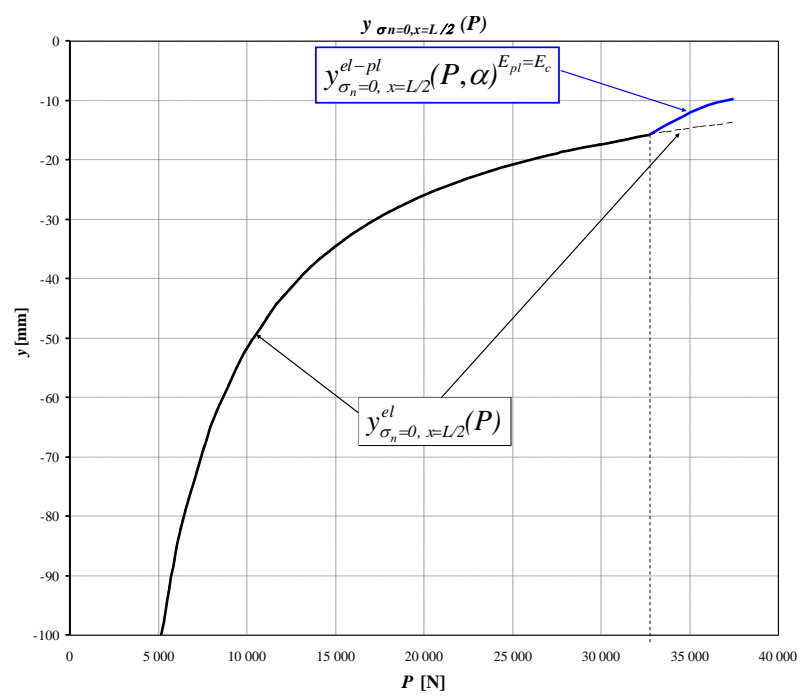

Fig. 24: Graph of the function $y \sigma_{n=0, x=L / 2}(P)$ with $E_{p l}=E_{c}=118115.5 \mathrm{MPa}$ and $J_{z}=J_{z}$ all of of the coordinate of the null normal stress $\sigma_{n}=0$ (the resultant neutral layer) in the critical cross-section $(x=L / 2)$ depending on the force $P$ compressing the pinned cylindrical column made of steel St 35 with $R=22 \mathrm{~mm}, t=1 \mathrm{~mm}, L=545 \mathrm{~mm}$

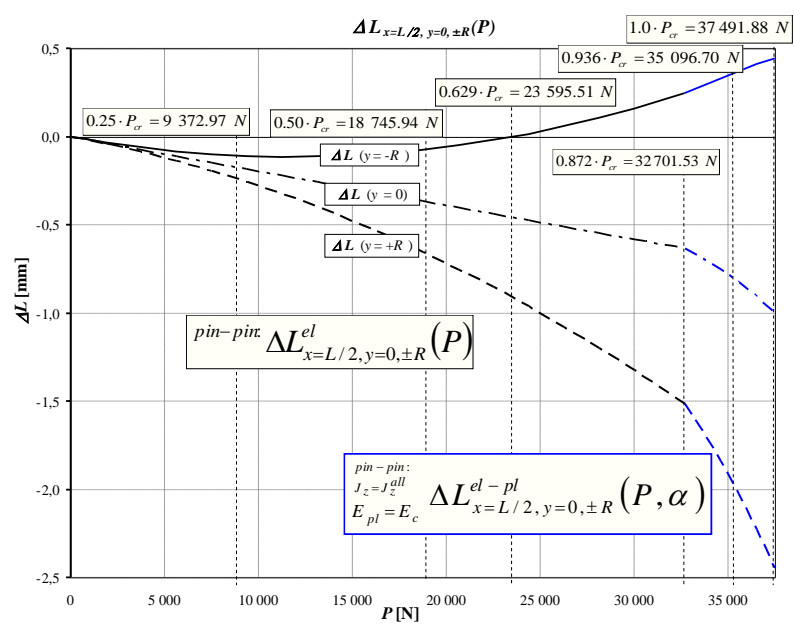

Fig. 25: Values of the extensions $\Delta L_{x=L / 2, y=0, \pm R}(P)$ with $E_{p l}=E_{c}=118115.5 \mathrm{MPa}$ and $J_{z}=J_{z}$ all on the two opposite and one central generating lines $(y=0, \pm R)$ in the critical (middle) cross-section $(x=L / 2)$ depending on the force $P$ compressing the pinned cylindrical column made of steel St 35 with $R=22 \mathrm{~mm}, t=1 \mathrm{~mm}, L=545 \mathrm{~mm}$ 


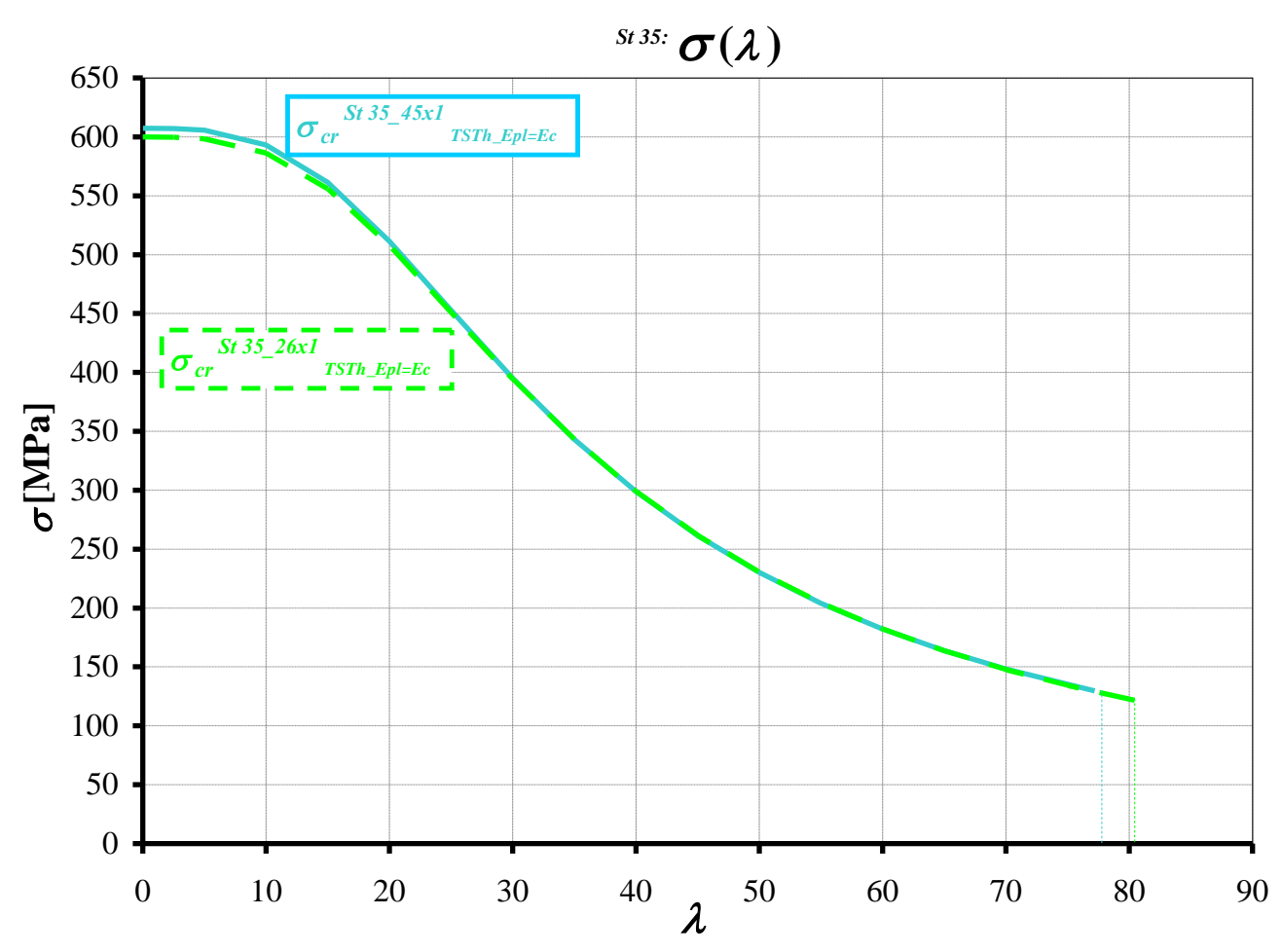

(a)

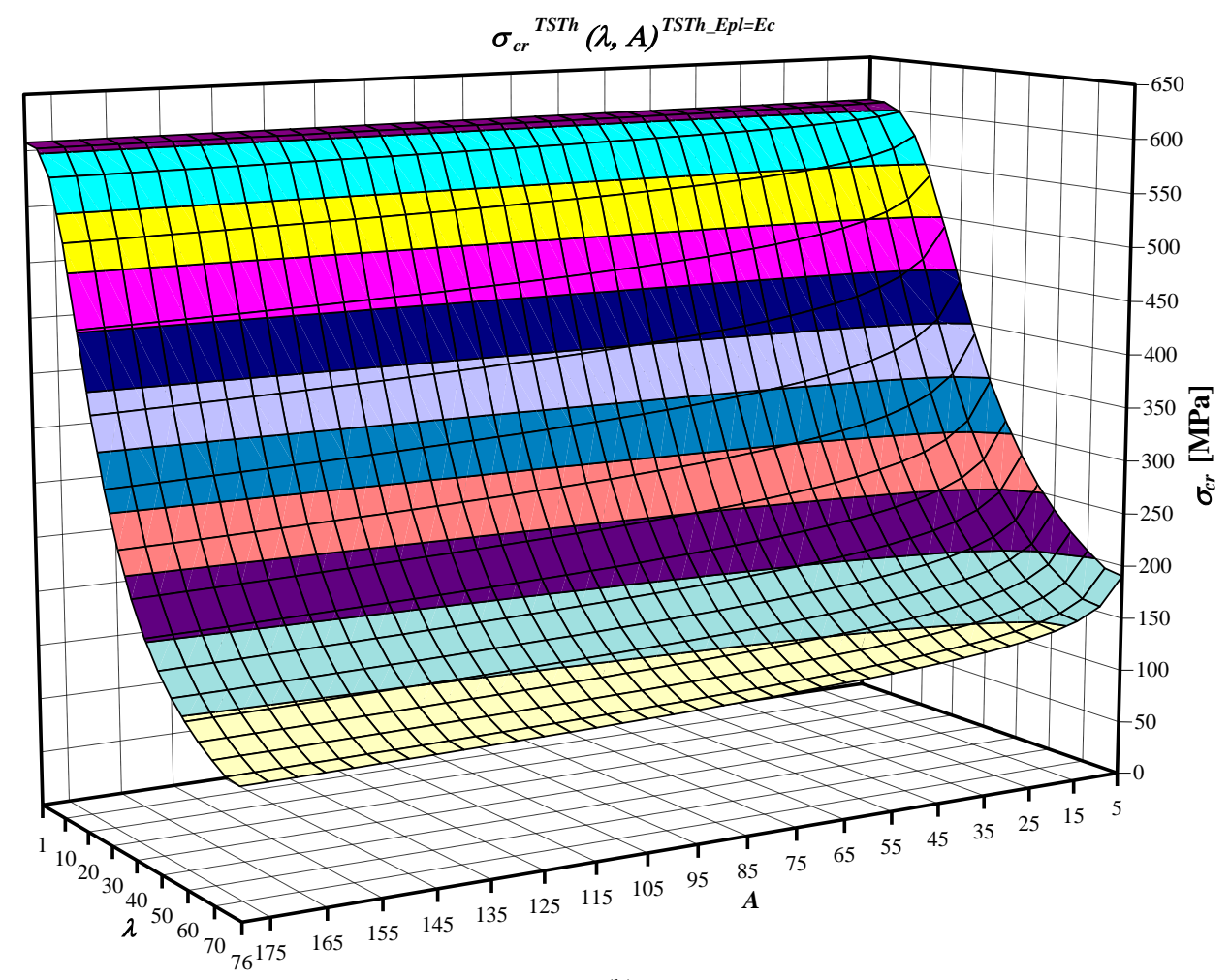

(b)

Fig. 26: Graphs of the theoretical functions calculated like pinned without friction (a): $\sigma_{c r}(\lambda)^{T S T h-E p l=E c}$, for the columns made of steel St35: $\phi 45 \times 1\left(E^{*}=202768.28 \mathrm{MPa}, R_{e}{ }^{*}=607.35 \mathrm{MPa}, \lambda_{l t d}=77.194\right)$ and $\phi 26 \times 1\left(E^{*}=193776.75 \mathrm{MPa}, R_{e}{ }^{*}=600.01\right.$ $\mathrm{MPa}, \lambda_{l t d}=80.528$ ), (b) surface function $\sigma_{c r}{ }^{e l-p l}(\lambda, A)^{T S T h_{-} E p l=E c}$ with $E_{p l}=E_{c}$ with $E_{p l}=0$ (and average values $E^{*}=198272.52$ $\left.\mathrm{MPa}, R_{e}{ }^{*}=603.68 \mathrm{MPa}, v=0.3, \lambda_{e l-l l}=78.86\right)$ 


\section{Discussion}

\section{A. Assumption: The Plastic Module Equals Zero $E_{p l}$ $=0$}

To check the possibility of a bigger simplification of a computing, next to the assumption that in the critical elastic-plastic transverse cross-section area keep a resistance both parts, i.e., elastic and plastic (in the elastic transverse cross-section area $A^{e l}$, with the static moment $S_{z}^{e l}$, there is the elastic Young's module $E>0$ and in the plastic transverse cross-section area $A^{p l}$, with the static moment $S_{z}^{p l}$, the plastic module equals compressing module $E_{p l}=E_{c}$ ), with simplification that in elastic-plastic states the moment of inertia is taken of whole transverse critical cross-section $J_{z}=J_{z}^{\text {all }}$, was also taken the assumption that the plastic module equals zehro $E_{p l}=0$.

On those assumptions were determined the equation of the elastic lines $y(x)^{e l}$, elastic slopes $(d y / d x)^{e l}$ (Fig. 27) and function of maximal deflection $y_{L / 2}(P)^{e l}$ in the elastic state were determined and (Fig. 28) for the cylindrical column in the elastic states with both pinned ends according to (Murawski, 2018).

Also the equation of the central elastic-plastic line $y(x)_{c r}{ }^{e l-p l}$, its elastic-plastic slopes $(d y / d x)_{c r}{ }^{e l-p l}$ (Fig. 27) and equation of maximal elastic-plastic deflection $y_{L / 2}(P)^{e l-p l}$ (Fig. 28) of the central line for the cylindrical column in the elastic-plastic states with both pinned ends at the critical situation were determined.

Figure 27 and 28 present the stability analysis: The elastic line $y(x)$, its slope $d y / d x$ and dependence $y_{L / 2}(P)$ with $E_{p l}=0$ of the cylindrical column made of St35 with $R=22$ $\mathrm{mm}, t=1 \mathrm{~mm}, L=545 \mathrm{~mm}$ compressed by ball-and-socket joints without friction ( $E=202768,28 \mathrm{MPa}$ was assumed).

Figure 29-40 show the graphs of the stresses $\sigma_{n}, \varepsilon_{y}(x, y)$, strains $\sigma_{n}, \varepsilon_{y}(x, y)$ and extensions $\Delta L, \Delta 2 t(x, y)$ with $E_{p l}=0$ and $J_{z}=J_{z}^{\text {all }}$ for $x=0 \div L$ and $y= \pm 0.2 \div 1.0 R$ in the pinned cylindrical column made of steel St35 with dimensions: $R=22 \mathrm{~mm}, t=1 \mathrm{~mm}, L=545 \mathrm{~mm}$ compressed for the column with both pinned ends in the elastic-plastic states, as the theoretical example.

From Fig. 29a and 29c for the analyzed case of compression with $P=0.25 \cdot P_{c r}=8810.615 \mathrm{~N}$ and bending, computed with $E_{p l}=0$, results that the courses of the normal stresses $\sigma_{y}(x, y)$, strains $\varepsilon_{y}(x, y)$ and extensions $\Delta L(x, y)$ are symmetrical in relation to the layer with geometrical axis, in which the stresses are equal to the pure compressive stresses $(R=0)$, but their values are bigger on the concave side. All values have the minus signs (are negative), i.e., all fibers are compressed and shortened.

From Fig. 29b and 29d results that the courses of the transverse stresses $\sigma_{y}(x, y)$, strains $\varepsilon_{y}(x, y)$ and extensions $\Delta 2 t(x, y)$, orthogonal to the normal stresses, strains and extensions, are also symmetrical in relation to the layer with geometrical axis $(R=0)$ with values bigger on the concave side but with the plus signs (are positive), what proves the existence of the tension in the transverse direction, orthogonal to the longitudinal axis.

From Fig. 30a and 30c for the analyzed case of compression with $P=0.5 \cdot P_{c r}=17621.23 \mathrm{~N}$ and bending, computed with $E_{p l}=0$, results that the courses of the normal stresses $\sigma_{y}(x, y)$, strains $\varepsilon_{y}(x, y)$ and extensions $\Delta L(x, y)$ are symmetrical in relation to the layer with geometrical axis, in which the stresses are equal to the pure compressive stresses $(R=0)$, but their values are bigger on the concave side. The values of the transverse strains $\sigma_{n}$ are analogous to the course of normal stresses $\varepsilon_{n}$, but with values decreased by the inverse $1 / E$ - of Young's modulus of column elasticity in the parallel direction to the axis. All values have the minus signs (are negative), i.e., all fibers are compressed and shortened.

From Fig. 30b and 30d results that the courses of the transverse stresses $\sigma_{y}(x, y)$, strains $\varepsilon_{y}(x, y)$ and extensions $\Delta 2 t(x, y)$, orthogonal to the normal stresses, strains and extensions, are also symmetrical in relation to the layer with geometrical axis $(R=0)$ with values bigger on the concave side but with the plus signs (are positive), what proves the existence of the tension in the transverse direction, orthogonal to the longitudinal axis.

From Fig. 31a and 31c for the analyzed case of compression with $P=0.67 \cdot P_{c r}=23608.460 \mathrm{~N}$ and bending, computed with $E_{p l}=0$, results that the courses of the normal stresses $\sigma_{y}(x, y)$, strains $\varepsilon_{y}(x, y)$ and extensions $\Delta 2 t(x, y)$ are symmetrical in relation to the layer with geometrical axis, in which the stresses are equal to the pure compressive stresses $(R=0)$, but their values are bigger on the concave side. All values, except the edge fibre on the convex side, have the minus signs (are negative), i.e., all fibers are compressed and shortened, except the edge fibre, which is unloaded and unextended.

From Fig. $31 \mathrm{~b}$ and $31 \mathrm{~d}$ results that the courses of the transverse stresses $\sigma_{y}(x, y)$, strains $\varepsilon_{y}(x, y)$ and extensions $\Delta 2 t(x, y)$, orthogonal to the normal stresses, strains and extensions, are also symmetrical in relation to the layer with geometrical axis $(R=0)$ with values bigger on the concave side but with the plus signs. The edge fibre also is unloaded and unextended.

From Fig. 32a and 32c for the analyzed case of compression with $P=0.813 \cdot P_{c r}=28652.120 \mathrm{~N}$ and bending, computed with $E_{p l}=0$, results that the courses of the normal stresses $\sigma_{y}(x, y)$, strains $\varepsilon_{y}(x, y)$ and extensions $\Delta L(x, y)$ are symmetrical in relation to the layer with geometrical axis $(R=0)$, in which the stresses are equal to the pure compressive stresses, but their values are bigger on the concave side. The values have the minus signs (are negative) in the internal fibers on the concave side-i.e., fibers are compressed and shortened and the plus signs are (positive) on the opposite convex side-fibers are tensed and extended. All fibers are in the elastic state yet. 
From Fig. $32 \mathrm{~b}$ and $32 \mathrm{~d}$ results that the courses of the transverse stresses $\sigma y(x, y)$, strains $\varepsilon y(x, y)$ and extensions $\Delta 2 t(x, y)$, orthogonal to the normal stresses, strains and extensions, are also symmetrical in relation to the layer with geometrical axis $(R=0)$ with values bigger on the concave side but with the plus signs (are positive) of the tension in the transverse direction. The values have the plus signs (are positive) in the transverse internal fibers on the concave side - i.e., fibers are tensed and extended and the minus signs (are negative) on the opposite convex side - fibers are compressed and shortened. All fibers are in the elastic state yet.

From Fig. 33a and $33 \mathrm{c}$ for the analyzed case of compression with $P=0.907 \cdot P_{c r}=31964.911 \mathrm{~N}$ and bending, computed with $E_{p l}=0$, results that the courses of the normal stresses $\sigma_{y}(x, y)$, strains $\varepsilon_{y}(x, y)$ and extensions $\Delta L(x, y)$ are symmetrical in relation to the layer with geometrical axis $(R=0)$, in which the stresses are equal to the pure compressive stresses, but their values are bigger on the concave side. The values have the minus signs (are negative) in the internal fibers on the concave side - i.e., fibers are compressed and shortened and the plus signs are (positive) on the opposite convex side - fibers are tensed and extended. A part of fibers are in the plastic state. The angle of plastic area is $\sigma=\sigma_{c r} / 2=24.60 \mathrm{deg}$.

From Fig. 33b and 33d results that the courses of the transverse stresses $\sigma_{y}(x, y)$, strains $\varepsilon_{y}(x, y)$ and extensions $\Delta 2 t(x, y)$, orthogonal to the normal stresses, strains and extensions, are also symmetrical in relation to the layer with geometrical axis $(R=0)$ with values bigger on the concave side but with the plus signs (are positive) of the tension in the transverse direction.

The values have the plus signs (are positive) in the transverse internal fibers on the concave side - i.e., fibers are tensed and extended and the minus signs (are negative) on the opposite convex side - fibers are compressed and shortened. A part of fibers are in the plastic state. The angle of plastic area is $\sigma=\sigma_{c r} / 2=24.60 \mathrm{deg}$.

From Fig. $34 \mathrm{a}$ and $34 \mathrm{c}$ for the analyzed case of compression with $P=1.0 \cdot P_{c r}=35242,46 \mathrm{~N}$ and bending, computed with $E_{p l}=0$, results that the courses of the normal stresses $\sigma_{y}(x, y)$, strains $\varepsilon_{y}(x, y)$ and extensions $\Delta L(x, y)$ are symmetrical in relation to the layer with geometrical axis $(R=0)$, in which the stresses are equal to the pure compressive stresses, but their values are bigger on the concave side. The values have the minus signs (are negative) in the internal fibers on the concave side - i.e., fibers are compressed and shortened and the plus signs are (positive) on the opposite convex side - fibers are tensed and extended. A part of fibers are in the plastic state. The angle of plastic area is $\sigma=\sigma_{c r}=49.20 \mathrm{deg}$.

From Fig. 34b and 34d results that the courses of the transverse stresses $\sigma_{y}(x, y)$, strains $\varepsilon_{y}(x, y)$ and extensions $\Delta 2 t(x, y)$, orthogonal to the normal stresses, strains and extensions, are also symmetrical in relation to the layer with geometrical axis $(R=0)$ with values bigger on the concave side but with the plus signs (are positive) of the tension in the transverse direction. The values have the plus signs (are positive) in the transverse internal fibers on the concave side - i.e., fibers are tensed and extended and the minus signs (are negative) on the opposite convex side - fibers are compressed and shortened. A part of fibers are in the plastic state. The angle of plastic area is $\sigma=\sigma_{c r}=49.20 \mathrm{deg}$.

Figure 35 and 36 show the surface functions of the normal stresses $\sigma_{n}(x, y)$ in the cylindrical pinned column made of steel St35 with dimensions: $R=22 \mathrm{~mm}, t=1$ $\mathrm{mm}, L=545 \mathrm{~mm}$ loaded with the force $P_{c r}=35242.46 \mathrm{~N}$ and computed with $E_{p l}=0$.

Figure 37 shows the surface functions of the normal stresses $\sigma_{n}(x, y)[\mathrm{MPa}]$, strains $\sigma_{n}$ and extensions $\Delta L$ [mm], related to the straight and Fig. 38 -related to the buckled, cylindrical column, loaded with the force $P_{c r}=$ $35242.46 \mathrm{~N}$ and computed with $E_{p l}=0$.

Figure 39 shows the surface functions of the transverse stresses $\sigma_{y}[\mathrm{MPa}]$, strains $\sigma_{y}$ and extensions $\Delta 2 t[\mathrm{~mm}]$ related to the straight and Fig. 40 -related to the buckled, cylindrical column, loaded with the force $P_{c r}$ $=35242,46 \mathrm{~N}$ and computed with $E_{p l}=0$.

Figure 41 presents the values of the coordinate $y_{\square n=0 \text {, }}$ $x=L / 2(P)$ of the zero normal stress in the critical crosssection for the analyzed cylindrical column compressed by ball-and-socket joints depending on the external load $P$ compressing the pinned cylindrical column made of steel St35 with $R=22 \mathrm{~mm}, t=1 \mathrm{~mm}, L=545 \mathrm{~mm}$ as the theoretical example computed with $E_{p l}=0$.

Figure 42 presents the values of the elongations $\Delta L_{x=L / 2, y= \pm R, 0}(P)$ in the critical (middle) cross-section of the cylindrical column on the two opposite generate lines and the central one $(y=0, \pm R)$ depending on the external load $P$ and computed with $E_{p l}=0$.

For computing were assumed the values of the steel St35 parameters (as the average for tubes $\sigma 26 \times 1$ and $\sigma 45 \times 1$, Murawski, 2020a): $E^{*}=198272.52 \mathrm{MPa}, R_{e}{ }^{*}=$ 603.68 MPa, $\sigma=0.3, \sigma_{\text {el-llt }}=78.86$.

On the assumption that $\sigma_{n}(x=L / 2, y=R \cos \alpha)=R_{e}{ }^{*}$ was determined the critical compressive stress $\sigma_{n}^{e i-p l}$.

Figure 43 shows the graphs of the theoretical functions calculated like pinned without friction: $\sigma_{c r}(\lambda)^{T S T h \_E p l=0}$, for the columns made of steel St35: $\sigma 45 \times 1\left(E^{*}=202768.28 \mathrm{MPa}, R_{e}{ }^{*}=607.35 \mathrm{MPa}, \sigma_{l t d}=\right.$ $77.194)$ and $\sigma 26 \times 1\left(E^{*}=193776.75 \mathrm{MPa}, R_{e}{ }^{*}=600.01\right.$ $\left.\mathrm{MPa}, \sigma_{l t d}=80.528\right)$ as well as the surface function $\sigma_{c r}{ }^{e l-p l}$

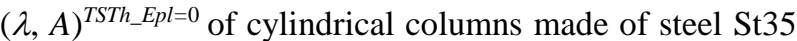
with $E_{p l}=0$ and $J_{z}=J_{z}$ all .

\section{B. Comparison of the Results}

In order to appreciate the theoretical results obtained from the TSTh they are compared to the experimental findings. 
Krzysztof Murawski / International Journal of Structural Glass and Advanced Materials Research 2021, Volume 5: 134.194 DOI: 10.3844/sgamrsp.2021.134.194

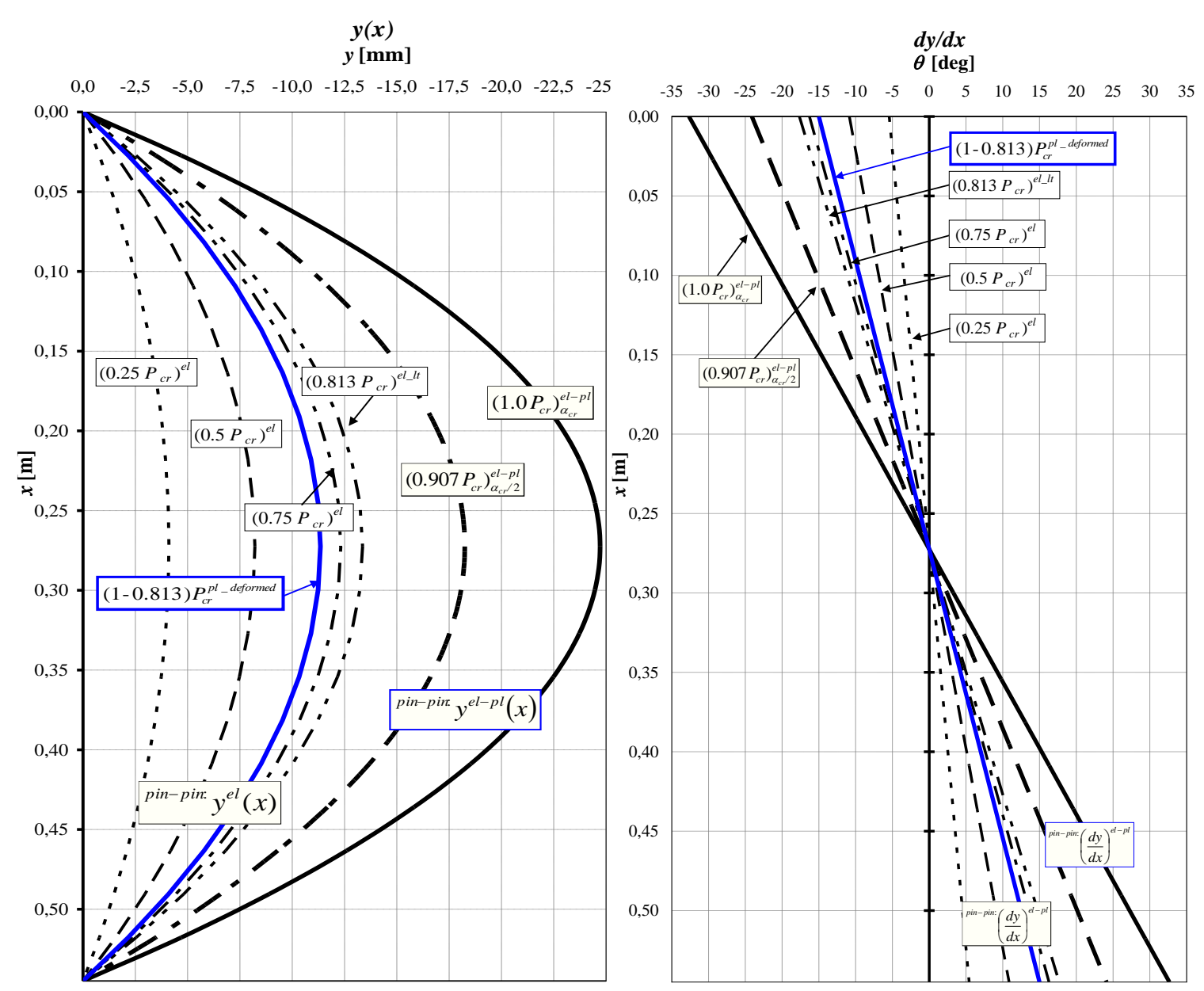

Fig. 27: Graphs of the: (a) curved axis $y(x)$ and (b) its slope $d y / d x$ with $E_{p l}=0$ of the cylindrical column made of St35 with $R=22 \mathrm{~mm}$, $t=1 \mathrm{~mm}, L=545 \mathrm{~mm}$ compressed by ball-and-socket joints without friction

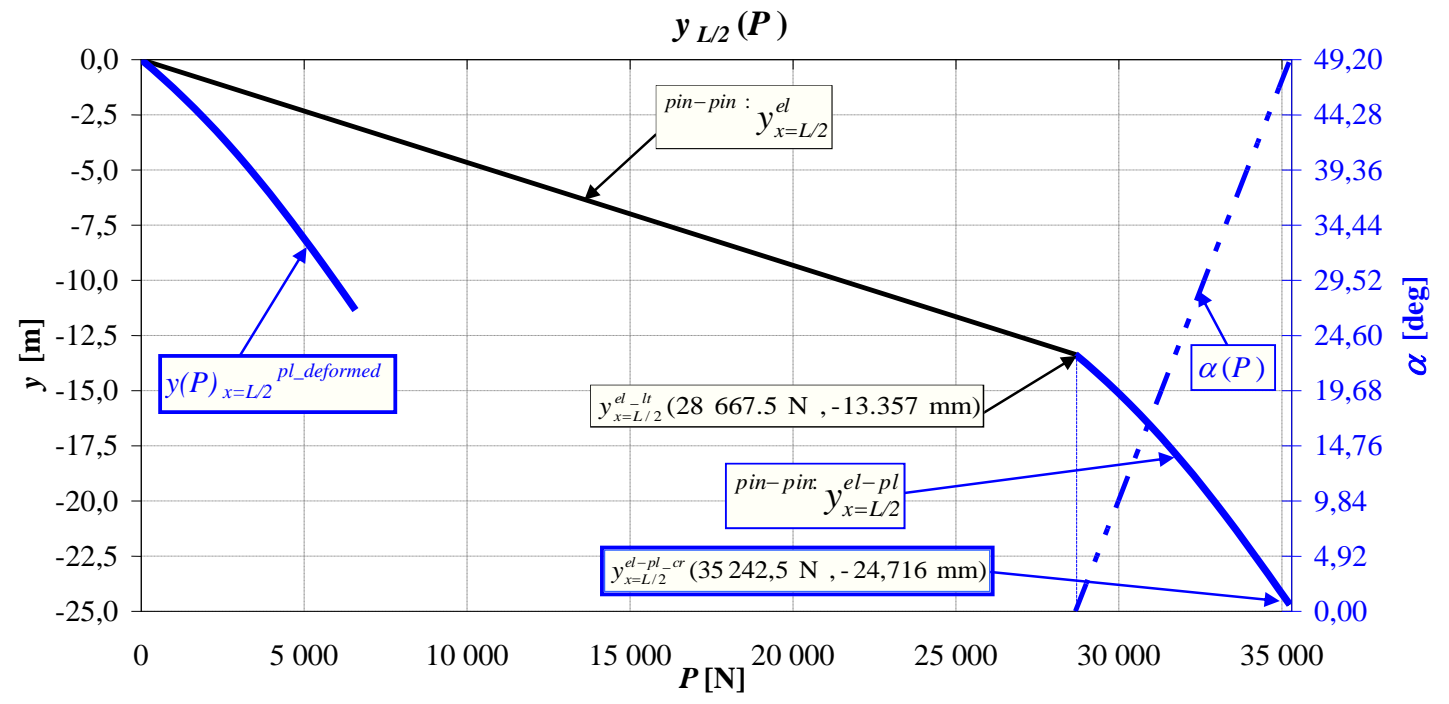

Fig. 28: Graph of the function $y_{L / 2}(P)$ with $E_{p l}=0$ of the cylindrical column made of steel St 35 with $R=22 \mathrm{~mm}, t=1 \mathrm{~mm}, L=545 \mathrm{~mm}$ compressed by ball-and-socket joints without friction 


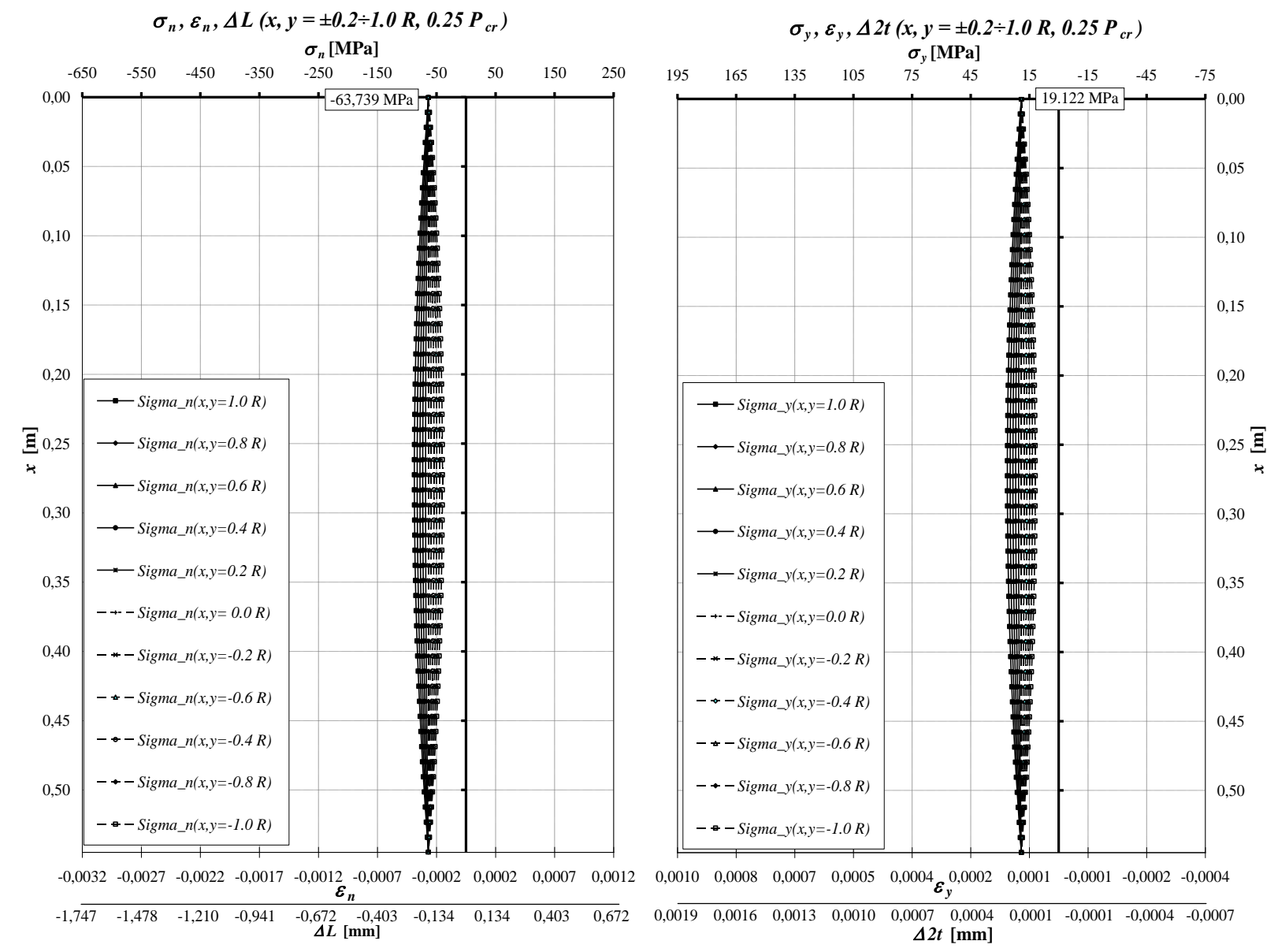

(a)

(b)

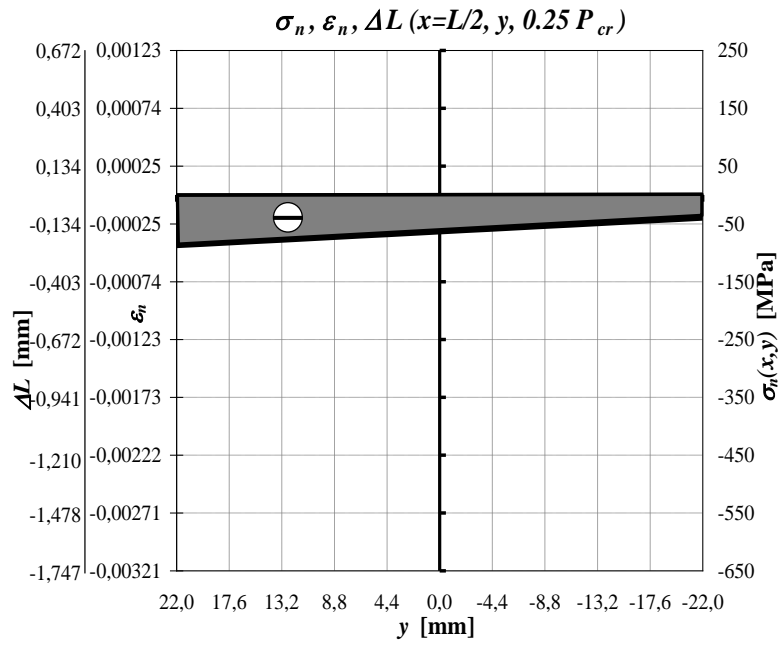

(c)

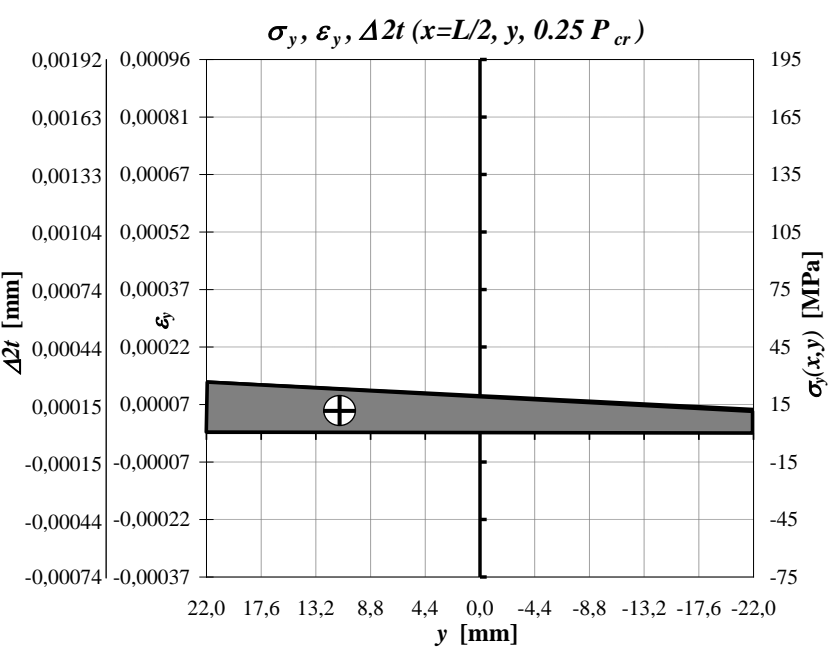

(d)

Fig. 29: Values of the stresses $\sigma_{n}, \varepsilon_{y}(x, y)$, strains $\sigma_{n}, \varepsilon_{y}(x, y)$ and extensions $\Delta L, \Delta 2 t(x, y)$ with $E_{p l}=0$ and $J_{z}=J_{z}^{\text {all }}$ for $x=0 \div L$ and $y= \pm$ $0.2 \div 1.0 R$ in the pinned cylindrical column made of steel St 35 with dimensions: $R=22 \mathrm{~mm}, t=1 \mathrm{~mm}, L=545 \mathrm{~mm}$ compressed with the force $P=0.25 \cdot P_{c r}=8810.615 \mathrm{~N}$ in the longitudinal $(\mathrm{a}, \mathrm{b})$ and transverse cross section $(\mathrm{c}, \mathrm{d})$ for $x=L / 2=272.5 \mathrm{~mm}$ 


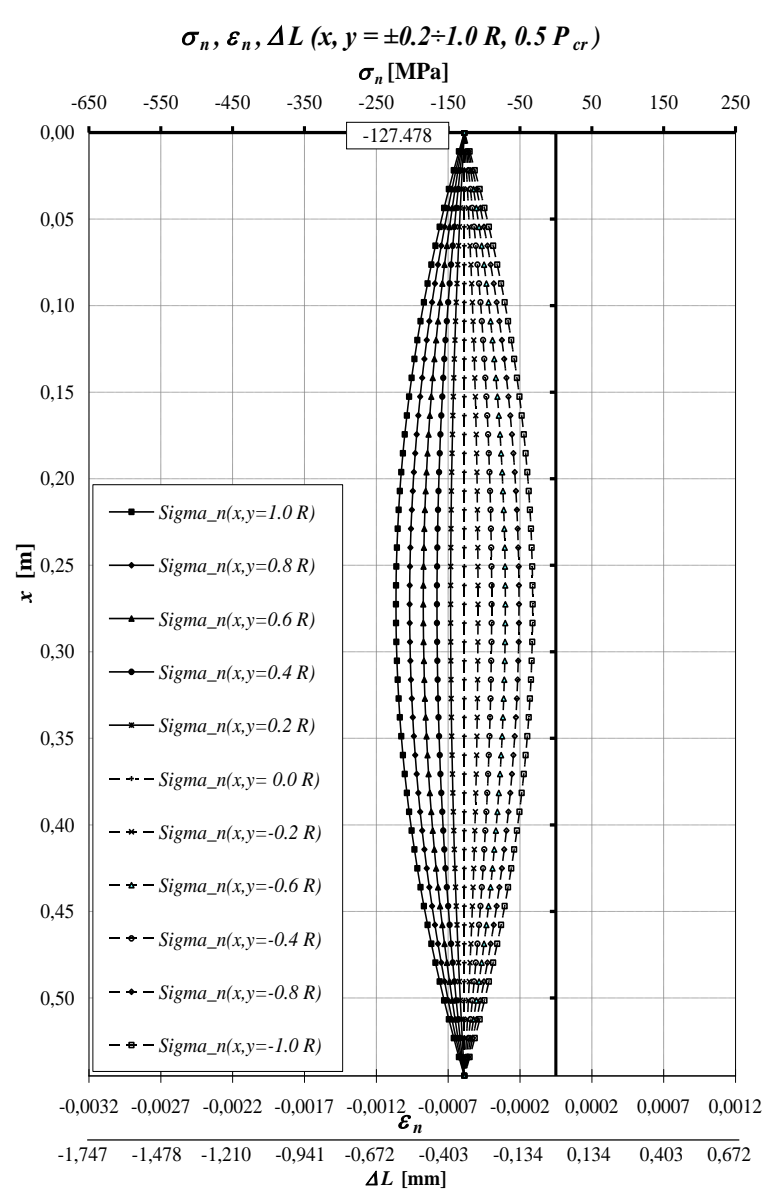

(a)

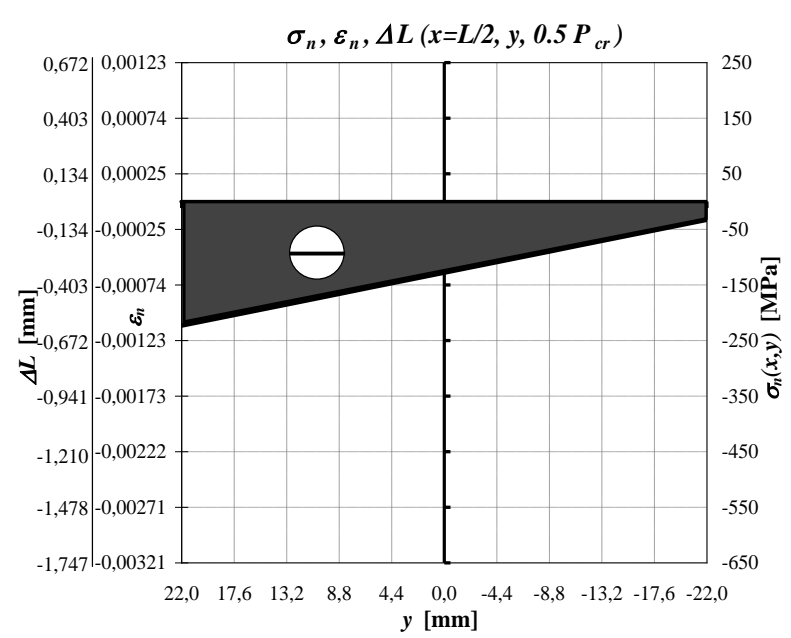

(c)

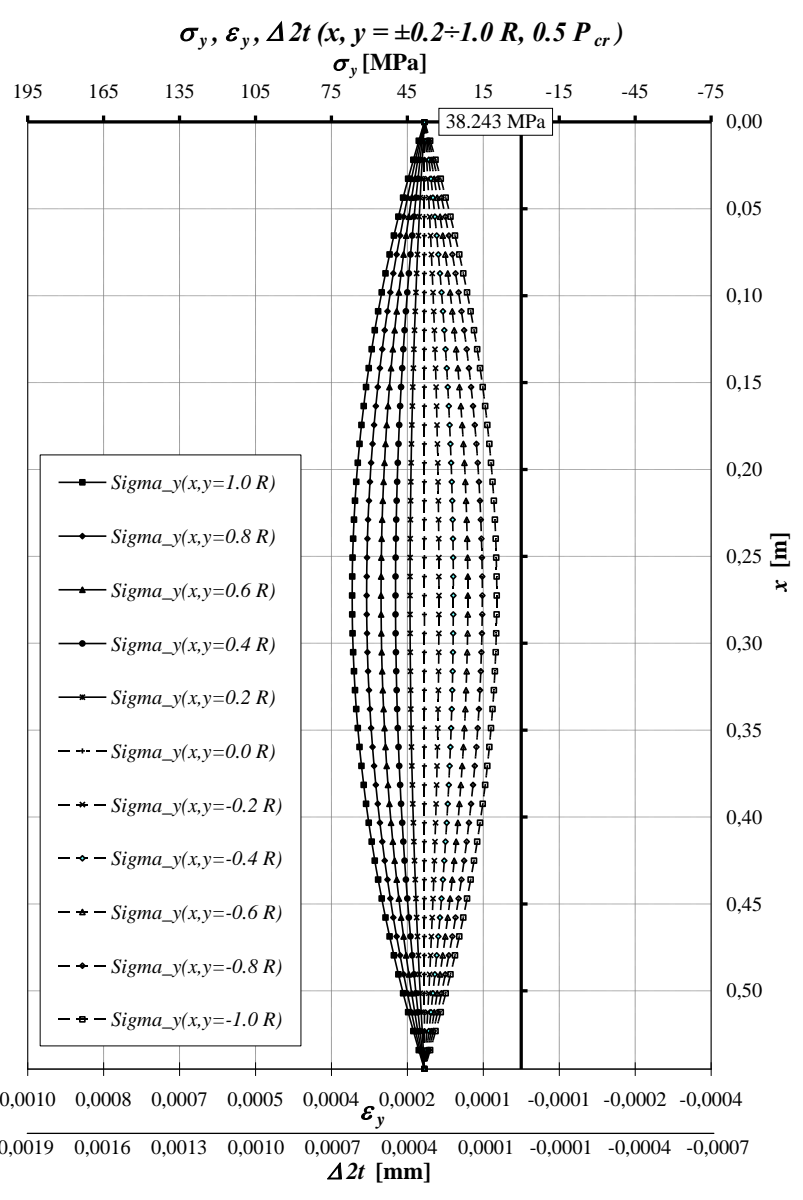

(b)

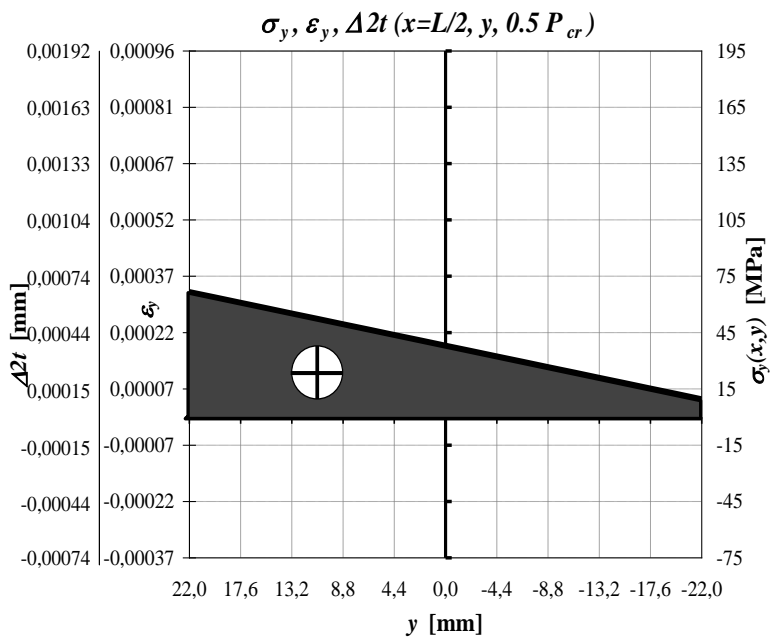

(d)

Fig. 30: Values of the stresses $\sigma_{n}, \sigma_{y}(x, y)$, strains $\varepsilon_{n}, \varepsilon_{y}(x, y)$ and extensions $\Delta L, \Delta 2 t(x, y)$ with $E_{p l}=0$ and $J_{z}=J_{z}$ all for $x=0 \div L$ and $y= \pm$ $0.2 \div 1.0 R$ in the pinned cylindrical column made of steel St 35 with dimensions: $R=22 \mathrm{~mm}, t=1 \mathrm{~mm}, L=545 \mathrm{~mm}$ compressed with the force $P=0.5 \cdot P_{c r}=17621.23 \mathrm{~N}$ in the longitudinal $(\mathrm{a}, \mathrm{b})$ and transverse cross section $(\mathrm{c}, \mathrm{d})$ for $x=L / 2=272.5 \mathrm{~mm}$ 


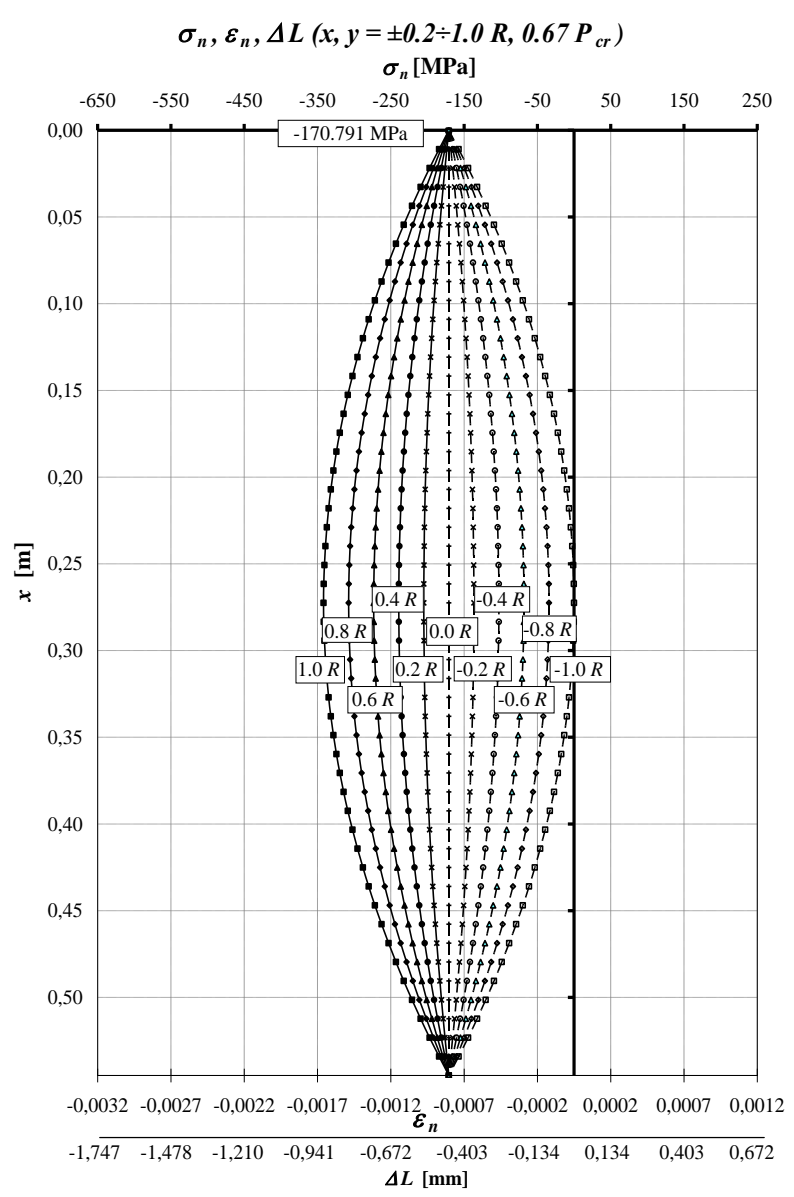

(a)

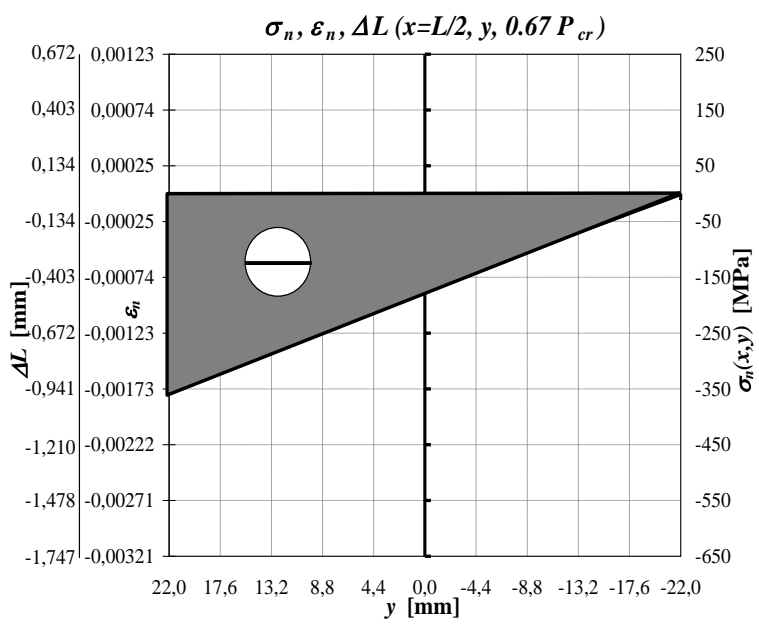

(c)

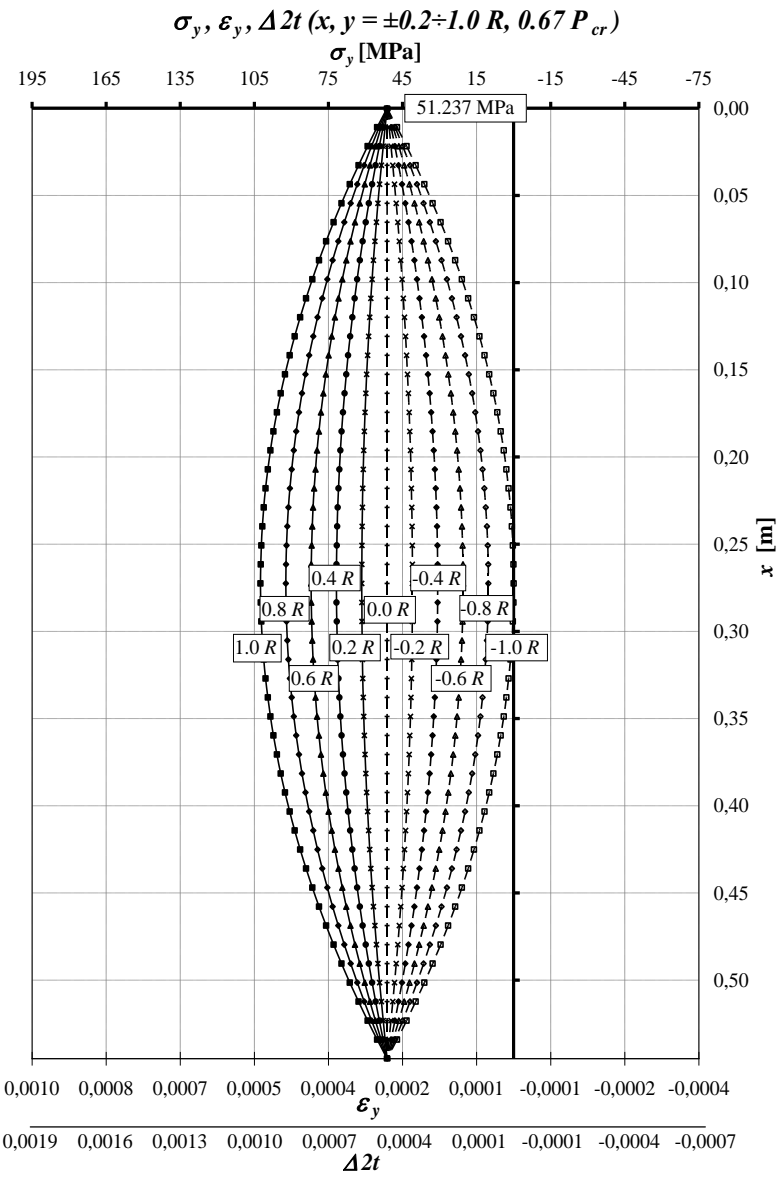

(b)

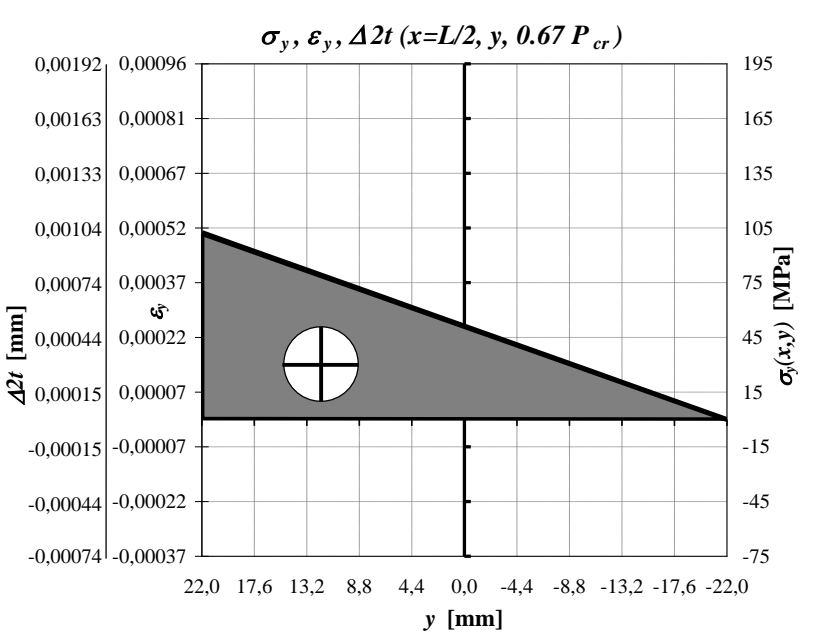

(d)

Fig. 31: Values of the stresses $\sigma_{n}, \sigma_{y}(x, y)$, strains $\varepsilon_{n}, \varepsilon_{y}(x, y)$ and extensions $\Delta L, \Delta 2 t(x, y)$ with $E_{p l}=0$ and $J_{z}=J_{z}^{\text {all }}$ for $x=0 \div L$ and $y= \pm$ $0.2 \div 1.0 R$ in the pinned cylindrical column made of steel St 35 with dimensions: $R=22 \mathrm{~mm}, t=1 \mathrm{~mm}, L=545 \mathrm{~mm}$ compressed with the force $P=0.67 \cdot P_{c r}=23608.460 \mathrm{~N}$ in the longitudinal $(\mathrm{a}, \mathrm{b})$ and transverse cross section $(\mathrm{c}, \mathrm{d})$ for $x=L / 2=272.5 \mathrm{~mm}$ 


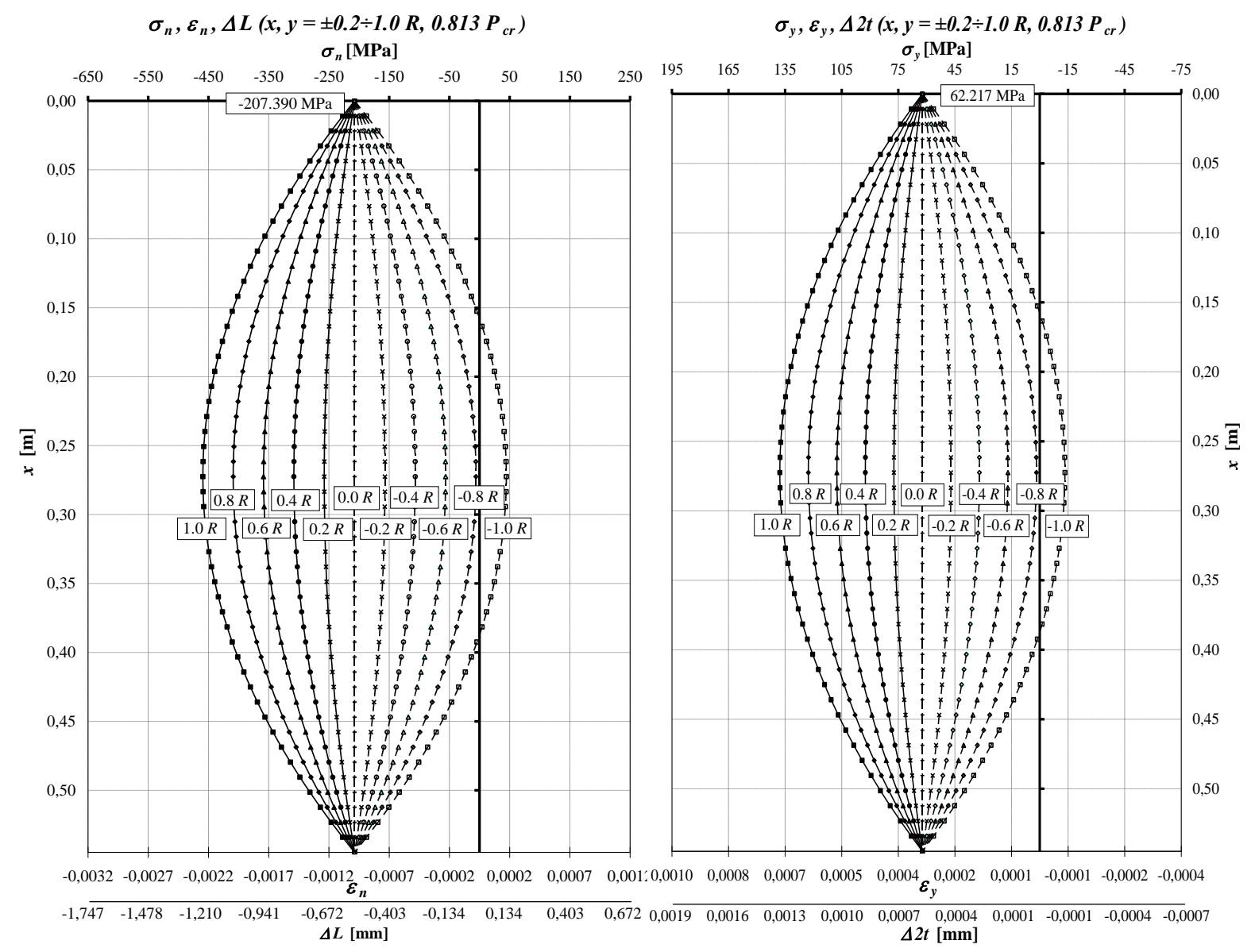

(a)

(b)

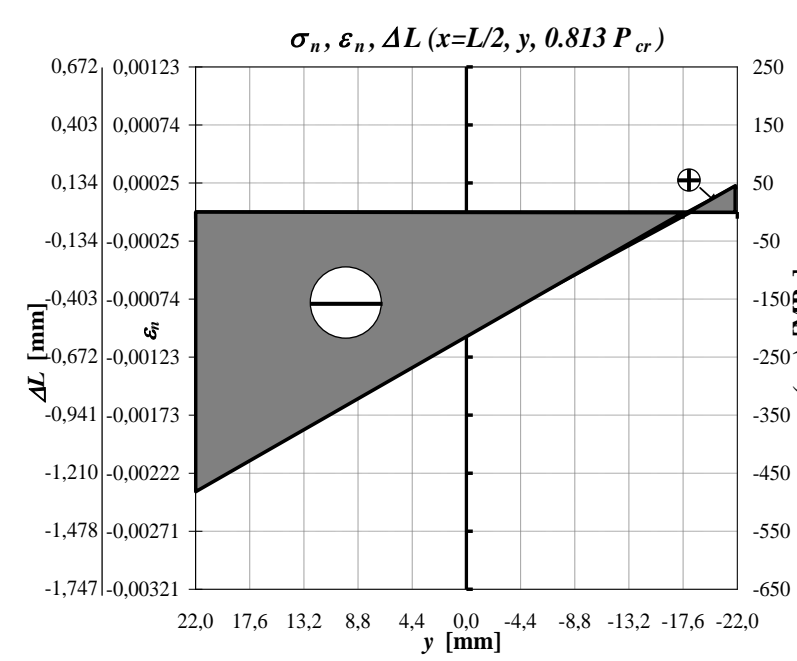

(c)

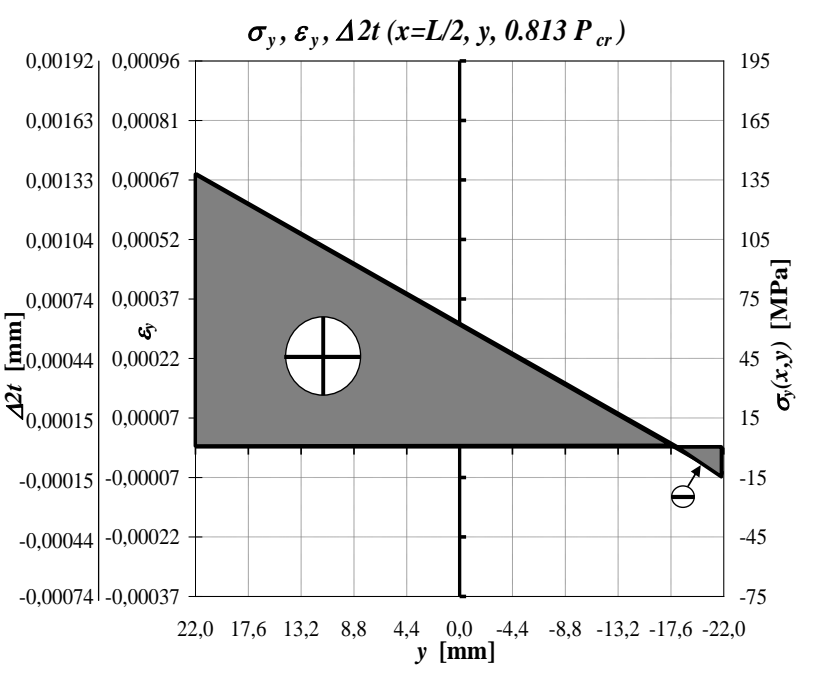

(d)

Fig. 32: Values of the stresses $\sigma_{n}, \sigma_{y}(x, y)$, strains $\varepsilon_{n}, \varepsilon_{y}(x, y)$ and extensions $\Delta L, \Delta 2 t(x, y)$ with $E_{p l}=0$ and $J_{z}=J_{z}$ all for $x=0 \div L$ and $y= \pm$ $0.2 \div 1.0 R$ in the pinned cylindrical column made of steel St 35 with dimensions: $R=22 \mathrm{~mm}, t=1 \mathrm{~mm}, L=545 \mathrm{~mm}$ compressed with the force $P=0.813 \cdot P_{c r}=28652.120 \mathrm{~N}$ in the longitudinal $(\mathrm{a}, \mathrm{b})$ and transverse cross section $(\mathrm{c}, \mathrm{d})$ for $x=L / 2=272.5 \mathrm{~mm}$ 
Krzysztof Murawski / International Journal of Structural Glass and Advanced Materials Research 2021, Volume 5: 134.194 DOI: 10.3844/sgamrsp.2021.134.194

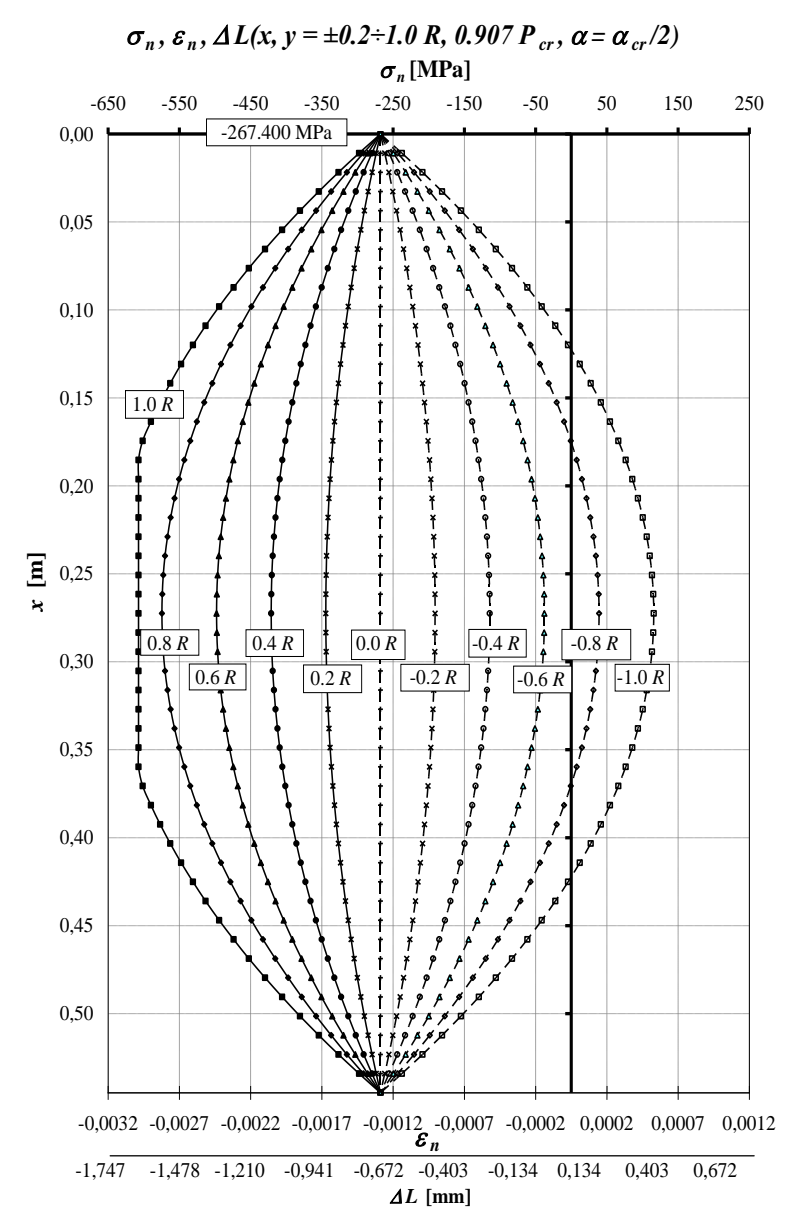

(a)

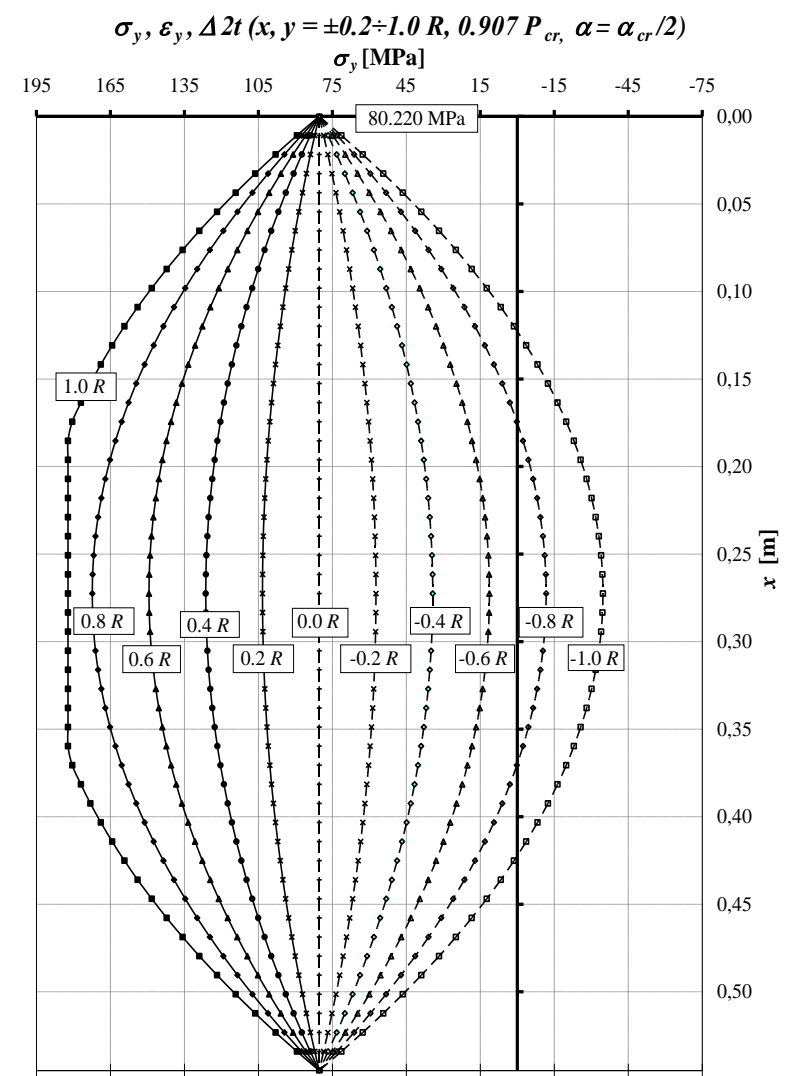

$\begin{array}{llllllllll}0,0010 & 0,0008 & 0,0007 & 0,0005 & 0,0004 & \varepsilon_{y}^{0,0002} & 0,0001 & -0,0001 & -0,0002 & -0,0004\end{array}$

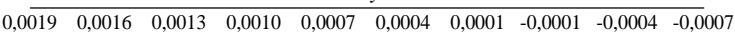
$\Delta 2 t[\mathrm{~mm}]$

(b)

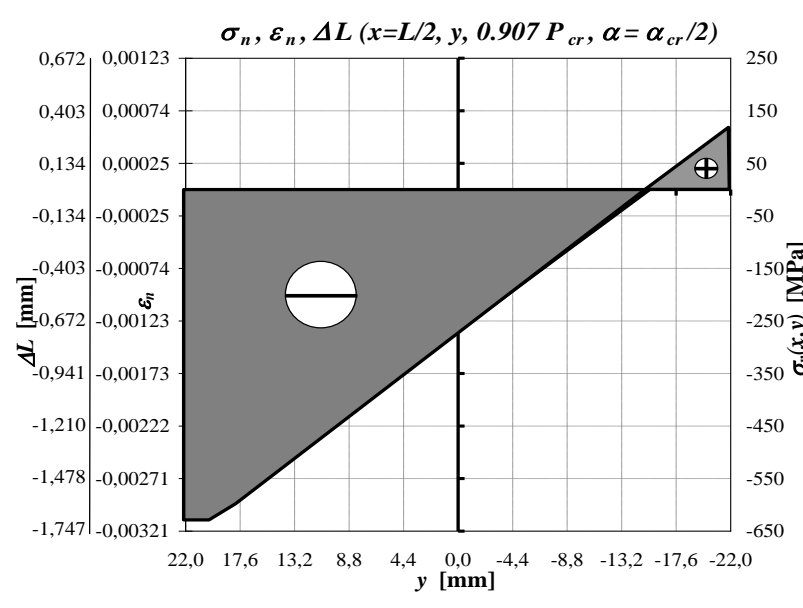

(c)

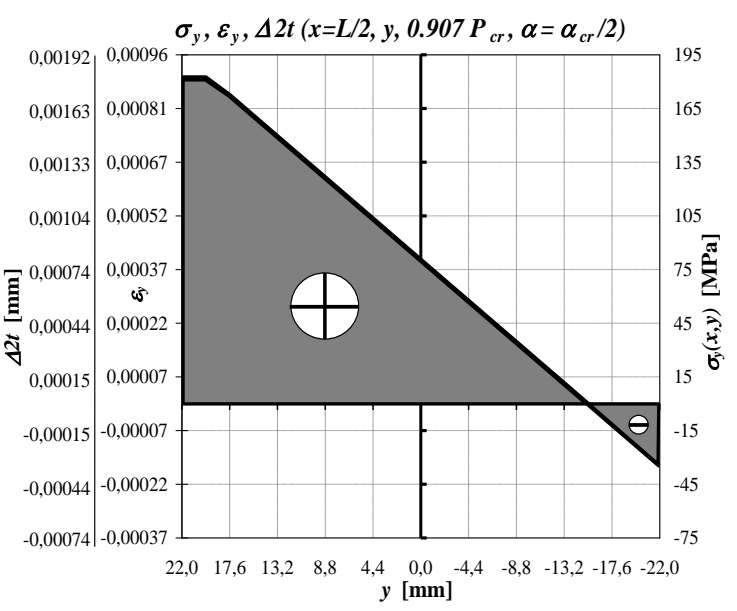

(d)

Fig. 33: Values of the stresses $\sigma_{n}, \sigma_{y}(x, y)$, strains $\varepsilon_{n}, \varepsilon_{y}(x, y)$ and extensions $\Delta L, \Delta 2 t(x, y)$ with $E_{p l}=0$ and $J_{z}=J_{z}$ all for $x=0 \div L$ and $y= \pm$ $0.2 \div 1.0 R$ in the pinned cylindrical column made of steel St 35 with dimensions: $R=22 \mathrm{~mm}, t=1 \mathrm{~mm}, L=545 \mathrm{~mm}$ compressed with the force $P=0.907 \cdot P_{c r}=31964.911 \mathrm{~N}$ by $\alpha=\alpha_{c r} / 2=24.60 \mathrm{deg}$ in the longitudinal $(\mathrm{a}, \mathrm{b})$ and transverse cross section (c, d) for $x=L / 2=272.5 \mathrm{~mm}$ 


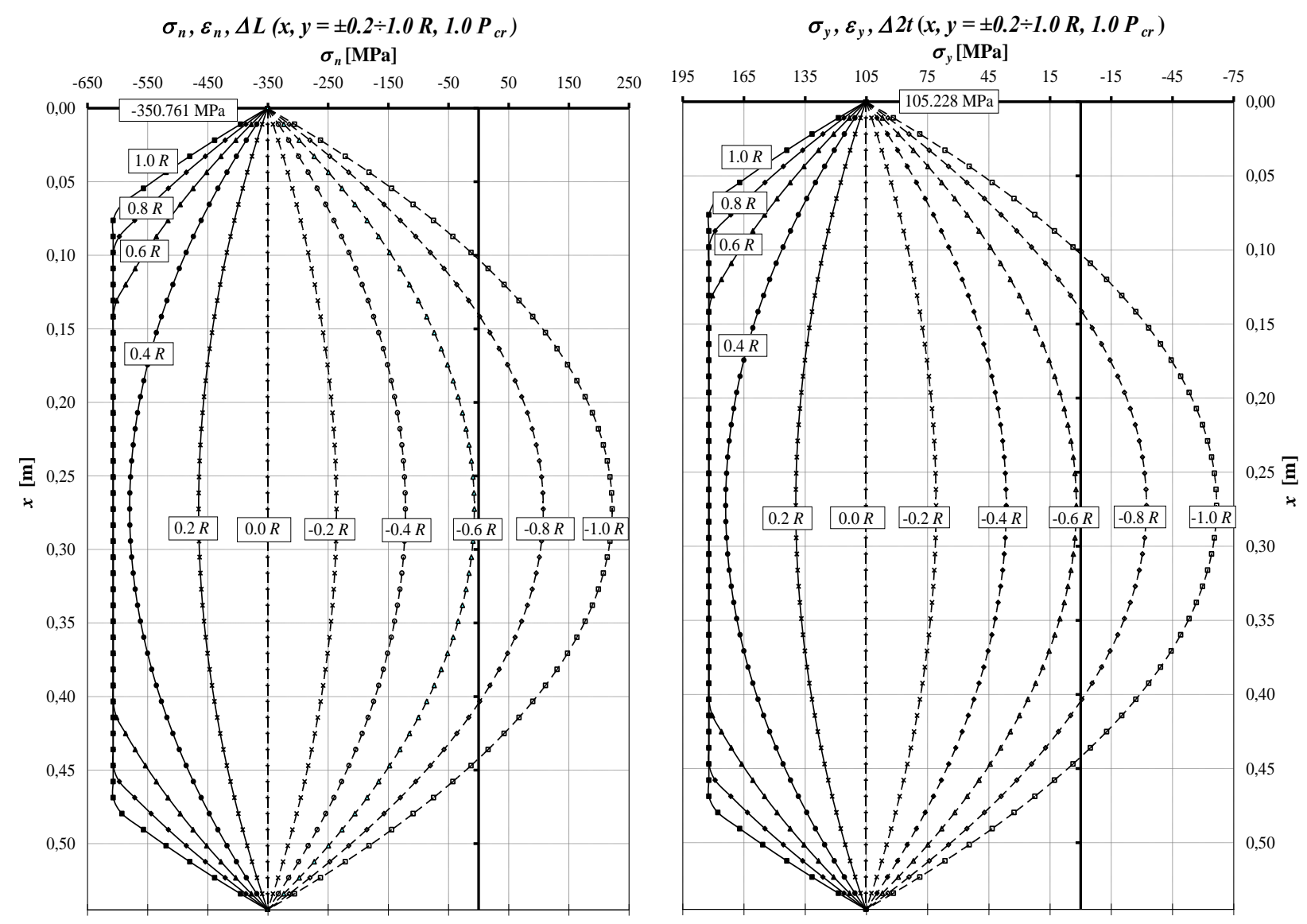

$\begin{array}{llllllllllllllllllllllll}-0,0032 & -0,0027 & -0,0022 & -0,0017 & -0,0012 & -0,0007 & -0,0002 & 0,0002 & 0,0007 & 0,0012 & 0,0010 & 0,0008 & 0,0007 & 0,0005 & 0,0004 & 0,0002 & 0,0001 & -0,0001 & -0,0002 & -0,0004\end{array}$

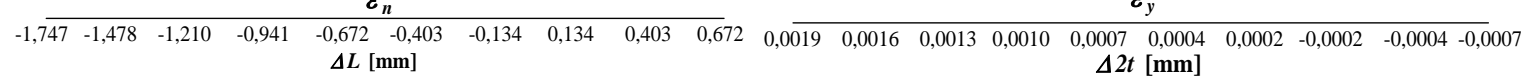

(a)

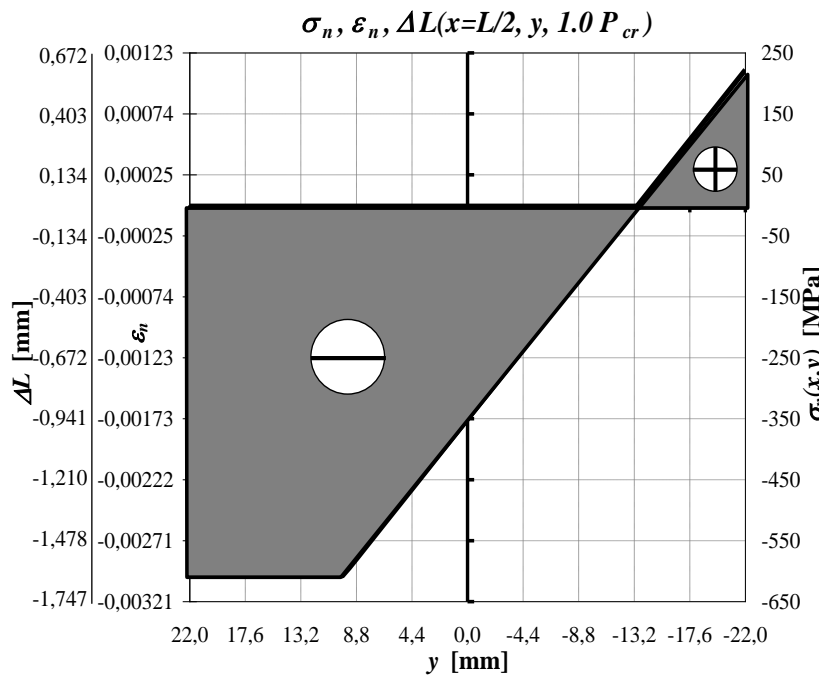

(c) (b)

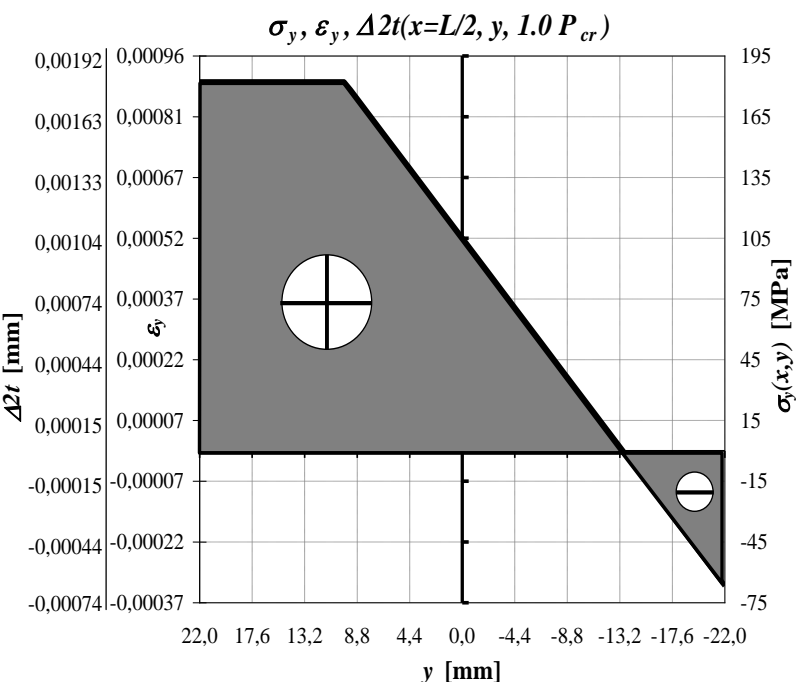

(d)

Fig. 34: Values of the stresses $\sigma_{n}, \sigma_{y}(x, y)$, strains $\varepsilon_{n}, \varepsilon_{y}(x, y)$ and extensions $\Delta L, \Delta 2 t(x, y)$ with $E_{p l}=0$ and $J_{z}=J_{z}$ all for $x=0 \div L$ and $y= \pm$ $0.2 \div 1.0 R$ in the pinned cylindrical column made of steel St 35 with dimensions: $R=22 \mathrm{~mm}, t=1 \mathrm{~mm}, L=545 \mathrm{~mm}$ compressed with the force $P=1.0 \cdot P_{c r}=35242.46 \mathrm{~N}$ by $\alpha=\alpha_{c} / 2=49.20 \mathrm{deg}$ in the longitudinal (a, b) and transverse cross section (c, d) for $x=L / 2=272.5 \mathrm{~mm}$ 

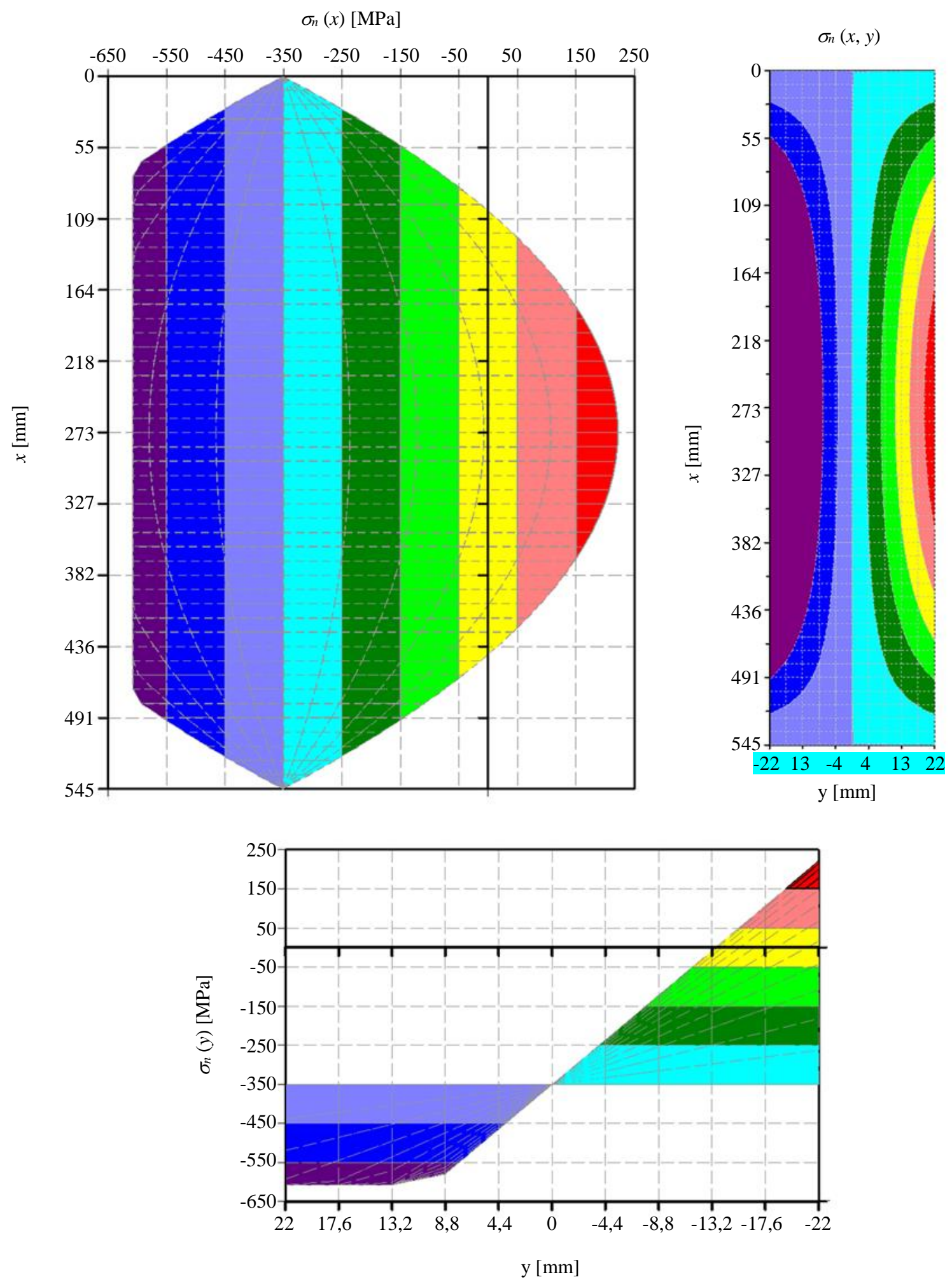

Fig. 35: Values of the stresses $\sigma_{n}(x, y)$ with $E_{p l}=0$ and $J_{z}=J_{z}$ all in the axially loaded with the force $P_{c r}$ cylindrical pinned column made of steel St35 with dimensions: $R=22 \mathrm{~mm}, t=1 \mathrm{~mm}, L=545 \mathrm{~mm}$ 

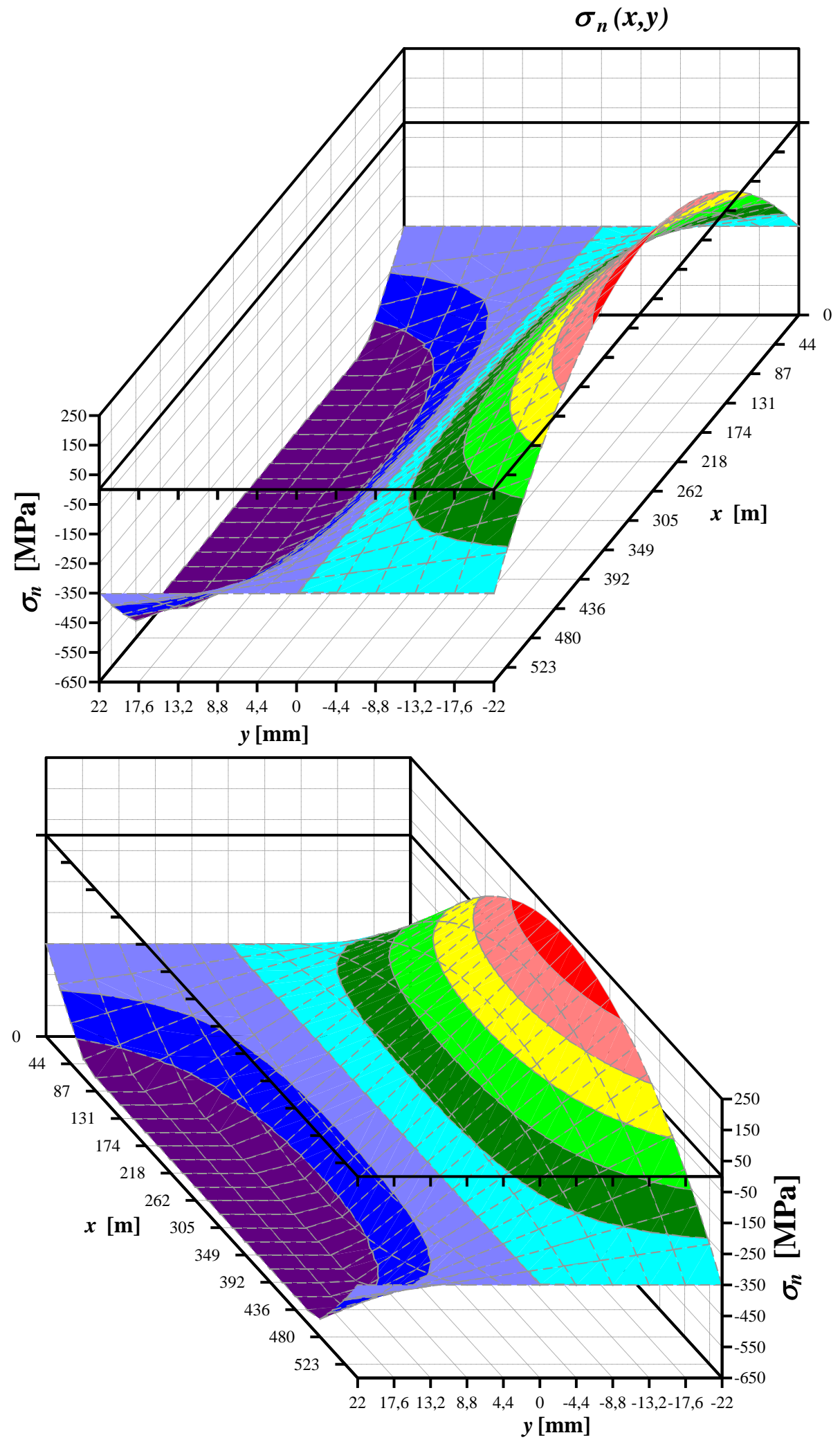

Fig. 36: Values of the stresses $\sigma_{n}(x, y)$ with $E_{p l}=0$ and $J_{z}=J_{z}$ all in the axially loaded with the force $P_{c r}$ cylindrical pinned column made of steel St35 with dimensions: $R=22 \mathrm{~mm}, t=1 \mathrm{~mm}, L=545 \mathrm{~mm}$ 


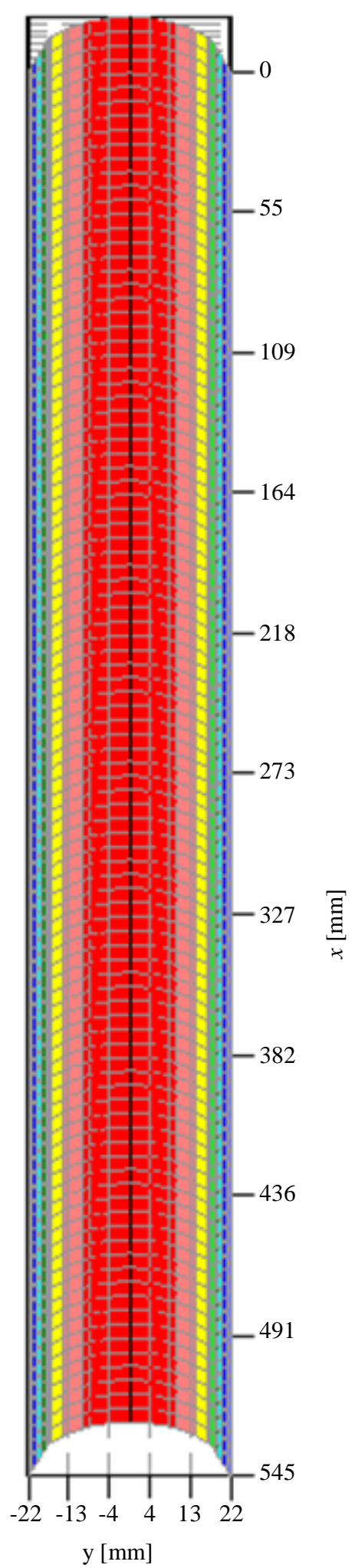

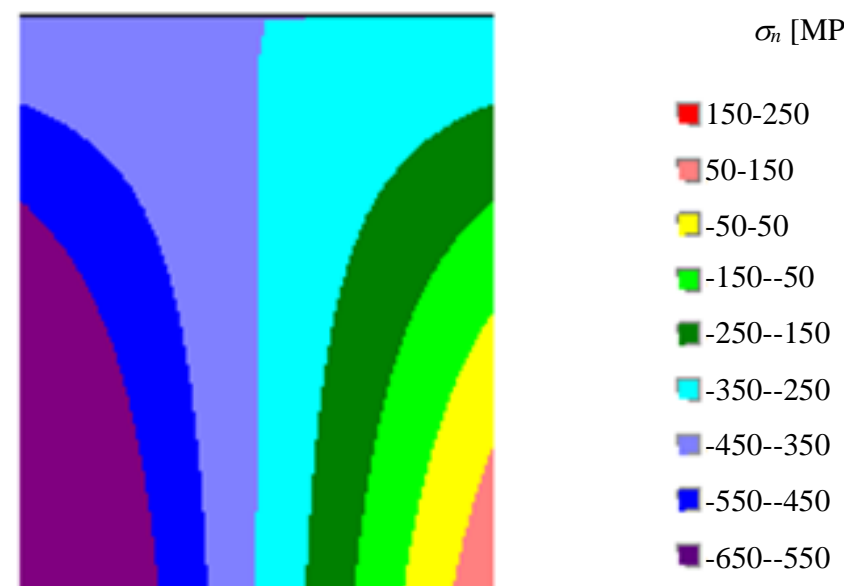

$\varepsilon_{n}$

0,0007-0,0012

밀 - $0,0002-0,0007$

๑-0,0003--0,0002

른 $-0,0008--0,0003$

] $-0,0013-0,0008$

밈-0,0017--0,0013

- $-0,0022--0,0017$

$-0,0027-0,0022$

$-0,0032--0,0027$

$\Delta L[\mathrm{~mm}]$

0,403-0,672

미 $0,134-0,403$

$-0,135-0,134$

$-0,403--0,135$

-0,672--0,403

-0,941--0,672

$-1,210--0,941$

- $-1,478--1,210$

$-1,747--1,478$

Fig. 37: Surface functions of the normal stresses $\sigma_{n}$ [MPa], strains $\varepsilon_{n}$ and extensions $\Delta L[\mathrm{~mm}]$ with $E_{p l}=0$ and $J_{z}=J_{z}^{\text {all }}$ related to the straight, pinned cylindrical column, compressed with the force $P_{c r}$ 

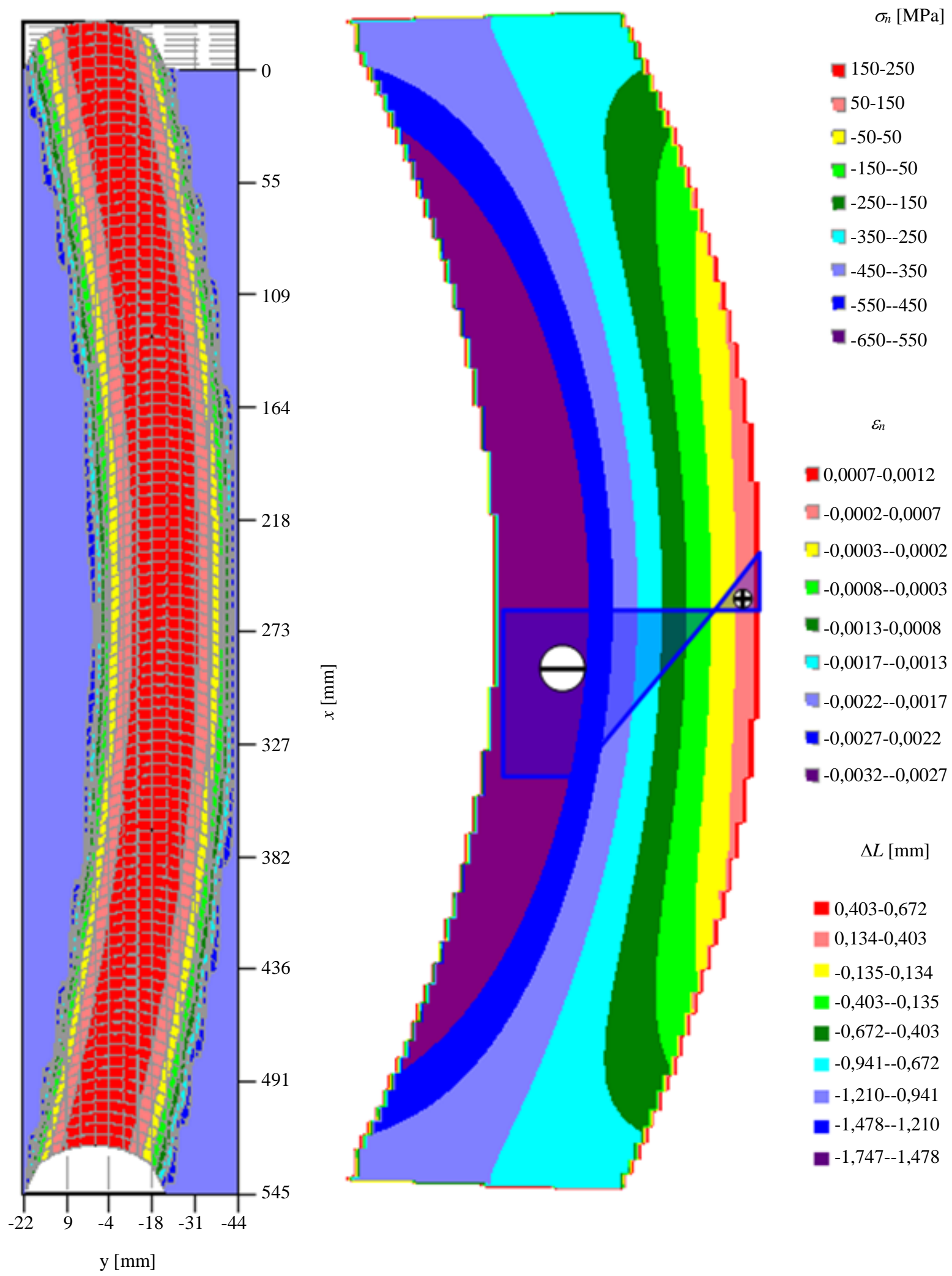

Fig. 38: Surface functions of the normal stresses $\sigma_{n}[\mathrm{MPa}]$, strains $\varepsilon_{n}$ and extensions $\Delta L[\mathrm{~mm}]$ with $E_{p l}=0$ and $J_{z}=J_{z}^{\text {all }}$ related to the buckled pinned cylindrical column, compressed with the force $P_{c r}$ 


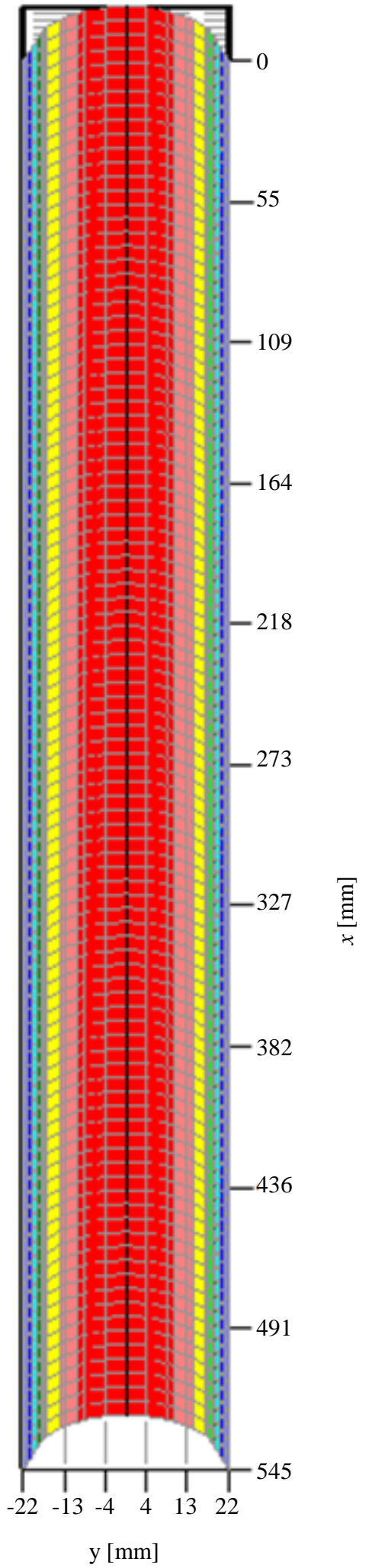

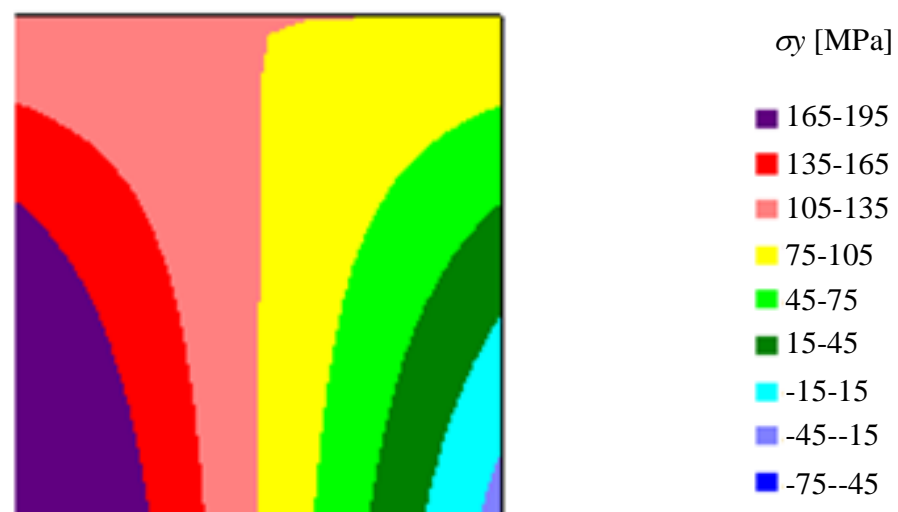

Ey

0,0008-0,0010

[-0,0007-0,0008

플 $-0,0005-0,0007$

-0,0004-0,0005

= $-0,0002-0,0004$

민 $-0,0001-0,0002$

$-0,0001-0,0001$

픈 $-0,0003--0,0001$

$-0,0004--0,0003$

$\Delta 2 t[\mathrm{~mm}]$

[0,0016-0,0019

0,0013-0,0016

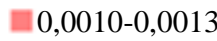

0,0007-0,0010

뭉,0004-0,0007

무 0,0002-0,0004

[1]-0,0001-0,0002

$-0,0004-1,0001$

$-0,0007-0,0004$

Fig. 39: Surface functions of the transverse stresses $\sigma_{y}[\mathrm{MPa}]$, strains $\varepsilon_{y}$ and extensions $\Delta 2 t[\mathrm{~mm}]$ with $E_{p l}=0$ and $J_{z}=J_{z}^{\text {all }}$ related to the straight, pinned cylindrical column, compressed with the force $P_{c r}$ 

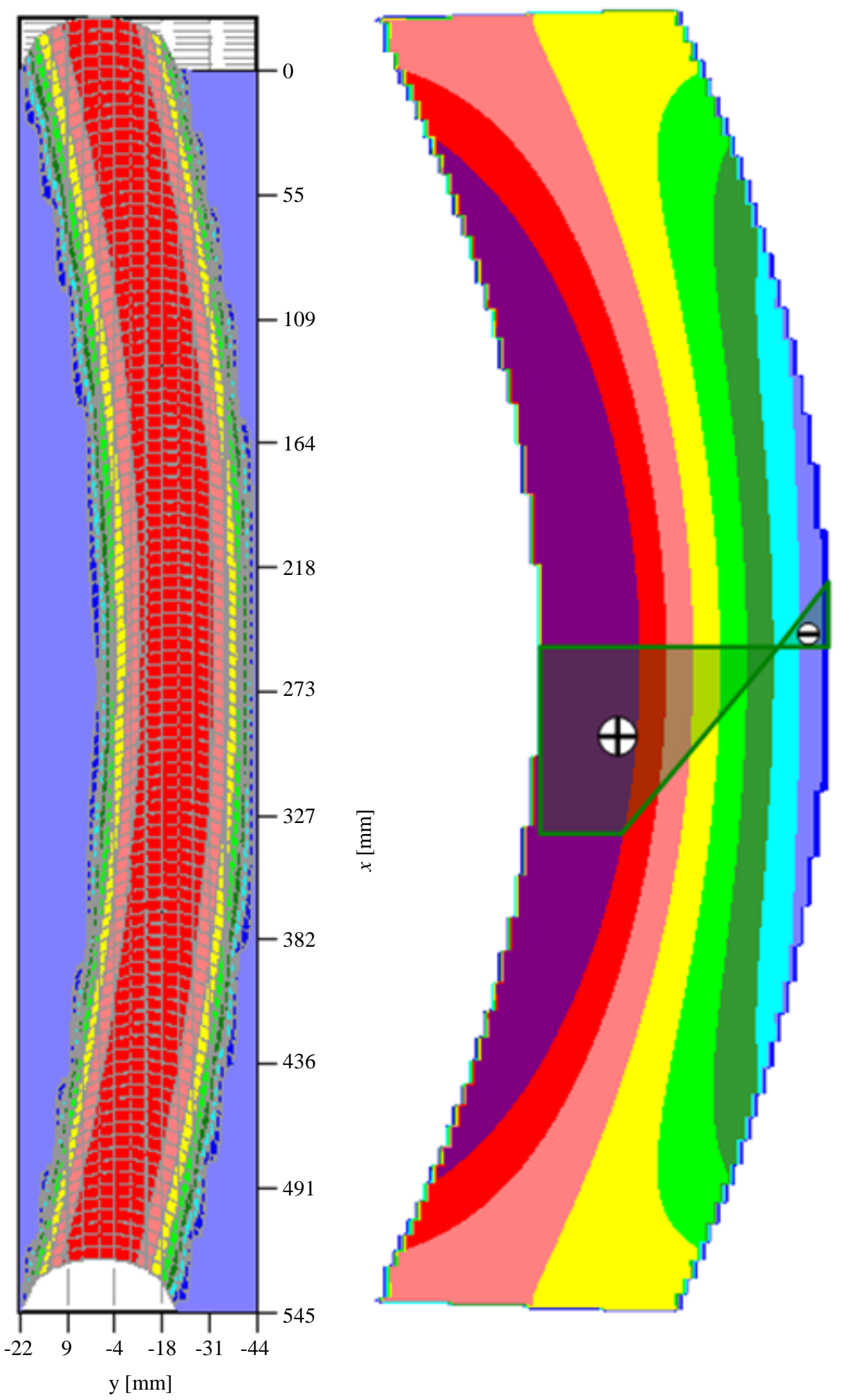

oy $[\mathrm{MPa}]$

- 165-195

" 135-165

민 $105-135$

75-105

는 45

민 15

$-15-15$

미 $-45--15$

- $-75--45$

$\varepsilon_{y}$

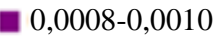

$-0,0007-0,0008$

프 - $-0,0005-0,0007$

-0,0004-0,0005

[1]-0,0002-0,0004

ㅁ. -0,0001-0,0002

[1] -0,0001-0,0001

= $-0,0003--0,0001$

$-0,0004--0,0003$

$\Delta 2 t[\mathrm{~mm}]$

- 0,0016-0,0019

0,0013-0,0016

미 0,0010-0,0013

0,0007-0,0010

미 0,0004-0,0007

미일

드 -0,0001-0,0002

므 -0,0004-1,0001

$-0,0007-0,0004$

Fig. 40: Surface functions of the transverse stresses $\sigma_{y}[\mathrm{MPa}]$, strains $\varepsilon_{y}$ and extensions $\Delta 2 t$ [mm] with $E_{p l}=0$ and $J_{z}=J_{z}{ }^{a l l}$ related to the buckled cylindrical pinned column, compressed with the force $P_{c r}$ 


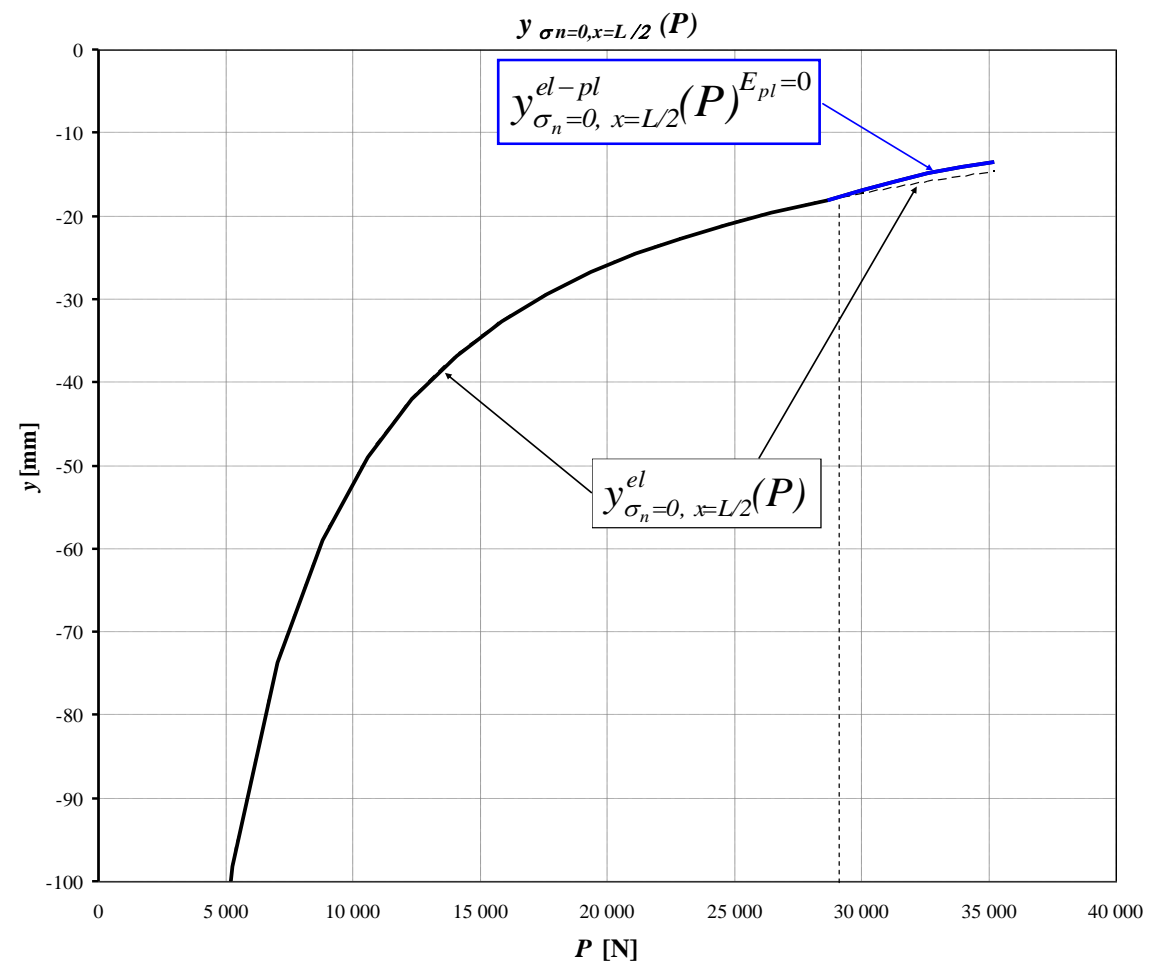

Fig. 41: Graph of the function $y_{\square n=0, x=L / 2}(P)$ with $E_{p l}=0$ and $J_{z}=J_{z}^{\text {all }}$ of the coordinate of the null normal stress $\sigma_{n}=0$ (the resultant neutral layer) in the critical cross-section $(x=L / 2)$ depending on the force $P$ compressing the pinned cylindrical column made of steel St35 with $R=22 \mathrm{~mm}, t=1 \mathrm{~mm}, L=545 \mathrm{~mm}$

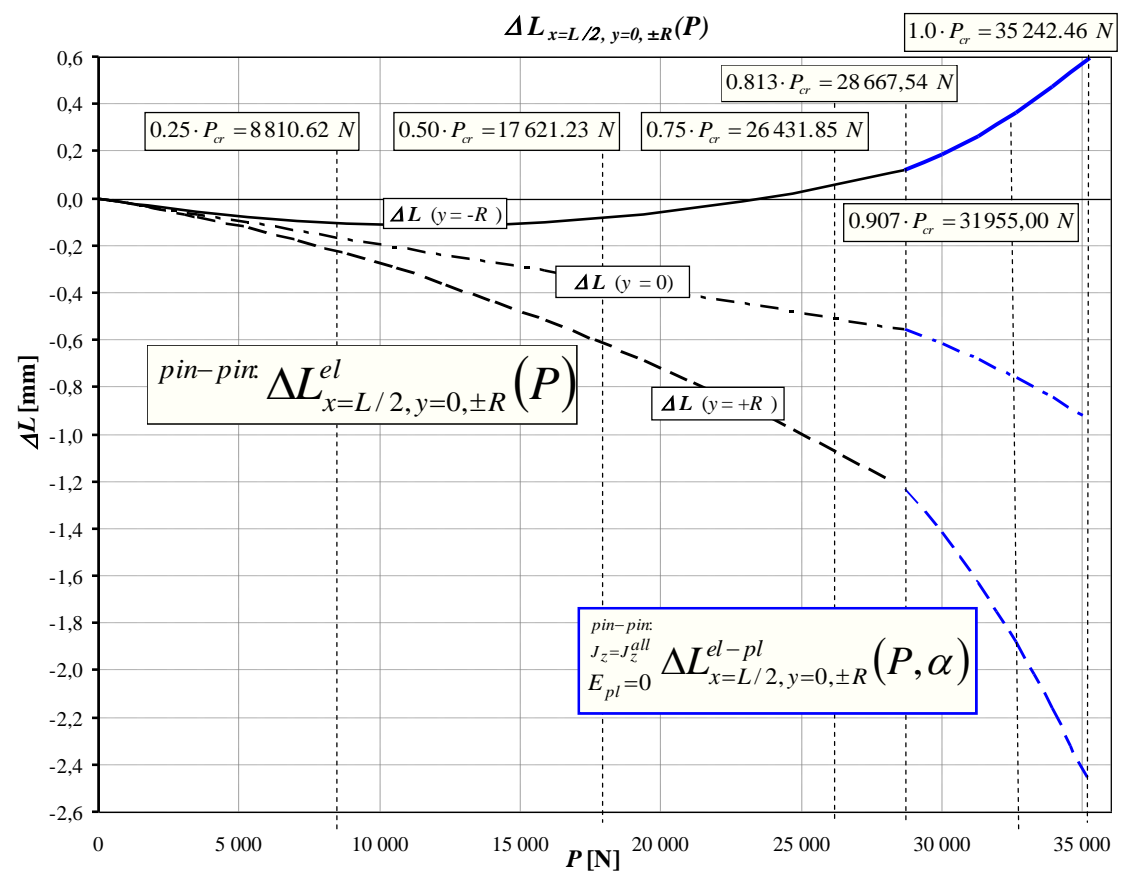

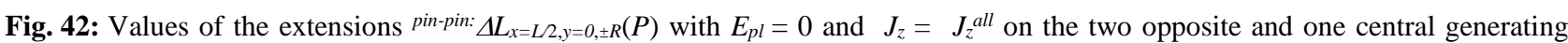
lines $(y=0, \pm R)$ in the critical (middle) cross-section $(x=L / 2)$ depending on the force $P$ compressing the pinned cylindrical column made of steel St 35 with $R=22 \mathrm{~mm}, t=1 \mathrm{~mm}, L=545 \mathrm{~mm}$ 


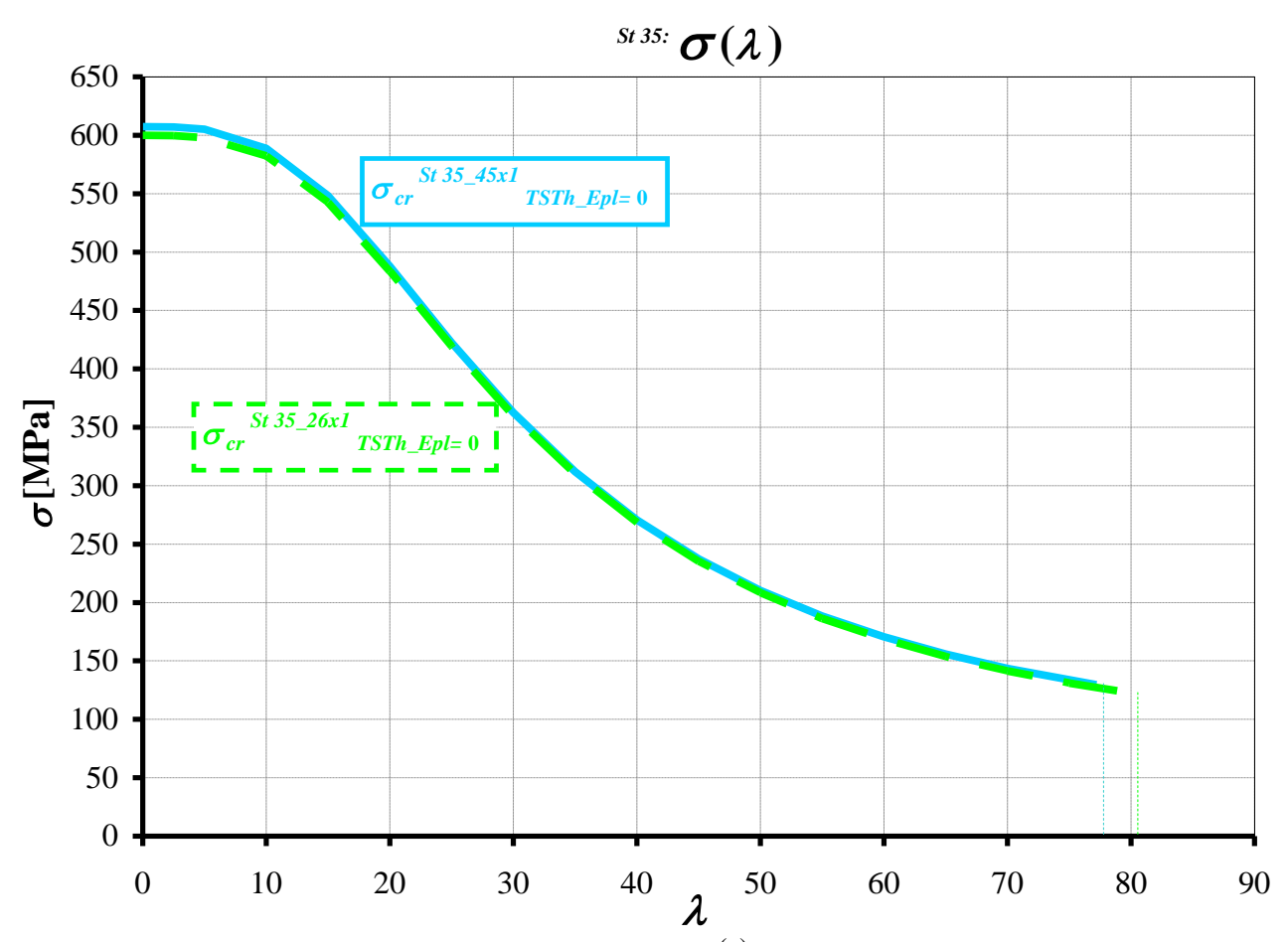

(a)

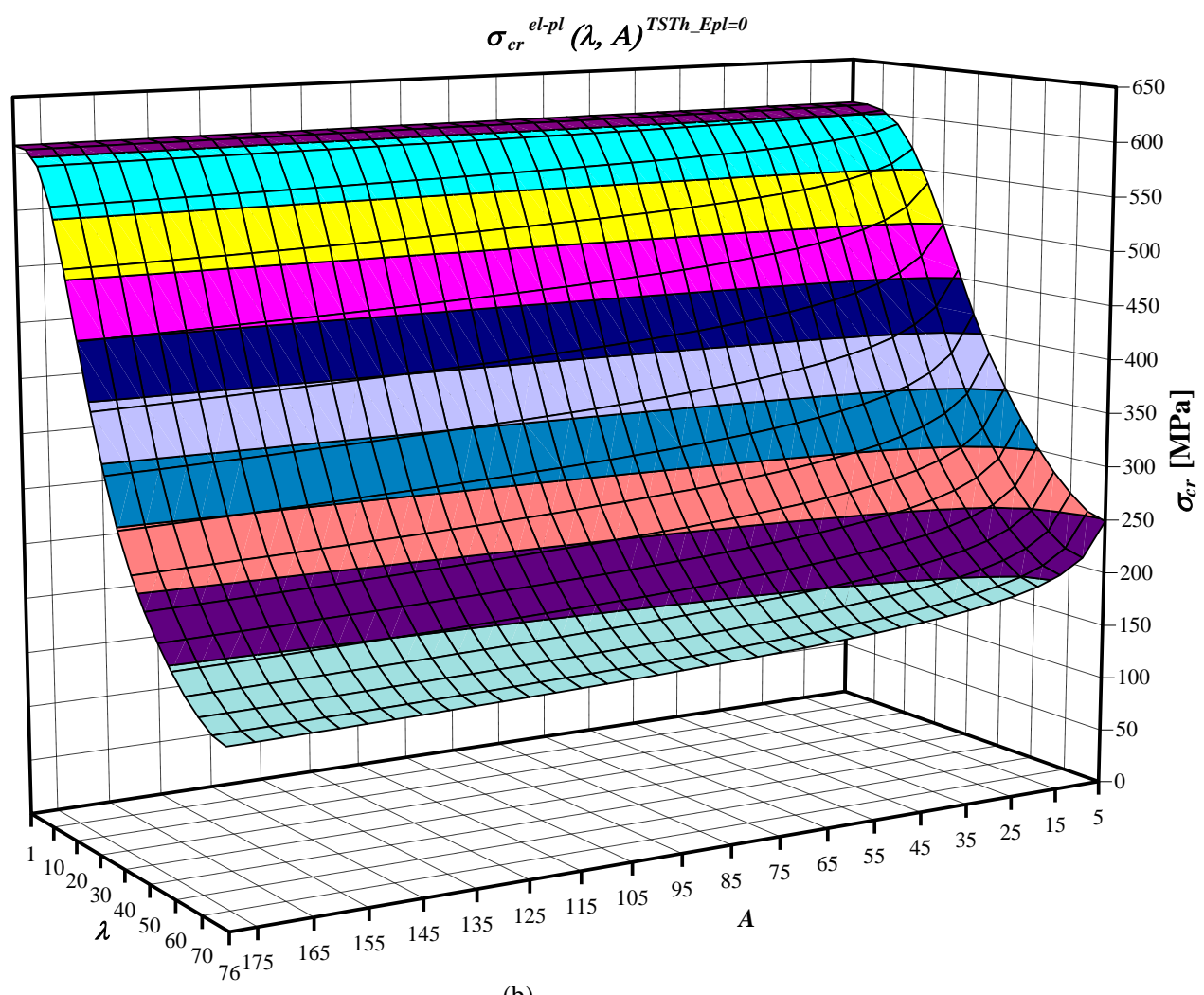

(b)

Fig. 43: Graphs of the theoretical functions calculated like pinned without friction: (a) $\sigma_{c r}(\lambda)^{T S T h_{-} E p l=0}$, for the columns made of steel St35: $\phi 45 \times 1\left(E^{*}=202768.28 \mathrm{MPa}, R_{e}{ }^{*}=607.35 \mathrm{MPa}, \lambda_{\text {lt }}=77.194\right)$ and $\phi 26 \times 1\left(E^{*}=193776.75 \mathrm{MPa}, R_{e}{ }^{*}=600.01 \mathrm{MPa}\right.$, $\lambda_{l t d}=80.528$ ), (b) surface function $\sigma_{c r}{ }^{e l-p l}(\lambda, A)^{T S T h-E p l=0}$ with $E_{p l}=0$ (and average values $E^{*}=198272.52 \mathrm{MPa}, R_{e}{ }^{*}=603.68$ $\mathrm{MPa}, v=0.3, \lambda_{e l-l t}=78.86$ ) 


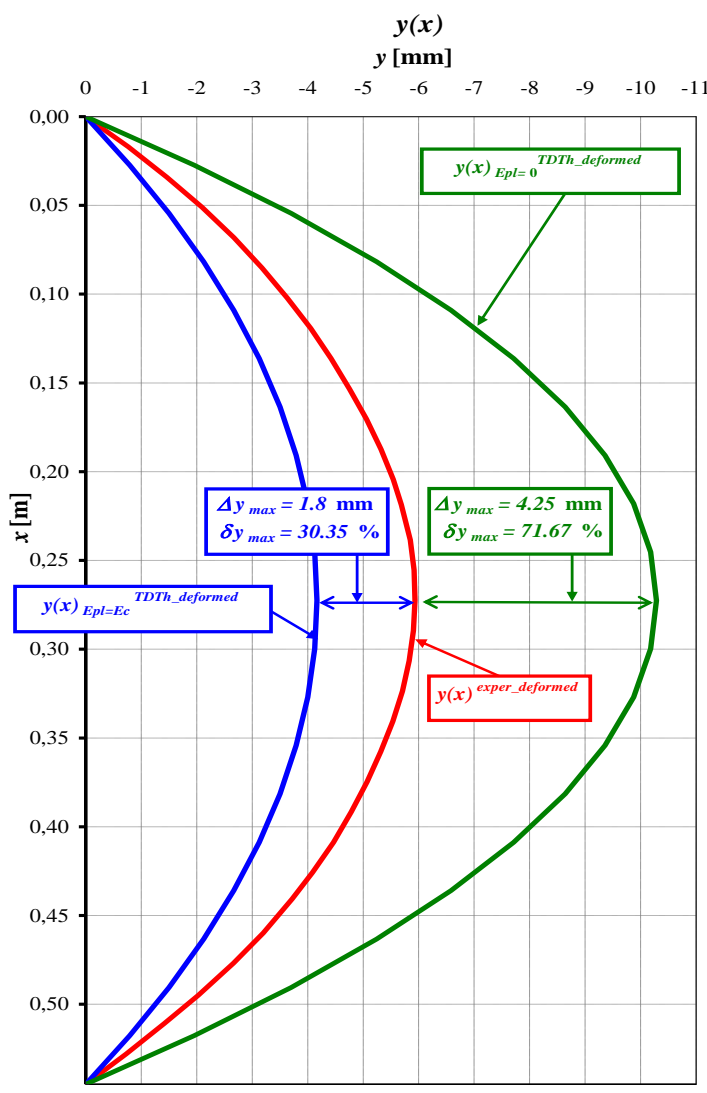

(a)

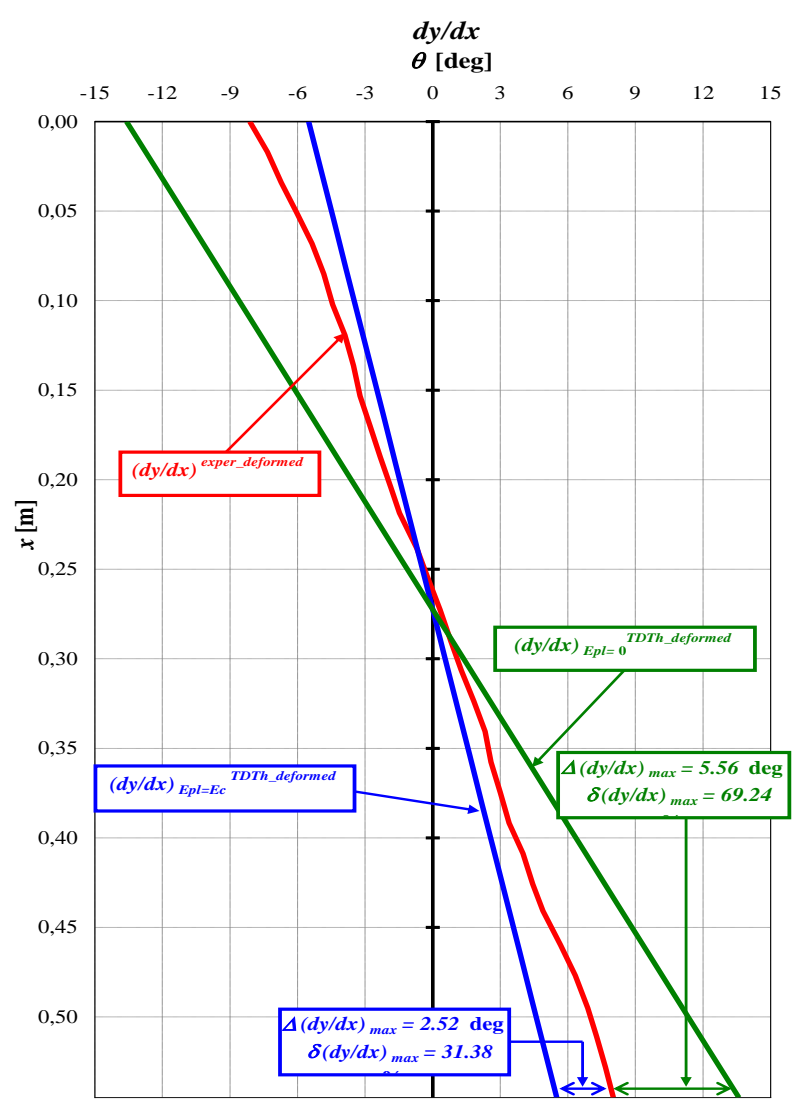

(b)

Fig. 44: Graphs of the: (a) curved axis $y(x)$ and (b) its slope $d y / d x$ of the cylindrical column made of St 35 with $R=22 \mathrm{~mm}, t=1 \mathrm{~mm}, L=$ $545 \mathrm{~mm}$ obtained from experiment, TSTh with $E_{p l}=E_{c}$, and $E_{p l}=0$

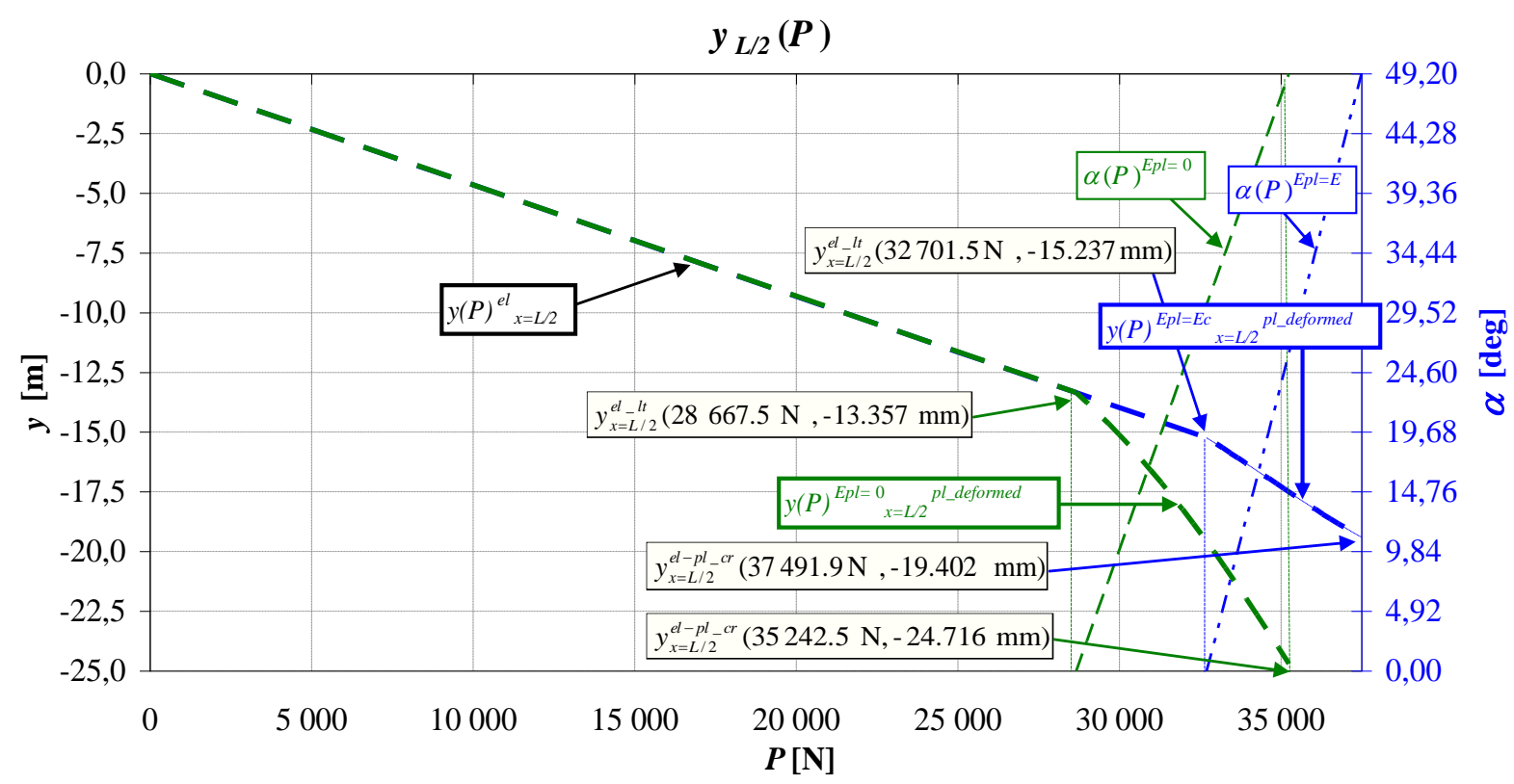

Fig. 45: Set of the graphs of the function $y_{L / 2}(P)$ with $E_{p l}=E_{c}$ and $E_{p l}=0$ of the cylindrical column made of steel St35 with $R=22$ $\mathrm{mm}, t=1 \mathrm{~mm}, L=545 \mathrm{~mm}$ compressed by ball-and-socket joints without friction 


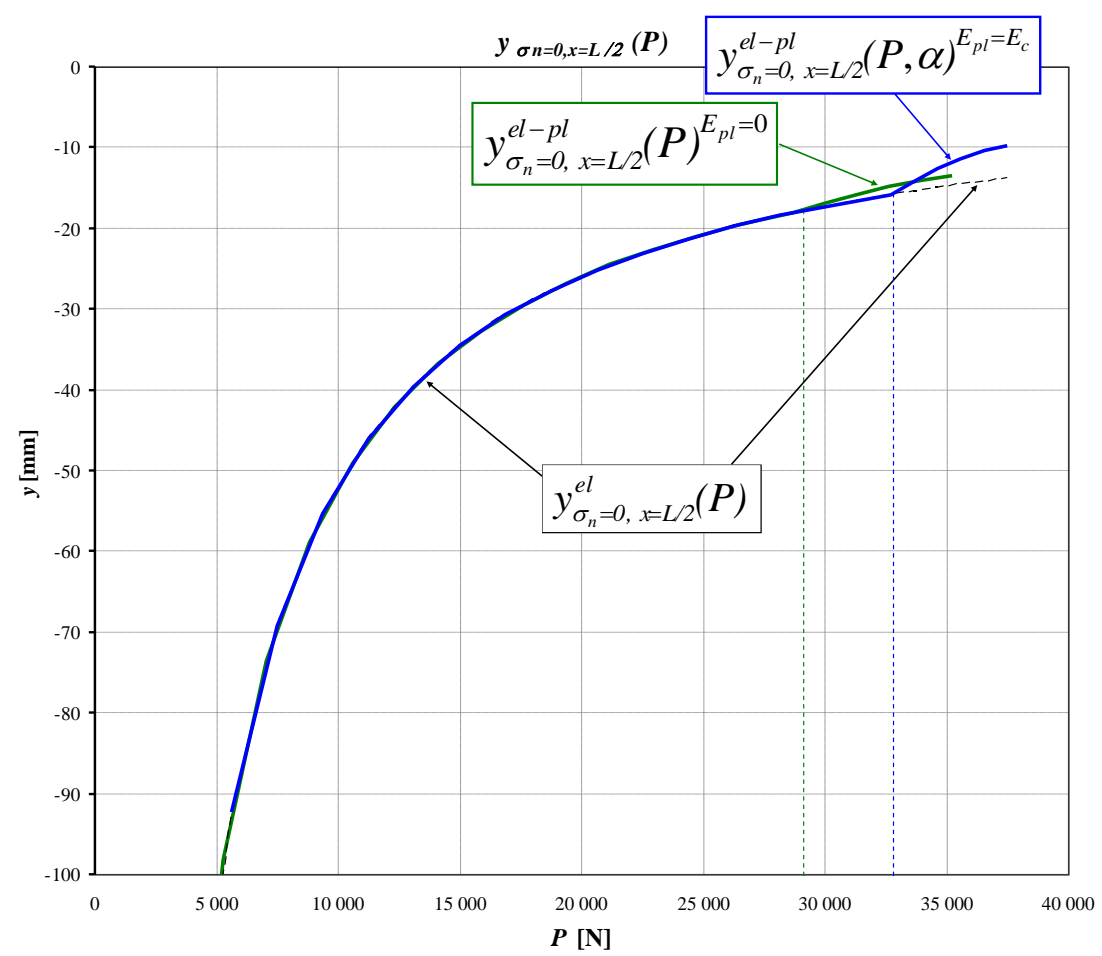

Fig. 46: Set of graphs of the functions $y_{\sigma n=0, x=L / 2}(P)$ with $E_{p l}=E_{c}$ and $E_{p l}=0$ by $J_{z}=J_{z}$ all of the coordinate of the null normal stress $\sigma_{n}=0$ (the resultant neutral layer) in the critical cross-section $(x=L / 2)$ depending on the force $P$ compressing the pinned cylindrical column made of steel St 35 with $R=22 \mathrm{~mm}, t=1 \mathrm{~mm}, L=545 \mathrm{~mm}$

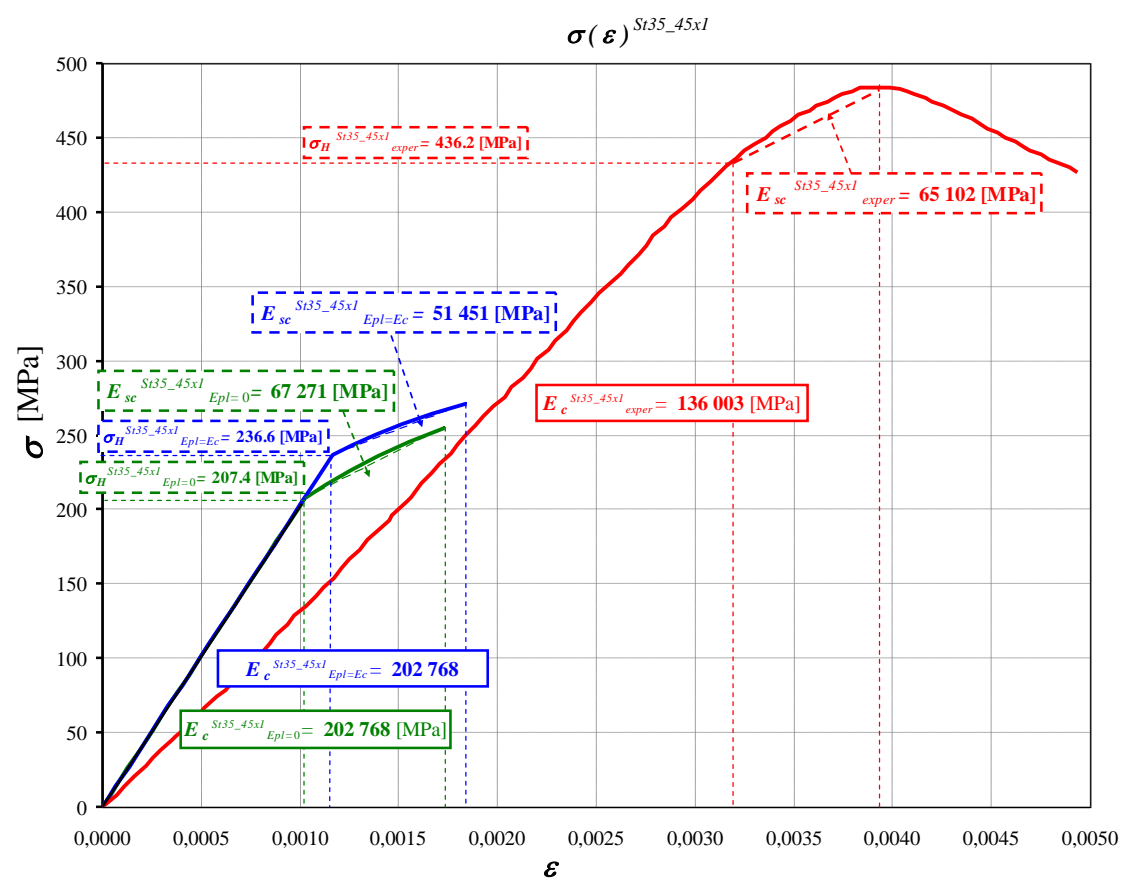

Fig. 47: Set of curves $\sigma(\varepsilon)$ of the column with dimensions $\phi 45 x 1 \times 545$ made of steel St35: from the experiment (pinned with friction), obtained according to TSTh from the function $\Delta L_{x=L / 2, y=0}(P)$ with $E_{p l}=E_{c}=118115.5 \mathrm{MPa}$ (from Fig. 25: The middle curve $\Delta L(y=0)$ ) and with $E_{p l}=0$ (from Fig.42: the middle curve $\Delta L(y=0)$ ) 


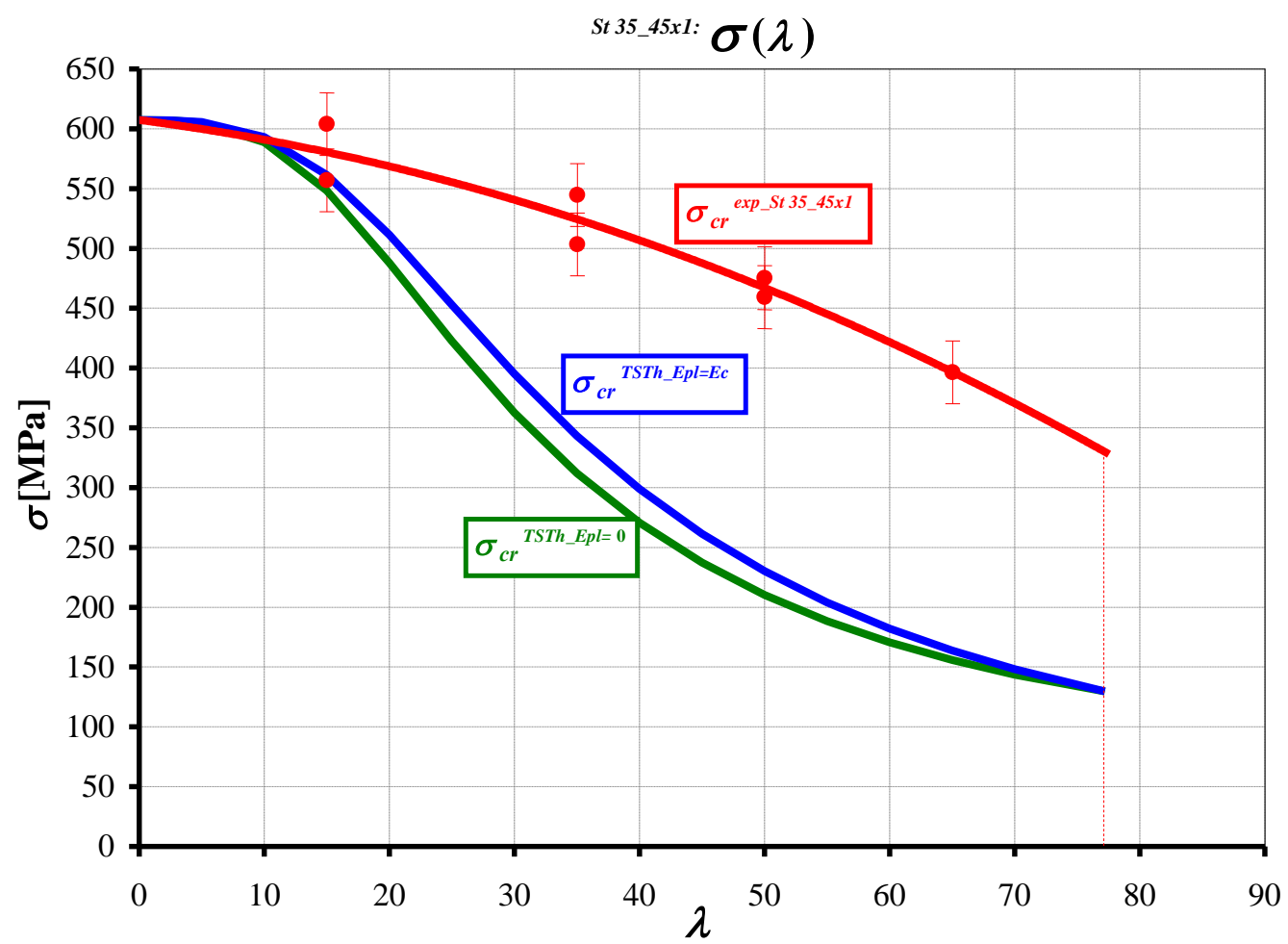

(a)

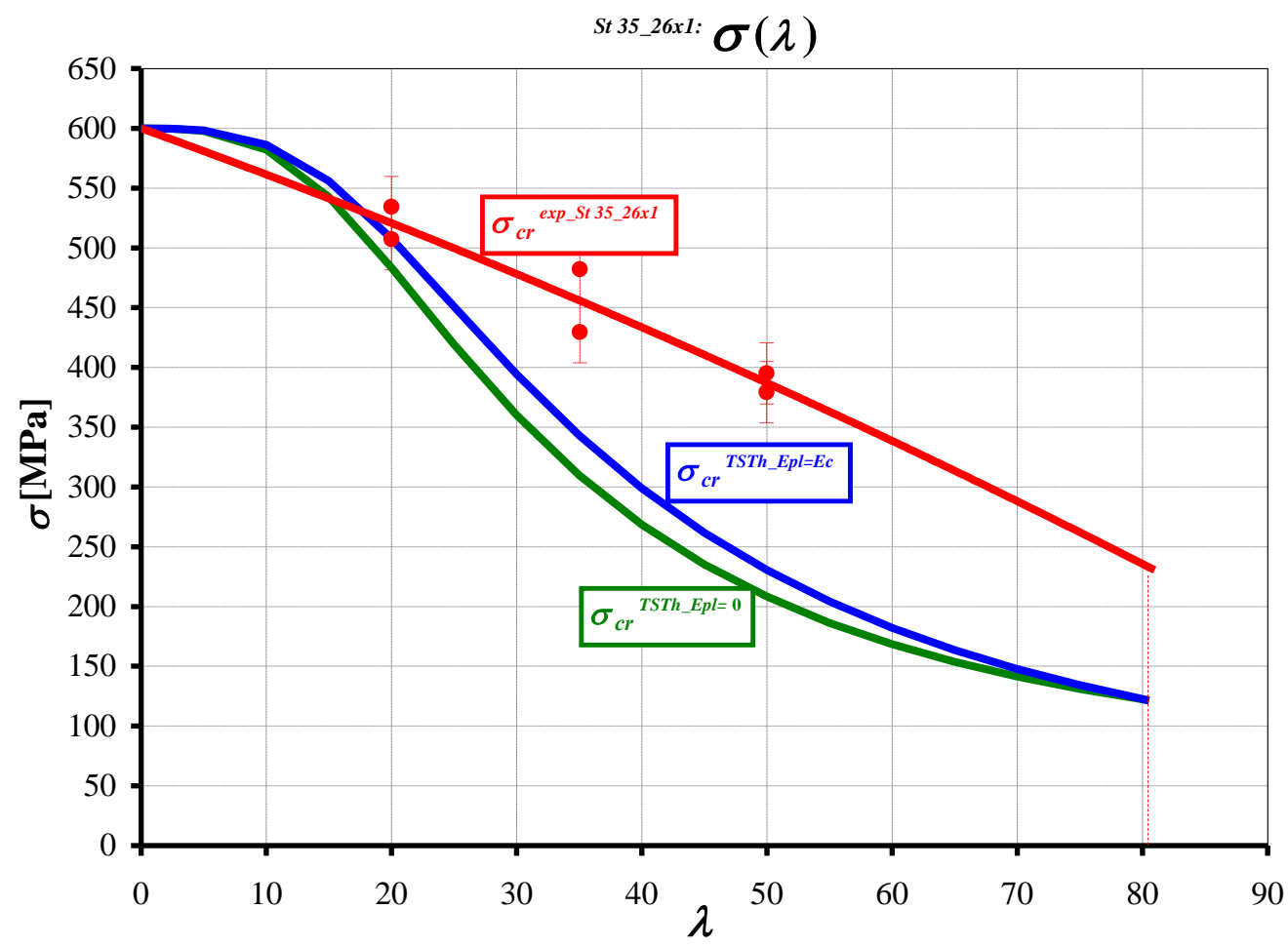

(b)

Fig. 48: Sets of the curves: approximated experimental $\sigma_{c r}(\lambda)^{\exp }$ of columns pinned with friction and theoretical $\sigma_{c r}(\lambda)^{T S T h}-E p l=E c$ as well as $\sigma_{c r}(\lambda)^{T S T h_{-} E p l=0}$ calculated like pinned without friction, for the columns made of steel St $35:\left(\right.$ a) $\phi 45 \times 1\left(E^{*}=\right.$ $\left.202768.28 \mathrm{MPa}, R_{e}{ }^{*}=607.35 \mathrm{MPa}, \lambda_{l t d}=77.194\right)$ and $(\mathrm{b}) \phi 26 x 1\left(E^{*}=193776.75 \mathrm{MPa}, R_{e}{ }^{*}=600.01 \mathrm{MPa}, \lambda_{l t d}=80.528\right)$ 


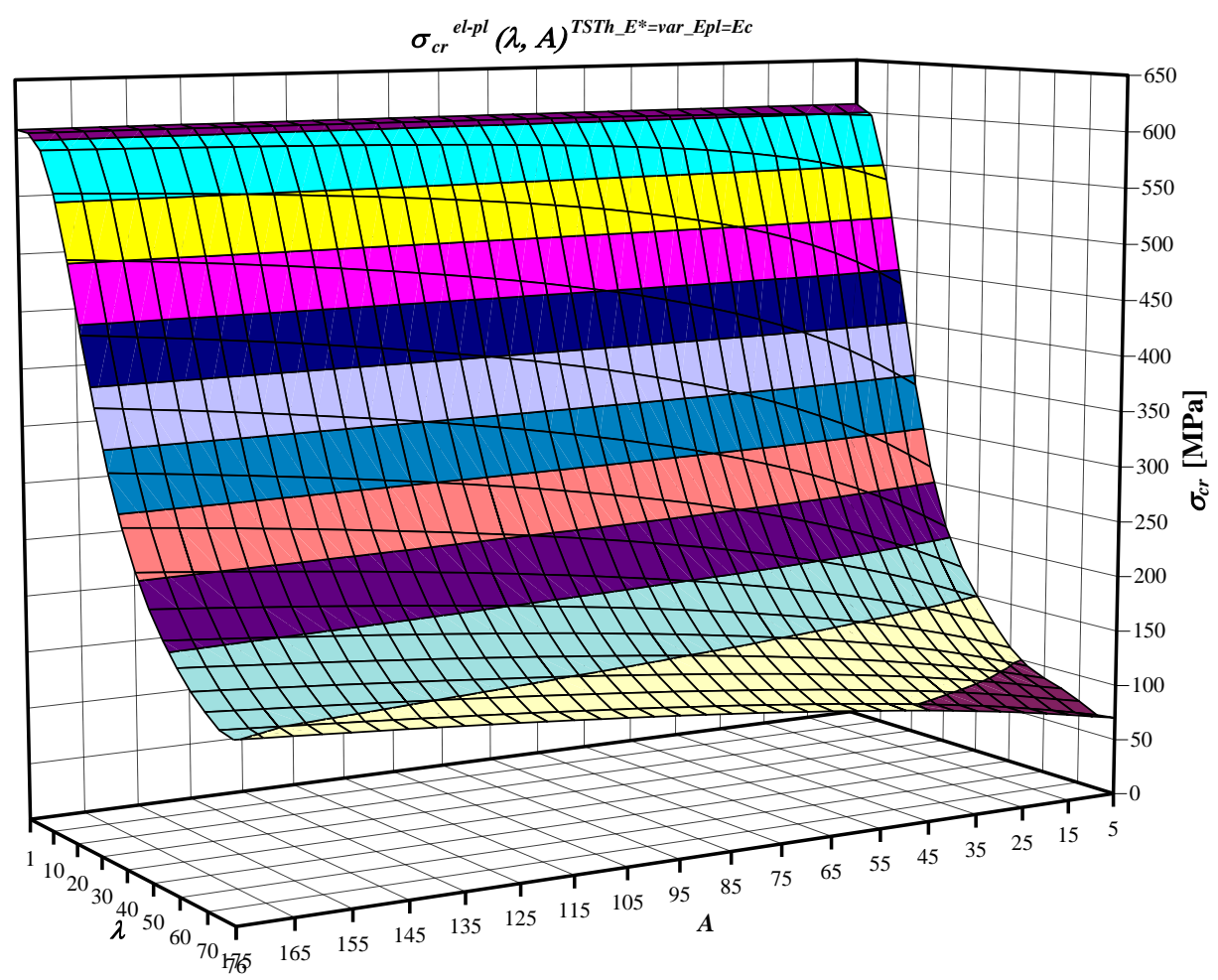

Fig. 49: Graph of the surface function $\sigma_{c r}{ }^{l-p l}(\lambda, A)^{T S T L_{-} E^{*}=v a{ }_{-} E p l=E c}$ with $E_{p l}=E_{c}$ and $J_{z}=J_{z}^{\text {all }}$ of the thin-walled cylindrical columns made of steel St 35 compressed by ball-and-socket joints without friction but with varying module $E^{*}$, as the theoretical example

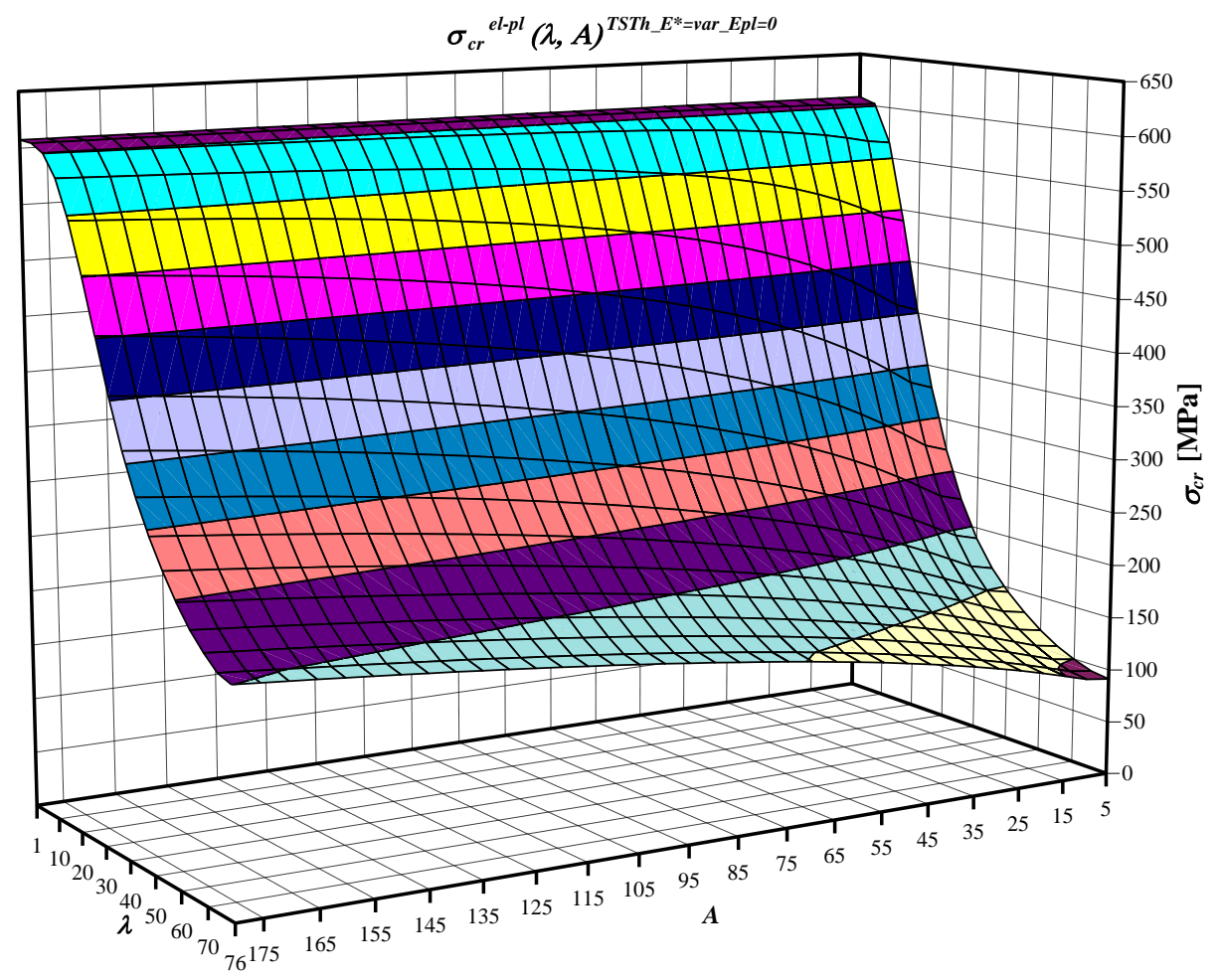

Fig. 50: Graph of the surface function $\sigma_{c r}^{e l-p l}(\lambda, A)^{T S T h_{-} E^{*}=v a r_{-} E p l=0}$ with $E_{p l}=0$ and $J_{z}=J_{z}^{\text {all }}$ of the thin-walled cylindrical columns made of steel St35 compressed by ball-and-socket joints without friction but with varying module $E^{*}$, as the theoretical example 
The experimental test of compressing was executed by ball-and-socket joints with friction between the balls and sockets. During test with so kind of joints made of steel the coefficient of friction is changing from $f_{\text {steel }} P \approx 0 \approx 0.1$ like for pair of lubricated steel elements, till $f_{\text {steel }} P \approx P c r \approx 1.0$, thus the joints are changing their boundary condition, i.e., their Degree of Freedom (DOF) are changing from almost free $R_{z}^{\sim \text { Free }}$ till constrained or almost constrained $R_{z}{ }^{\text {Constr }}$.

Naturally, that cause a certain additional increase of the needed force $P$ during compressing: at beginning about $10 \%$ and later more, so at the end it is already like a clamped joint. However, one is certain that the compressive critical force for a pinned column at both ends should not be bigger than for column clamped at both ends: $P_{c r}$ pinned $<P_{c r}$ clamped.

So using ball-and-socket joints we need to remember that at the start of loading we have almost pinned joints at both ends of a column, but later with bigger loading the joints are going to be clamped and ends are fixed and to rotate them an additional part of the load is needed.

That causes that a column compressed in a test stand by ball-and-socket joints gets a bigger value of the critical compressing force than calculated theoretically, but not bigger than a critical force for a column with clamped both ends.

From Fig. 8 and 27 result that the deflection of the axis line of the column and its slope, increases linearly in the elastic state. Later, in the elastic-plastic state, the deflection of the column and the angle of deflection increase nonlinearly progressively, i.e., with every step of load the deflection is bigger than for a previous step.

Figure 44 shows the graphs of the curved axis $y(x)$ and its slope $d y / d x$ of the cylindrical column made of St35 with $R=22 \mathrm{~mm}, t=1 \mathrm{~mm}, L=545 \mathrm{~mm}$ obtained from experiment, TSTh with $E_{p l}=E_{c}$ and TSTh with $E_{p l}=0$.

The maximal departures between the curved axes $y(x)_{E p l=E c}{ }^{\text {TDTh_deformed }}$ and $y(x)^{\text {exper_deformed }}$ are $\sigma y_{\max }=1.8$ $\mathrm{mm}$ and $\sigma y_{\max }=30.35 \%$ as well as between the curved axes $y(x)_{E p l=0}{ }^{\text {TDTh_deformed }}$ and $y(x)^{\text {exper_deformed }}$ are $\sigma_{\max }=$ $4.25 \mathrm{~mm}$ and $\sigma y_{\max }=71.67 \%$.

The maximal departures between the slopes of the curved axes $(d y / d x)_{\mathrm{Epl}=E c}{ }^{\text {TDTh_deformed }}$ and $(d y / d x)^{\text {exper_deformed }}$ are $\sigma(d y / d x)_{\max }=2.52 \mathrm{deg}$ and $\sigma(d y / d x)_{\max }=31.38 \%$ as well as between the curved axes $(d y / d x)_{E p l=0}$ TDTh_deformed and $(d y / d x)^{\text {exper_deformed }}$ are $\sigma(d y / d x)_{\max }=5.56 \mathrm{deg}$ and $\sigma(d y / d x)_{\max }=69.24 \%$.

In Fig. 9 and 28 shows the set of graphs of the function $y_{L / 2}(P)$. There is shown that the deflection of the column increases linearly in the elastic state and nonlinearly progressively with the assumed linear increase of the angle of the plastic area - $\sigma(P)$.

Figure 45 shows the set of graphs of the function $y_{L / 2}(P)$ with $E_{p l}=E_{c}$ and $E_{p l}=0$ of the cylindrical column made of steel St35 with $R=22 \mathrm{~mm}, t=1 \mathrm{~mm}, L=545 \mathrm{~mm}$ compressed by ball-and-socket joints without friction.
It is seen that the graph with $E_{p l}=0$ has bigger maximal deflection $y^{\text {el-pl_cr }}{ }_{x=L / 2}{ }^{\max }=24.716 \mathrm{~mm}$ at lower critical compressing force $P^{e l-p l}{ }_{c r}=35242.5 \mathrm{~N}$, when the graph with $E_{p l}=E_{c}$ has lower maximal deflection $y^{e l-p l \_c r}{ }_{x=L / 2}^{\max }=19.402$ $\mathrm{mm}$ at bigger critical compressing force $P^{e l-p l}=37491.1 \mathrm{~N}$.

Fig. $12 \div 23$ and $29 \div 40$ show very similar states of stresses $\sigma_{n}, \varepsilon_{y}(x, y)$, strains $\sigma_{n}, \varepsilon_{y}(x, y)$ and extensions $\Delta L, \Delta 2 t(x, y)$, but for different characteristic forces and for different ranges: for column made of steel St35 with $R=$ $22 \mathrm{~mm}, t=1 \mathrm{~mm}, L=545 \mathrm{~mm}$ compressed by ball-andsocket joints without friction computed with $E_{p l}=E_{c}$ the $P_{c r}=37491.9 \mathrm{~N}$ and the range for the stresses $\sigma_{n}(x, y)$ is $607.35 \div 105.5 \mathrm{MPa}$ when for $\sigma_{n}(x, y)$ computed with $E_{p l}$ $=0$ the $P_{c r}=35242.5 \mathrm{~N}$ and the range for the stresses $\sigma_{n}(x, y)$ is $-607.35 \div 222.09 \mathrm{MPa}$. Figure 46 shows the set of graph of the function $y_{\sigma_{n}=0, x=L / 2}(P)$ with $E_{p l}=E_{c}$ and $E_{p l}$ $=0$ by $J_{z}=J_{z}{ }^{\text {all }}$ of the coordinate of the null normal stress $\sigma_{n}=0$ (the resultant neutral layer) in the critical crosssection $(x=L / 2)$ depending on the force $P$ compressing the pinned cylindrical column made of steel St35 with $R$ $=22 \mathrm{~mm}, t=1 \mathrm{~mm}, L=545 \mathrm{~mm}$.

It is seen that the graph with $E_{p l}=0$ gets earlier the elastic-plastic states, at $P=28667.535 \mathrm{~N}$ and has bigger coordinates of the null normal stress $\sigma_{n}=0$ in the critical cross-section $(x=L / 2)$ in the elastic-plastic states.

The graph with $E_{p l}=E_{c}$ gets later the elastic-plastic states, at $P=32701.534 \mathrm{~N}$ and has smaller coordinates of the null normal stress $\sigma_{n}=0$ in the critical crosssection in the elastic-plastic states.

Figure 47 shows the set of curves $\sigma(\lambda)$ of the compressed column with dimensions $\sigma 45 \times 1 \times 545$ made of steel St35: From the experiment (pinned with friction), obtained according to TSTh from the function $\Delta L_{x=L / 2, y=0}(P)$ with $E_{p l}=E_{c}=118115.5 \mathrm{MPa}$ (Fig. 25: From the middle curve $\Delta L(y=0))$ and with $E_{p l}=0$ (Fig. 42: From the middle curve $\Delta L(y=0))$.

It is seen that the both graphs from the TSTh: with $E_{p l}$ $=0$ and with $E_{p l}=E_{c}=118115.5 \mathrm{MPa}$ gets the same value of the compress module $E_{c}^{\mathrm{TSTh}}=202768 \mathrm{MPa}$ in the elastic state and different secant modules: $E_{s c}{ }^{E p l=0}=$ $67271 \mathrm{MPa}$ and $E_{s c}{ }^{E p l=E c}=51451 \mathrm{MPa}$ in elastic-plastic states. Also stresses limiting elastic state are different $\sigma_{H}^{E p l=0}=207.4 \mathrm{MPa}$ and $\sigma_{H}^{E p l=E c}=236.6 \mathrm{MPa}$.

The curve obtained from the experiment has: $E_{c}{ }^{\text {exper }}=$ $136003 \mathrm{MPa}$ in the elastic state, $E_{s c}$ expe $=65102 \mathrm{MPa}$ in the elastic-plastic states and the stress limiting elastic state $\sigma_{H}{ }^{\text {exper }}=436.2 \mathrm{MPa}$. So it is seen that the experimental curve is quite different from the theoretical curves: the compress module $E_{c}{ }^{\text {exper }}$ is 1,5 times smaller than $E_{c}{ }^{T S T h}$, secant modules $E_{s c}$ are comparable, but stress limiting elastic state $\sigma_{H}{ }^{\text {exper }}$ is bigger about 2 times than $\sigma_{H}{ }^{T S T h}$. Those differences probably are caused by compressing columns throw ball-and-socket joints with friction, departures of measuring and simplifications assumed in the TSTs. 
Figure 48 presents the sets of the curves: approximated experimental $\sigma_{c r}(\lambda)^{\exp }$ of columns pinned with friction and theoretical $\sigma_{c r}(\lambda)^{T S T h \_E p l=E c}$ as well as $\sigma_{c r}(\lambda)^{T S T h \_E p l=0}$ calculated like pinned without friction, for the columns made of steel St35: (a) $\sigma 45 \times 1\left(E^{*}=202768.28 \mathrm{MPa}, R_{e}{ }^{*}=\right.$ $\left.607.35 \mathrm{MPa}, \sigma_{l t d}=77.194\right)$ and (b) $\sigma 26 \times 1\left(E^{*}=193776.75\right.$ $\left.\mathrm{MPa}, R_{e}{ }^{*}=600.01 \mathrm{MPa}, \sigma_{l t d}=80.528\right)$.

It is seen that the shape of the theoretical function for columns pinned at both ends $\sigma_{c r}{ }^{\text {el-pl }}(\lambda)^{T S T h}$ calculated like compressed through ball-and-socket joints without friction in dependence on the slenderness ratio $\sigma$ (for a constant value of transverse cross-section area $A$ ) is similar to the shape of a ski-jumping take-off runway (it has nonlinearity according to a third degree line with a point of changing a sign of an incline) when the approximated experimental curve $\sigma_{c r}{ }^{\exp }(\lambda)$ has a parabolic shape (it has nonlinearity like a second degree line) as well as the experimental curve has bigger values for bigger slenderness ratios $\lambda$.

We see also in Fig. 48 that the curves $\sigma_{c r}{ }^{e l-}$ ${ }^{p l}(\lambda)^{T S T h_{-} E p l=E c}$ with $E_{p l}=E_{c}$ have slightly bigger values than the curves $\sigma_{c r}{ }^{e l-p l}(\lambda)^{T S T h \_E p l=0}$ with $E_{p l}=0$ except the boundary points of the range $\left(\lambda=0\right.$ and $\left.\lambda=\lambda_{\text {ltd }}\right)$, where they are equal. So it is seen that the experimental curves are quite different from the theoretical curves and those differences probably are caused by compressing columns throw ball-and-socket joints with friction, departures of measuring and simplifications assumed in the TSTh.

From the graphs we see bigger differences between experimental and theoretical values for bigger values of the slenderness ratio $\lambda$ what can be explained by the bigger structural elasticity of longer columns with the same transverse cross-section area $A$.

To avoid or limit that phenomenon, the compressing in the test stand should be executed not by ball-andsocket joints, which always have friction between ball and sockets, but by knife-and-plate joints with strongly reduced friction.

\section{Assumption: The Module $E^{*}$ is Varying}

In Fig. 25 in the paper (Murawski, 2020a) it is seen that the columns with bigger transverse cross-section area $A$ have bigger values of the modules $E^{*}$ (the value of module $E$ in the crossing of graphs of compress module $E_{c}$ and secant compress module $E_{s c}$ ) and in Fig. 26 (Murawski, 2020a) as well as in Fig. 48 it is seen that critical compressing stresses $\sigma_{c r}{ }^{\exp }(\lambda)$ are bigger for columns with bigger cross-section area $A$ for the same slenderness ratios $\lambda$. But in Fig. 26b and 43b it is seen that according to TSTh the columns with bigger transverse cross-section area $A$ have smaller values of the critical compressing stresses $\sigma_{c r}^{\text {TSTh }}(\lambda)$ for the same slenderness ratios $\lambda$. It is seen also in Fig. 26a and 43a in which the graphs are made for varying values of $E^{*}$ (it is assumed that values of $R_{e}{ }^{*}$ and $\lambda_{\text {ltd }}$ are almost the same).
So to get an accordance of theoretical graphs with experimental it can be assumed that the module $E^{*}$ should be varying.

In Fig. 49 is shown the surface function $\sigma_{c r}{ }^{e l-p l}(\lambda$, $A)^{T S T h \_E^{*}=v_{a}-E p l=E c}$ with $E_{p l}=E_{c}$ and $J_{z}=J_{z}$ all of the thinwalled cylindrical columns made of steel St35 compressed by ball-and-socket joints without friction but with varying module $E^{*}[\mathrm{MPa}]^{=} \mathrm{A}\left[\mathrm{mm}^{2}\right] .1600[\mathrm{MPa}]+$ $7000[\mathrm{MPa}]$ as the hypothetical example of the surface function with bigger values of the critical compressing stresses for bigger values of the transverse cross-section area $A$ for the same slenderness ratios $\lambda$.

In Fig. 50 is shown the surface function $\sigma_{c r}{ }^{e l-p l}(\lambda$, $A)^{T S T h \_E^{*}}=v_{a} r_{-} E p l=0$ with $E_{p l}=0$ and $J_{z}=J_{z}$ all of the thinwalled cylindrical columns made of steel St35 compressed by ball-and-socket joints without friction but with varying module $E^{*}[\mathrm{MPa}]^{=} \mathrm{A}\left[\mathrm{mm}^{2}\right] .1600[\mathrm{MPa}]+$ $7000[\mathrm{MPa}]$ as the hypothetical example of the surface function with bigger values of the critical compressing stresses for bigger values of the transverse cross-section area $A$ for the same slenderness ratios $\lambda$.

So it is seen from Fig. 49 and 50 that the surface function $\sigma_{c r}{ }^{e l-p l}(\lambda, A)^{T S T h-E^{*}}=v a r_{-} E p l=E c$ with $E_{p l}=E_{c}$ gets bigger values than the surface function $\sigma_{c r}{ }^{e l-p l}(\lambda$, $A)^{T S T h_{-} E^{*}=v a r_{-} E p l=0}$ with $E_{p l}=0$ except the boundary line of the range $(\lambda=0)$, where they are equal.

\section{Conclusion}

In the paper is presented the analysis of stability and of stress and strain states of the pinned cylindrical thinwalled column according to the TSTh. There are discussed two simplified methods.

It was assumed that in the critical elastic-plastic transverse cross-section there are the elastic and plastic parts of the area, keeping a resistance, i.e.

1. In the elastic part of the transverse cross-section $A^{e l}$, with the static moment $S_{z}^{e l}$, there is the elastic Young's module $E>0$

2. In the plastic part of the transverse cross-section $A^{p l}$, with the static moment $S_{z}^{p l}$, there is the plastic module $E_{p l}$

In order to simplify calculations were assumed the simplifications:

3. The whole moment of inertia of a cross-section area is taken into account $J_{z}=J_{z}^{\text {all }}$ as keeping the resistance

4. The plastic module equals compress module $E_{p l}=E_{c}$ taken from experimental researches

Or as the bigger simplification:

5. The plastic module equals compressing module $E_{p l}=0$. 
Based on the presented results the following important remarks can be concluded:

1. According to the TSTh, the evolutions of the functions of an elastic line $y(x)$ and its slope $d y / d x$ with $E_{p l}=E_{c}$ of the same column are smaller and closer to the experimental ones than those with $E_{p l}=0$

2. The graph of the function of the maximal deflection $y_{L / 2}(P)$ with $E_{p l}=E_{c}$ has lower maximal deflection $y(x=L / 2)$ at bigger critical compressing force $P_{c r}$ than with $E_{p l}=0$ of the same column

3. The same column computed according to the TSTh with $E_{p l}=E_{c}$ gets the bigger critical compressive force $P_{c r}$ and very similar states of the stresses $\sigma_{n}$, $\sigma_{y}(x, y)$, strains $\varepsilon_{n}, \varepsilon_{y}(x, y)$ and extensions $\Delta L, \Delta 2 t(x, y)$, (but the ranges of them are narrower) than for that one computed with $E_{p l}=0$

4. The function $y_{n}=0, x=L / 2(P)$ of the coordinate of the null normal stress $\sigma_{n}=0$ (the resultant neutral layer) in the critical cross-section $(x=L / 2)$ computed with $E_{p l}=0$ gets earlier the elastic-plastic states and has bigger values in the elastic-plastic states than that computed with $E_{p l}=E_{c}$ of the same column

5. The graph $y_{n}=0, x=L / 2(P)$ results with the conclusion that the resultant neutral layer moves from infinity and goes asymptotically to the zero with an increasing load and while the line of forces entries in the plastic zone in the critical transverse section the resultant neutral layer moves quicker to the zero;

6. The curve $\sigma(\varepsilon)$ of the pinned with friction compressed column obtained from the experiment gets bigger stress limiting elastic state $\sigma_{H}{ }^{\text {exper }}$, lower compress module $E_{c}{ }^{\text {exper }}$ and similar secant compress module $E_{s c}$ exper than obtained according to TSTh

7. The theoretical curves $\sigma_{c r}^{e l-p l}(\lambda)^{T S T h}$ for columns pinned at both ends with $E_{p l}=E_{c}$ as well as with $E_{p l}$ $=0$ calculated like compressed through ball-andsocket joints without friction in dependence on the slenderness ratio $\lambda$ (for a constant value of transverse cross-section area $A$ ) is similar to the shape of a ski-jumping take-off runway (it has the nonlinearity according to a third degree line with a point of changing a sign of an incline)

8. The theoretical curves $\sigma_{c r}{ }^{e l-p l}(\lambda)^{T S T h}$ with $E_{p l}=E_{c}$ gets slightly bigger values than those with $E_{p l}=0$ except the boundary points of the range $\left(\lambda 0\right.$ and $\left.\lambda=\lambda_{\text {ltd }}\right)$, where they are equal

9. The approximated experimental curves $\sigma_{c r}{ }^{\exp }(\lambda)$ have a parabolic shape (it has nonlinearity like a second degree line) and the experimental curves have bigger values than theoretical $\sigma_{c r}{ }^{e l-p l}(\lambda)^{T S T h}$ for the same slenderness ratios $\lambda$ and the critical cross-section $A$

10. The experimental curves are quite different from the theoretical curves and those differences probably are caused by compressing columns throw ball-and- socket joints with friction, departures of measuring and simplifications assumed in the TSTh

11. To avoid or limit that phenomenon, the compressing in the test stand should be executed not by ball-andsocket joints, which always have friction between ball and sockets, but by knife-and-plate joints with strongly reduced friction

\section{Ethics}

This article was preceded by the preprint (Murawski, 2021) changed according to the issuer requirements and reviewers' and own author's corrections. The author confirms that He has read and approved the manuscript, and no ethical issues are involved.

\section{References}

Abbas, R. M., \& Awazli, A. G. (2017). Behavior of Reinforced Concrete Columns Subjected to Axial Load and Cyclic Lateral Load. Journal of Engineering, 23(2), 21-40.

https://joe.uobaghdad.edu.iq/index.php/main/article/ view/69

Abdel-Karim, M., Abdel-Rahman, G., Said, M., \& Shaaban, I. (2017). Proposed Model for Strength Analysis of HSC Eccentrically Loaded Slender Columns. Magazine of Concrete Research, 70. https://doi.org/10.1680/jmacr.17.00137

Abdulazeez, M., ElGawady, M., \& Abdelkarim, O. (2018). Bending and Buckling Behavior of HollowCore FRP-Concrete-Steel Columns. Journal of Bridge Engineering, 24. https://doi.org/10.1061/(ASCE)BE.19435592.0001419

Abed, F., AlHamaydeh, M., \& Barakat, S. (2013). Nonlinear Finite-Element Analysis of Buckling Capacity of Pretwisted Steel Bars. Journal of Engineering Mechanics, ASCE, 139, 791-801. https://doi.org/10.1061/(ASCE)EM.19437889.0000528

Abedini, M., Mutalib, A., Zhang, C., Mehrmashhadi, J., Raman, S. N., Alipour, R., Momeni, T., \& Mussa, M. (2020). Large deflection behavior effect in reinforced concrete columns exposed to extreme dynamic loads. Frontiers of Structural and Civil Engineering, 14. https://doi.org/10.1007/s11709020-0604-9

Ahiwale, D., Khartode, R., Bhapkar, A., Narule, G., \& Sharma, K. (2020). Influence of compressive load on concrete filled steel tubular column with variable thickness. Innovative Infrastructure Solutions, 6, 1-14. https://doi.org/10.1007/s41062-020-00390-z 
Alencar, G., Silva J. G. S., Jesus A. M. P., \& Calçada R. (2018). Evaluation of distortion-induced fatigue cracking of highway bridge critical details considering road surface deterioration effects. $19^{\text {th }}$ International Colloquium on Mechanical Fatigue of Metals (ICMFM), Porto, Portugal.

Al-Kamal, M. (2016). Design for Prestressed Concrete Flexural Members against Progressive Collapse. Thesis for $\mathrm{PhD}$.

Alomarah, A., Masood, S., \& Ruan, D. (2020). Out-ofplane and in-plane compression of additively manufactured auxetic structures. Aerospace Science and Technology, 106, 106107. https://doi.org/10.1016/j.ast.2020.106107

Alvarenga, A. R., \& Silveira, R. A. (2006). Considerations on advanced analysis of steel portal frames. In Proceedings of ECCM III European Conference on Computational Mechanics Solids, Structures and Coupled Problems in Engineering (p. 2119).

Ammash, H. K. (2017). Shape optimization of innovation cold-formed steel columns under uniaxial compressive loading. Jordan Journal of Civil Engineering, 11(3).

Ananthi, G. B. G., \& Anbarasu, M. (2015). A Study on Cold-formed Steel Lipped Built up Channel Sections Subjected to Axial Compression.

Ananthi, G. B., Roy, K., \& Lim, J. B. P. (2021). Nonlinear behaviour and design of web stiffened battened built-up stainless steel channel sections under axial compression. Structures, 30. https://doi.org/10.1016/j.istruc.2021.01.014

Andreev, V. I., \& Tsybin, N. Y. (2015). On the Stability of Rod with Variable Cross-section. Procedia Engineering, 111, 42-48. https://doi.org/10.1016/j.proeng.2015.07.033

Anuntasena, W., Lenwari, A., \& Thepchatri, T. (2019). Finite Element Modelling of Concrete-Encased Steel Columns Subjected to Eccentric Loadings. Engineering Journal.

https://doi.org/10.4186/ej.2019.23.6.299

Atteya, M., Shaat, A., \& Sayed-Ahmed, E. (2017). Effect of CFRP Bonded Length on the Strength of Axially loaded HSS. Al-Azhar University Civil Engineering Research Magazine (CERM), 39(2), 89-96. http://www.azharcermjournal.com/CERMF1704/P1 7-04-08.pdf

Avcar, M. (2014). Elastic Buckling of Steel Columns Under Axial Compression. American Journal of Civil Engineering, 2, 102-108. https://doi.org/10.11648/j.ajce.20140203.17

Avci-Karatas, C. (2020). Time History Analysis of a Reinforced Concrete (RC) Building in Hilly Terrain Subjected to Earthquake. 6th International Congress on Engineering, Architecture and Design, Istanbul/Turkey.
Baru, A. (2017). An Investigation of Buckling Phenomenon in Steel Elements. Heriot Watt University, School of Energy, Geoscience, Infrastructure and Society. https://doi.org/10.13140/RG.2.2.36815.48803

Bedon, C., \& Amadio, C. (2017). STRUCTURAL GLASS ELEMENTS-Unified approach for the buckling verification. Structural, 212. https://doi.org/10.12917/Stru212.18

Bedon, C., \& Amadio, C. (2018). Buckling analysis and design proposal for 2-side supported double Insulated Glass Units (IGUs) in compression. Engineering Structures, 168, 23-34. https://doi.org/10.1016/j.engstruct.2018.04.055

Beylergil, B., Aktaş, A., \& Cunedioglu, Y. (2012). Buckling and compressive failure of stepped lap joints repaired with composite patches. Journal of Composite Materials, 26, 3213. https://doi.org/10.1177/0021998312437001

Brank, B., Perić, D., \& Damjanić, F. B. (1997). On Large Deformations of Thin Elasto-Plastic Shells: Implementation of a Finite Rotation Model for Quadrilateral Shell Element. International Journal for Numerical Methods in Engineering. 40. 689-726. https://doi.org/10.1002/(SICI)1097-

0207(19970228)40:4<689::AID-NME85>3.0.CO;2-7

Brasil, R., \& Wahrhaftig, A. D. M. (2018). Experimental Evaluation of the Effect of Geometric Nonlinearities on Structural Resonances. Lecture Notes in Civil Engineering, 611-618. https://doi.org/10.1007/9783-319-67443-8_53

Broujerdian, V., Ghadami A., Pourmoosavi, G., \& Mahyar, P. (2018). Valid simulation of the composite behavior of steel bridges. The 2018 Structures Congress (Structures18), Songdo Convensia, Incheon, Korea. https://www.researchgate.net/publication/342510290_ Valid_simulation_of_the_composite_behavior_of_stee 1_bridges

Can, Y., Güçlü, H., Kasar, İ., \& Yazici, M. (2018). Finite Element Simulation of the Telescopic Crash Boxes Designing by Adhesively Bonded Coaxial Aluminum Tubes. $5^{\text {th }}$ International Conference on Computational and Experimental Science and Engineering (ICCESEN-2018), 12-16 October, Antalya-Turkey.

Civalek, Ö., \& Avcar, M. (2020). Free vibration and buckling analyses of CNT reinforced laminated nonrectangular plates by discrete singular convolution method. Engineering with Computers, 1-33. https://doi.org/10.1007/s00366-020-01168-8

Cuong-Le, T., Nguyen, K. D., Nguyen-Trong, N., Khatir, S., Nguyen-Xuan, H., \& Abdel-Wahab, M. (2021). A three-dimensional solution for free vibration and buckling of annular plate, conical, cylinder and cylindrical shell of FG porous-cellular materials using IGA. Composite Structures, 259, 113216. https://doi.org/10.1016/j.compstruct.2020.113216 
D’Aniello, M., Della Corte, G., \& Mazzolani, F. M. (2006, August). Seismic upgrading of RC buildings by buckling restrained braces: experimental results vs. numerical modeling. In Proceedings of Fifth International Conference on Behavior of Steel Structures in Seismic Areas (STESSA 2006).

Dabaon, M., Abdel-Moez, O. M., Salama, M. I., \& Abd ElLateef, T. H. (2001). Buckling Loads of Columns With Gradually Changing Cross-Section Subjected to Combined Axial Loading. In Fourth Alexandria International Conference on Structure and Geotechnical Engineering, Alexandria, Cairo, Egypt.

Demir, Ç., \& Civalek, Ö. (2017). On the analysis of microbeams. International Journal of Engineering Science, 121, 14-33.

https:/www.sciencedirect.com/science/article/abs/pi i/S0020722517313411

Doan, Q. H., Thai, D.-K., \& Tran, N. L. (2020). A Numerical Study of the Effect of Component Dimensions on the Critical Buckling Load of a GFRP Composite Strut under Uniaxial Compression. Materials, 13, 931. https://doi.org/10.3390/ma13040931

Dubina, D., \& Ungureanu, V. (2000). Elastic-plastic interactive buckling of thin-walled steel compression members.

https://scholarsmine.mst.edu/isccss/15iccfss/15iccfss -session4/2/

Eissa, M., Saeed, N. A., \& El-Ganini, W. A. (2014). Saturation-based active controller for vibration suppression of a four-degree-of-freedom rotorAMB system. Nonlinear Dynamics, 76(1), 743-764. https://link.springer.com/article/10.1007/s11071013-1166-3

Engesser, F. (1889). Ober die knickfestigkeit gerader stabe (On the Buckling Strength of Straight Struts) Zeitschrift fur Architektur und Ingenieurwesen.

Esmaeili, A., Ghane, E., Mohammadi, B. (2020). On the use of digital image correlation for translaminar fracture of off-axis composite.

Euler, L. (1744). Methodus inveniendi lineas curvas maximi minimive proprietate gaudentes. Apud Marcum-Michaelem Bousquet.

Fraldi, M., Nunziante, L., Carannante, F., Prota, A., Manfredi, G., \& Cosenza, E. (2008). On the prediction of the collapse load of circular concrete columns confined by FRP. Engineering Structures, 30(11), 3247-3264. https://doi.org/10.1016/j.engstruct.2008.04.036

Goroshko, A., Royzman, V., \& Petraschuk, S. (2020). Simulation of a thin long rod that does not have critical forces and does not lose stability to Euler. Problems of Tribology, 25, 3/97-2020, 25-3 I. https://doi.org/10.31891/2079-1372-2020-97-3-25-31
Hassan, F. F., \& Al-Zaidee, S. R. (2020). Deformation and strength of inclined RC isolated columns using experimental and three-dimensional finite element analyses. IOP Conference Series: Materials Science and Engineering, 745. https://doi.org/10.1088/1757899X/745/1/012129

Hedayat, A. A., Jazebi, E., Asadabadi, S., \& Iranpour, A. (2018). Flexural Strength Prediction of Welded Flange Plate Connections Based on Slenderness Ratios of Beam Elements Using ANN. Advances in Civil Engineering, 1-17. https://doi.org/10.1155/2018/8059190

Hosseinpour, E., Baharom, S. B., \& Yadollahi, Y. (2015). Evaluation of Steel Shear Walls Behavior with Sinusoidal and Trapezoidal Corrugated Plates. Advances in Civil Engineering, 1-11. https://doi.org/10.1155/2015/715163

Isleem, H., Wang, Z., Wang, D., \& Smith, S. (2018). Monotonic and Cyclic Axial Compressive Behavior of CFRP-Confined Rectangular RC Columns. Journal of Composites for Construction, 22. https://doi.org/10.1061/(ASCE)CC.19435614.0000860

Ismail, M. (2011). Evaluating the Dynamical Behavior and Stability of Pipes Conveying Fluid. Thesis for PhD. https://doi.org/10.13140/RG.2.2.34510.87369

Ivanov, A. I. (2019). Vibrations of Shaft Caused by Inertial Excitations. Journal of Mining and Geological Science, 62, 19-24.

Jakab, A., Nehme, K., \& Nehme, S. G. (2016). Fracture Behaviour of Glass Columns Experimental Study of Axial Loaded Glass Columns. 3rd International Conference on Competitive Materials and Technology Processes (IC-CMTP3) IOP Publishing Conf. Series: Materials Science and Engineering 123, 012056. https://doi.org/10.1088/1757$899 X / 123 / 1 / 012056$

Jasiński, F. (1895). Badania nad sztywnością prętów ściskanych (in Polish). Przegląd Techniczny, Warszawa. https://polona.pl/item/badania-nadsztywnoscia-pretowsciskanych,ODM1NTgwMDA/8/\#info:metadata

Johnson, C. G., Jain, U., Hazel, A., Pihler-Puzović, D., \& Mullin, T. (2017). On the buckling of an elastic holey column. Proceedings of the Royal Society A: Mathematical, Physical and Engineering Sciences, 473(2207), 20170477. https://doi.org/10.1098/rspa.2017.0477

Kalamara, R., Bedon, C., \& Eliášová, M. (2016). Experimental investigation for the structural performance assessment of square hollow glass columns. Engineering Structures, 113(4):1-15. https://doi.org/10.1016/j.engstruct.2016.01.028 
Kambe, W., Takahashi, S., Ito, T., \& Aoki, K. (2013). An experimental study on compression resistant performance of thick plywood as an axial member. Journal of Structural and Construction Engineering (Transactions of AIJ). 78. 355-361. https://doi.org/10.3130/aijs.78.355

Kármán, T. (1910). Untersuchungen über Knickfestighkeit. Mitteilungen über Forschungsarbeiten auf dem Gebiete des Ingenieurwesens, 81, Berlin. https://link.springer.com/chapter/10.1007\%2F978-3662-01994-8_1

Khalil, A.-H. (2004). Performance of Hybrid Reinforced Axially Loaded Reinforced Concrete Slender Columns. Ain Shams Engineering Journal, 39(4).

Kılıç, M., \& Çinar, M. (2020). Buckling Behavior of Sulfate-Corroded Thin-Walled Cylindrical Steel Shells Reinforced with CFRP. Iranian Journal of Science and Technology, Transactions of Civil Engineering, 1-16. https://doi.org/10.1007/s40996020-00494-7

Kiss, L. (2020a). Stability of fixed-fixed shallow arches under arbitrary radial and vertical forces. Magazine of Civil Engineering, 95, 31-41. https://doi.org/10.18720/MCE.95.3

Kiss, L. (2020b). Stability of pinned-rotationally restrained arches. Theoretical and Applied Mechanics, 10-10. https://doi.org/10.2298/TAM200402010K

Kudryavtsev, S. (2019). Buckling behavior of steel column with triangularly corrugated web. MATEC Web of Conferences, 279, (23-26), 02007. https://doi.org/10.1051/matecconf/201927902007

Kukhar, V., Artiukh, V., Serduik, O., \& Balalayeva, E. (2016). Form of Gradient Curve of Temperature Distribution of Lengthwise the Billet at Differentiated Heating before Profiling by Buckling. Procedia Engineering, 165, 1693-1704. https://doi.org/10.1016/j.proeng.2016.11.911

Krishan, A. L., Chernysova, E. P., \& Astafyeva, M. A. (2019, December). Behavior of compressed concrete in a glass fiber-reinforced shell. In IOP Conference Series: Materials Science and Engineering (Vol. 687, No. 3, p. 033034). IOP Publishing.

Lepik, Ü. (1999). Bifurcation analysis of elastic-plastic cylindrical shells. International Journal of NonLinear Mechanics, 34(2), 299-311.

https://www.sciencedirect.com/science/article/abs/pi i/S0020746298000328

Li, Z., He, M., Tao, D., \& Li, M. (2015). Experimental buckling performance of scrimber composite columns under axial compression. Composites Part B Engineering 86.

https://doi.org/10.1016/j.compositesb.2015.10.023
Lilkova-Markova, S., \& Dzhupanov, V. (2001). Dynamic Stability of Cantilevered Pipes Supported by Additional Structural Spring Supports. Part 1, Short Pipes. National Congress of TAM, 528-534.

Lilkova-Markova, S., \& Lolov, D. (2018). Multi-Segment Integration Technique for Solving the Stability Problem of an Axially Compressed Column. XVIII Anniversary International Scientific Conference by Construction and Arhitecture VSU'2018.

Lolov, D., \& Lilkova-Markova, S. (2006). Dynamic stability of a curved pipe bent in the arc of a circle on hinge supports at the ends. Sadhana, 31, 537-541. https://doi.org/10.1007/BF02715912.

Łukowicz, A., Deniziak, P., Migda, W., GordziejZagórowska, M., \& Szczepański, M. (2016). Innovative cold-formed GEB section under compression. Chapter in the book: Metal Structures. https://doi.org/10.1201/b21417-14

Mansour, M. M., Ibrahim, S. M., \& Korashy, M. (2019). Analytical Approach for Lateral Torsional Buckling Strength of Triangular Web Profile Steel Beams. International Journal of Scientific and Engineering Research, 10, 321-328.

Maraveas, C., Gernay, T., \& Franssen, J. M. (2018). An equivalent stress method for considering local buckling in beam finite elements in the fire situation. Proceedings of SiF 2018. https://orbi.uliege.be/handle/2268/222702

Massumi, A., Sadeghi, K., \& Moshtagh, E. (2018). Effects of Deviation in Materials' Strengths on the Lateral Strength and Damage of RC Frames. Structural Engineering \& Mechanics, 68, 289-297. https://doi.org/10.12989/sem.2018.68.3.289

Megahed, K. (2016). Experimental and theoretical analysis of concrete encased cold formed steel composite column. Thesis for Master Degree. https://doi.org/10.13140/RG.2.2.20548.48005

Mehrabi, P., Honarbari, S., Rafiei, S., Jahandari, S., \& Bidgoli, M. A. (2021). Seismic response prediction of FRC rectangular columns using intelligent fuzzy-based hybrid metaheuristic techniques. Journal of Ambient Intelligence and Humanized Computing, 1-19. https://doi.org/10.1007/s12652-020-02776-4

Melo, W. I. G., \& Barbosa, N. P. (2020). Dynamic Modeling of Metal Columns with Open Thin-Walled Sections. International Journal of Steel Structures, 20. https://doi.org/10.1007/s13296-020-00326-4

Milašinović, D. D., Vlajić, L. M., \& Miličić, I. M. (2003). Prediction of buckling curves of steel columns using by rheological analogy. Materijali i Konstrukcije, 46(3-4), 8-13. http://scindeks.ceon.rs/article.aspx artid=054307980304008M 
Mohabeddine, A. I., Correia, J. A. F. O., \& Castro, J. (2020). Evaluation of Rotation Capacity of Steel Wide Flange Members Subjected to Lateral Cyclic Loading. 17th World Conference on Earthquake Engineering, Sendai, Japan.

Mondal, J., \& Chatterjee, S. (2021). Controlling self-excited vibration of a nonlinear beam by nonlinear resonant velocity feedback with time-delay. International Journal of Non-Linear Mechanics, 131, 103684. https://doi.org/10.1016/j.ijnonlinmec.2021.103684

Murawski, K. (1992). Stability of thin shell columns in elasto-plastic states. 14 Międzynarodowe Sympozjum Naukowe Studentów i Młodych Pracowników Nauki. Mechanika, Zielona Góra, 38-43.

Murawski, K. (1999). The Modelling of Energy Consuming Process in Layered Vehicles Bumper (in Polish), Doctor's thesis. Poznan University of Technology, Faculty of Hardworking Machines and Vehicles.

Murawski, K. (2002a). The Engesser-Shanley modified theory of stability of thin-walled cylindrical rods with example of use for steel St35. Acta Scientiarum Polonorum, Architectura, 1-2.

Murawski, K. (2002b). Stability analysis of a thin-walled plywood cylindrically shaped element. Annals of Warsaw Agricultural University, Forestry and Wood Technology, Special Number I, Warsaw Agricultural University Press, Warsaw, 230-234.

Murawski, K. (2003a). Theory of stability of layered cylindrical rods in elasto-plastic states exemplified by steel R35. Electronic Journal of Polish Agricultural Universities. Civil Engineering, 2(6).

Murawski, K. (2003b). Stability analysis in elastic states of very slender cylindrical shaped plywood compressed by balls. Annals of Warsaw Agricultural University, Forestry and Wood Technology, 53, 257-260.

Murawski, K. (2003c). Stability analysis of layered cylindrical plywood shape. Annals of Warsaw Agricultural University, Forestry and Wood Technology, (53), 252-256.

Murawski, K. (2003d). Stresses and strains analysis in elastic states of very slender cylindrical shaped plywood compressed by balls. Ann. Warsaw Agric. Univ. SGGW-AR, For Wood Technol, 53, 247-251.

Murawski, K. (2004a). Stability analysis in elastic states of very slender rods fixed by one end with stresses and strains analysis as exemplified by cylindrical shaped plywood made of birch. Acta Scientiarum Polonorum, Silvarum Colendarum Ratio et Industria Lignaria, 3(1), 2004.

Murawski, K. (2004b). The Euler's modified theory of stability with stresses and strains analysis on example of very slender cylindrical shells made of steel. Acta Scientiarum Polonorum, Architectura, 3(1), 2004.
Murawski, K. (2004c). Stability analysis in elastic states of very slender square-shaped plywood tube compressed by ball-and-socket joints. Annals of Warsaw Agricultural University, Forestry and Wood Technology, Number 55, Warsaw Agricultural University Press, Warsaw, 383-386.

Murawski, K. (2004d). Stresses and strains analysis in elastic states of very slender square-shaped plywood compressed by ball-and-socket joints. Annals of Warsaw Agricultural University, Forestry and Wood Technology, Number 55, Warsaw Agricultural University Press, Warsaw, 387-391.

Murawski, K. (2004e). Finite Element Method Analysis of stability in elastic states of very slender cylindrical shaped plywood compressed by balls. Annals of Warsaw Agricultural University, Forestry and Wood Technology, (55), 373-377.

Murawski, K. (2004f). Finite Element Method Postbuckling Analysis of stresses and strains in elastic states of very slender cylindrically-shaped plywood compressed by ball-and-socket joints. Annals of Warsaw Agricultural University, Forestry and Wood Technology, Number 55, Warsaw Agricultural University Press, Warsaw, 378-382.

Murawski, K. (2005). Stability analysis in elastic states of compressed very slender square shaped plywood tube fixed by one end. Roczniki Akademii Rolniczej w Poznaniu CCCLXVIII, Technol. Drewn, 40, 51-59.

Murawski, K. (2007a). Movement of the neutral layer during lose of stability in the critical cross section of very slender cylindrical shaped plywood compressed by ball-and-socket joints. Annals of Warsaw University of Life Sciences-SGGW. Forestry and Wood Technology, 62.

Murawski, K. (2007b). Finite Element Method Postbuckling Analysis of stresses and strains in elastic states of very slender cylindrical shaped plywood compressed by balls. Annals of Warsaw University of Life Sciences-SGGW, Forestry and Wood Technology 62, 62-66.

Murawski, K. (2008a). Critical stress of squat cylindrical and square shaped plywood made of birch compressed by ball-and-socket joints according to the EngesserKármán-Shanley's modified hypothesis, Annals of Warsaw University of Life Sciences - SGGW Forestry and Wood Technology, 64, 116-119.

Murawski, K. (2008b). Critical stress of squat cylindrical and square shaped plywood made of birch compressed by ball-and-socket joints according to the Ylinen hypothesis Annals of Warsaw University of Life Sciences-SGGW Forestry and Wood Technology, 64, $120-123$ 
Murawski, K. (2008c). Critical stress of squat cylindrical and square shaped plywood made of birch compressed by ball-and-socket joints according to the Březina's hypothesis, Annals of Warsaw University of Life Sciences-SGGW Forestry and Wood Technology, 64, 124-126.

Murawski, K. (2008d). Critical stress of squat cylindrical and square shaped plywood compressed by ball-andsocket joints according to the Tetmajer-Jasiński hypothesis. Annals of Warsaw University of Life Sciences - SGGW Forestry and Wood Technology No 64, 2008, 113-115.

Murawski, K. (2008e). Critical stress of squat cylindrical and square shaped plywood compressed by ball-andsocket joints according to the Johnson-Ostenfeld hypothesis, Krzysztof Murawski, Annals of Warsaw University of Life Sciences - SGGW Forestry and Wood Technology No 64, 2008, 127-129. http://agro.icm.edu.pl/agro/element/bwmeta1.eleme nt.agro-f24911b1-dd1b-45c0-bd63-8668786cd878

Murawski, K. (2011a). Teoria technicznej stateczności smukłych prętów sklejkowych. Oficyna Wydawnicza Politechniki Warszawskiej. ISBN 978-83-7207-959-6

Murawski, K. (2011b). Theory of Technical Stability of Slender Plywood Rods. Publishing House of Warsaw University of Technology, ISBN 978-837207-968-8.

Murawski, K. (2011c). Modelowanie procesu pochłaniania energii w warstwowych zderzakach. Oficyna Wydawnicza Politechniki Warszawskiej, ISBN: 978-83-7207-973-2

Murawski, K. (2017a). Modelling of the Energyabsorptive Process in Layered Bumpers. Lulu Press, Inc. ISBN 978-1-387-37333-8.

Murawski, K. (2017b). Technical stability of continuously loaded thin-walled slender columns. ISBN 978-1-387-36762-7.

Murawski, K. (2018). Technical Stability of Very Slender Thin-walled Orthotropic Columns. ISBN 978-0-359-01937-3.

Murawski, K. (2019). Stability, shell stress and strain technical analysis in elastic states of very slender rectangular column compressed by ball-and-socket joints without friction.

https://doi.org/10.13140/RG.2.2.28299.64808

Murawski, K. (2020a). Lateral Buckling in Elastic-plastic States of Thin-walled Semi-slender Columns Made of Steel R35 According to Known Hypotheses. https://doi.org/10.13140/RG.2.2.23578.59845

Murawski, K. (2020b). Experimental Results of Lateral Buckling of Thin-walled Semi-slender Columns with Pinned Ends Made of Steel R35 in the Elastic-plastic States in Comparison to the Known Hypotheses. https://doi.org/10.13140/RG.2.2.21559.75688
Murawski, K. (2020c). Comparison of the Known Hypotheses of Lateral Buckling in the ElasticPlastic States of Thin-Walled Semi-Slender Columns. International Journal of Structural Glass and Advanced Materials Research, 4(1), 233-253. https://doi.org/10.3844/sgamrsp.2020.233.253

Murawski, K. (2021). Technical Buckling, Stress and Strain Simplified Analysis of Semi-slender Thinwalled Cylindrical Pinned Column. https://doi.org/10.13140/RG.2.2.27295.89761

Murawski, K., \& Kłos, R. (2007). Experimental determining of extensions during test of stability of the rode $870 \times \phi 12 \mathrm{~mm}$ made of pine compressed by ball-and-socket joints. Ann. Warsaw Agricult. Univ.-SGGW, For and Wood Technol, 62, 70-72.

Nakashima, M., Iwai, S., Iwata, M., Takeuchi, T., Konomi, S., Akazawa, T., \& Saburi, K. (1994). Energy dissipation behavior of shear panels made of low yield steel. Earthquake Engineering \& Structural Dynamics, 23, 1299-1313. https://doi.org/10.1002/eqe.4290231203

Nam, V. H., Vinh, P. V., Chinh, N. V., Thom, D., \& Hong, T. T. (2019). A New Beam Model for Simulation of the Mechanical Behaviour of Variable Thickness Functionally Graded Material Beams Based on Modified First Order Shear Deformation Theory. Materials, 12, 404. https://doi.org/10.3390/ma12030404

Naseri, R., Showkati, H., \& Firouzsalari, S. E. (2020). Buckling behaviour of GFRP cylindrical shells subjected to axial compression load. Composite Structures.

https://doi.org/10.1016/j.compstruct.2020.113269

Nazarimofrad, E., \& Shokrgozar, A. (2019). Seismic performance of steel braced frames with selfcentering buckling-restrained brace utilizing superelastic shape memory alloys. The Structural Design of Tall and Special Buildings, 28. https://doi.org/10.1002/tal.1666

Noaman, A. (2011). Elastic Buckling of Slender Non Prismatic Piles Partially or Completely Embedded in Elastic Foundation Soil Using the Finite Differences Method. Iraqi Journal of Civil Engineering, 7, 13-20.

Ostenfeld, A. (1898). Exzentrische und zentrische Knickfestigkeit. VDI-Z, 94, 1462-1470.

Özbaşaran, H., Aydın, R., \& Dogan, M. (2015). An alternative design procedure for lateral-torsional buckling of cantilever I-beams. Thin-Walled Structures, 90, 235-242. https://doi.org/10.1016/j.tws.2015.01.021

Oliveira, T. V., Dias, C. A. C., Sousa, R. A., Pasquetti, E., \& Souza, R. M. D. (2017). Analytical study of the shear effect on the buckling of columns on elastic medium. https://doi.org/10.20906/CPS/CILAMCE2017-0274 
Papanastasiou, P., \& Durban, D. (1999). Bifurcation of elastoplastic pressure-sensitive hollow cylinders.

Patel, V. I., Liang, Q. Q., \& Hadi, M. N. (2015). Nonlinear analysis of concrete-filled steel tubular columns. https://ro.uow.edu.au/eispapers/4778/

Pearson, C. E. (1950). Bifurcation criterion and plastic buckling of plates and columns. Journal of the Aeronautical Sciences, 17(7), 417-424. https://arc.aiaa.org/doi/abs/10.2514/8.1674?journalC ode=jans

Phungpaingam, B., Athisakul, C., \& Chucheepsakul, S. (2011). Alternative Model for Postbuckling Analysis of a Nonlinearly Elastic Column. 16th National Convention in Civil Engineering. Chonburi, Thailand, Volume: STR0038.

Pinarbasi, S., Genc, T., Akpinar, E., \& Okay, F. (2020). Comparison of Design Guidelines for Hot-Rolled IShaped Steel Compression Members according to AISC 360-16 and EC3. Advances in Civil Engineering, 1-20. https://doi.org/10.1155/2020/6853176

Qays, S., \& Al-Zuhairi, A. (2020). Structural Performance of Slender RC Columns with Cross and Square-Shaped under Compression Load. IOP Conference Series: Materials Science and Engineering, 881, 012040. https://doi.org/10.1088/1757-899X/881/1/012040

Qi, Y., Xie, L., Bai, Y., Liu, W., \& Fang, H. (2019). Axial Compression Behaviours of Pultruded GFRPWood Composite Columns. Sensors, 19(4), 755. https://doi.org/10.3390/s19040755

Raheem, S. E. A., Seed, F. K. A., Ahmed, H. H., \& Gamal, Y. (2013). Dynamic Non-Linear Behaviour of Cable Stayed Bridges Under Seismic Loading. Life Science Journal, $10 . \quad 3725-3741$. https://doi.org/10.21608/jesaun.2014.114273

Rajkannu, S., \& Sanjeevi, A. J. (2020). Flexuraltorsional buckling strength of thin-walled channel sections with warping restraint. Journal of Constructional Steel Research, 169, 106041. https://doi.org/10.1016/j.jcsr.2020.106041

Razdolsky, A. G. (2018). Determination of Slenderness Ratio for Laced and Battened Columns. Practice Periodical on Structural Design and Construction, 23(4). https://doi.org/10.1061/(ASCE)SC.19435576.0000383

Rostami, S. A. L., \& Kolahdooz, A. (2019). Experimental and FEM Analysis of Ribs Defects on Composite Lattice Cylindrical Shells.

Roy, K., Ting, T. C. H., Lau, H. H., \& Lim, J. B. P. (2019). Experimental and numerical investigations on the axial capacity of cold- formed steel built-up box sections. Journal of Constructional Steel Research. https://doi.org/10.1016/j.jcsr.2019.05.038
Saberi, H., Kolmizadeh, V., Mokhtari, A., \& Saberi, V. (2020). Investigating of the Effect of Concrete Confinement on the Axial Performance of Circular Concrete Filled Double-Skin Steel Tubular (CFDST) Long Columns. https://doi.org/10.22075/JRCE.2020.19167.1362

Saeed, N. A. (2019). On vibration behavior and motion bifurcation of a nonlinear asymmetric rotating shaft. Archive of Applied Mechanics, 89(9), 1899-1921. https://link.springer.com/article/10.1007/s00419$019-01551-\mathrm{y}$

Saeed, N. A. (2020). On the steady-state forward and backward whirling motion of asymmetric nonlinear rotor system. European Journal of MechanicsA/Solids, 80, 103878.

https://www.sciencedirect.com/science/article/abs/pi i/S0997753819304978

Saeed, N. A., \& Eissa, M. (2018). Bifurcations of periodic motion of a horizontally supported nonlinear Jeffcott rotor system having transversely cracked shaft. International Journal of Non-Linear Mechanics, 101, 113-130.

https://www.sciencedirect.com/science/article/abs/pi i/S0020746217308508

Saeed, N. A., \& Eissa, M. (2019). Bifurcation analysis of a transversely cracked nonlinear Jeffcott rotor system at different resonance cases. Insertional Journal Accusation Vibe, 24(2), 284-302.

Saeed, N. A., Awwad, E. M., EL-meligy, M. A., \& Nasr, E. A. (2021a). Analysis of the rub-impact forces between a controlled nonlinear rotating shaft system and the electromagnet pole legs. Applied Mathematical Modelling, 93, 792-810. https://www.sciencedirect.com/science/article/abs/pi i/S0307904X21000160

Saeed, N. A., Awwad, E. M., El-Meligy, M. A., \& Nasr, E. A. (2021b). Sensitivity analysis and vibration control of asymmetric nonlinear rotating shaft system utilizing 4-pole AMBs as an actuator. European Journal of Mechanics-A/Solids, 86, 104145.

https://www.sciencedirect.com/science/article/abs/pi i/S0997753820305325

Saeed, N. A., Awwad, E. M., El-Meligy, M. A., \& Nasr, E. S. A. (2020a). Radial Versus Cartesian Control Strategies to Stabilize the Nonlinear Whirling Motion of the Six-Pole Rotor-AMBs. IEEE Access, 8, 138859-138883.

https://ieeexplore.ieee.org/abstract/document/9151120/

Saeed, N. A., Mahrous, E., \& Awrejcewicz, J. (2020b). Nonlinear dynamics of the six-pole rotor-AMB system under two different control configurations. Nonlinear Dynamics, 101(4), 2299-2323. https://link.springer.com/article/10.1007/s11071020-05911-0 
Saeed, N. A., Mohamed, M. S., \& Elagan, S. K. (2020c). Periodic, Quasi-Periodic and Chaotic Motions to Diagnose a Crack on a Horizontally Supported Nonlinear Rotor System. Symmetry, 12(12), 2059. https://www.mdpi.com/2073-8994/12/12/2059

Saingam, P., Sutcu, F., Terazawa, Y., Fujishita, K., Lin, P.-C., Celik, O., \& Takeuchi, T. (2020). Composite behavior in RC buildings retrofitted using bucklingrestrained braces with elastic steel frames. Engineering Structures, 219, 110896. https://doi.org/10.1016/j.engstruct.2020.110896

Sanchez, H., \& Salas, C. C. (2008). Deformation of Steel Straight Pipes With Internal Pressure Under Axial Compression and Bending Load by Seismic Action. Proceedings of the International Conference on Offshore Mechanics and Arctic Engineering - OMAE, 3. https://doi.org/10.1115/OMAE2008-57491

Selvaraj, S., \& Madhavan, M. (2021). Design of coldformed steel built-up columns subjected to localglobal interactive buckling using direct strength method. Thin-Walled Structures, 159, 107305. https://doi.org/10.1016/j.tws.2020.107305

Seyranian, A. P., \& Privalova, O. G. (2003). The Lagrange problem on an optimal column: Old and new results. Structural and Multidisciplinary Optimization, 25(5), 393-410.

https://doi.org/10.1007/s00158-003-0333-4

Shanley, F. R. (1947). Inelastic column theory. Journal of the Aeronautical Sciences, 14(5), 261-268. https://arc.aiaa.org/doi/abs/10.2514/8.1346

Silvestre, N., Abambres, M., \& Camotim, D. (2018). Influence of the deformation mode nature on the $1 \mathrm{st}$ order post-yielding strength of thin-walled beams. Thin-Walled $\quad$ Structures, 128, 71-79. https://www.sciencedirect.com/science/article/abs/pi i/S0263823117301684

Simão, P. D., Rodrigues, J. P., Barros, H., Ferreira, C., Adam, J. M., \& Delatte, N. (2019). GBT RayleighRitz analysis of slender elasto-plastic steel columns under fire conditions. In Proceedings of the 3rd International Conference on Recent Advances in Nonlinear Design Resilience and Rehabilitation of StructuresCOIMBRA (pp. 436-447).

Slimani, A., Ammari, F., \& Adman, R. (2018). The effective length factor of columns in unsymmetrical frames asymmetrically loaded. Asian Journal of Civil Engineering 19(4). https://doi.org/10.1007/s42107-018-0038-z

Słowiński, K., \& Piekarczyk, M. (2017). Determination of the plastic limit load for a cylindrical shell under general loading conditions using FEA. https://suw.biblos.pk.edu.pl/resourceDetailsBPP\&r $\mathrm{Id}=75598$
Sofiyev, A. H., \& Avcar, M. (2010). The stability of cylindrical shells containing an FGM layer subjected to axial load on the Pasternak foundation. Engineering, 2(04), 228.

Sofiyev, A. H., Schnack, E., Deniz, A., Zerin, Z., \& Avcar, M. (2012). Stability analysis of FGM layered shells in the surrounding medium. Acta Physica Polonica-Series A General Physics, 121(1), 162.

Sofiyev, A., Aksogan, O., Schnack, E., \& Avcar, M. (2008). The stability of a three-layered composite conical shell containing a FGM layer subjected to external pressure. Mechanics of Advanced Materials and Structures, 15(6-7), 461-466.

Solazzi, L., 2010. Experimental evaluation of the buckling phenomena in the new joint design for upper deck structure of a bridge. EPJ Web of Conferences, 6. https://doi.org/10.1051/epjconf/20100608001

Taraghi, P., Zirakian, T., Karampour, H., 2021. Parametric study on buckling stability of CFRPstrengthened cylindrical shells subjected to uniform external pressure. Thin-Walled Structures, 161. https://doi.org/10.1016/j.tws.2020.107411

Tarsha, I., \& Takla, M. (2016). Ultimate load for composite column subjected to ISO 834 fire. https://www.researchgate.net/publication/33247073 1_Ultimate_load_for_composite_column_subjected _to_ISO_834_fire

Terazawa, Y., Suma, K., Iwanaga, M., Maehara, S., \& Takeuchi, T. (2020). Buckling Strength of Latticed Domes of Grid-Purlin With Beams. AIJ Journal of Technology and Design, 26, 899-904. https://doi.org/10.3130/aijt.26.899

Tetmajer, L. (1886). Mittheilungen der Anstalt zur Prüfung von Baumaterialien am eidg. Polytechnikum in Zürich. 1.Heft: Methoden und Resultate der Prüfung natürlicher und künstlicher Bausteine, Zürich.

Than, C., Hai, L. V., Vo, H. N., Nguyen, V., Bui, V. N., Thi, T. M., \& Ang, K. K. (2018). A Moving Element Method for the Dynamic Analysis of Composite Plate Resting on a Pasternak Foundation Subjected to a Moving Load. International Journal of Computational Methods, 16 https://doi.org/10.1142/S0219876218501244

Thumrongvut, J., \& Tiwjantuk, P. (2018). Strength and Axial Behavior of Cellular Lightweight Concrete-Filled Steel Rectangular Tube Columns under Axial Compression. Materials Science Forum. 941. 2417-2422.

https://doi.org/10.4028/www.scientific.net/MSF.941 .2417

Toufik, B., Ammari, F., \& Adman, R. (2018). Influence of load position on critical lateral torsional buckling moment of laterally restrained beam at tense flange. Asian Journal of Civil Engineering 19(02). https://doi.org/10.1007/s42107-018-0067-7 
Viana, H., Lanna, R., Costa, R., \& Lavall, A. (2020). Formulation for nonlinear dynamic analysis of steel frames considering the plastic zone method. Engineering Structures, 223. https://doi.org/10.1016/j.engstruct.2020.111197

Virgens, J., Gomes, R., Trautwein, L., Guimarães, G., \& Vaz, A. (2019). Experimental analysis of eccentrically loaded reinforced concrete columns with an added jacket of self-compacting concrete. Revista IBRACON de Estruturas e Materiais, 12, 329-336. https://doi.org/10.1590/s198341952019000200007

Voyiadjis, G. Z., \& Woelke, P. (2008). Elasto-plastic and damage analysis of plates and shells. Springer Science \& Business Media.

Wahrhaftig, A. D. M. (2020). Time-dependent analysis of slender, tapered reinforced concrete columns. Steel and Composite Structures, 36(2), 229-247. https://doi.org/10.12989/SCS.2020.36.2.229

Wahrhaftig, A. D. M., Brasi, R. M. L. R. F., \& Machado, M.A.S. (2008). Evaluation of the Buckling Critical Load of Bars Subjected to their Self-Weight. The Ninth International Conference on Computational Structures Technology. https://doi.org/10.4203/ccp.88.13

Wahrhaftig, A. D. M., Brasil, R. M. L. R. F., \& César, S. F. (2016). Creep in the fundamental frequency and stability of a slender wooden column of composite section. https://doi.org/10.1590/010067622016000600018

Wahrhaftig, A. D. M., Magalhães, K. M. M., \& Nascimento, L. S. M. S. C. (2021). Stress assessment in reinforcement for columns with concrete creep and shrinkage through Brazilian technical normative. Journal Braz. Socology Mechicen Science Engerning, 43, 6. https://doi.org/10.1007/s40430-020-02731-6

Wahrhaftig, A. D. M., Silva, M. A., \& Brasil, R. M. L. R. F. (2019). Analytical determination of the vibration frequencies and buckling loads of slender reinforced concrete towers. Latin American Journal of Solids and Structures, 16. https://doi.org/10.1590/1679-78255374

Wahrhaftig, A. D. M., Magalhaes, K., \& Siqueira, G. H. (2020a). Evaluation of limit state of stress and strain of free-fixed columns with variable geometry according to criteria from the Brazilian code for concrete structures. Latin American Journal of Solids and Structures, 17. https://doi.org/10.1590/1679-78255780
Wahrhaftig, A. M., Magalhaes, K., Brasil, R. M. L. R. F., \& Murawski, K. (2020b). Evaluation of Mathematical Solutions for the Determination of Buckling of Columns Under Self-weight. https://doi.org/10.1007/s42417-020-00258-7

Wankhade, R., \& Bendine, K. (2017). Optimal shape control of piezolaminated beams with different boundary condition and loading using genetic algorithm. International Journal of Advanced Structural Engineering (IJASE), 9, 375-384. https://doi.org/10.1007/s40091-017-0173-X

Yiotis, A., Katsikadelis, J., \& Kounadis, A. (1982). Stability Analysis of Box-Shaped Structures of Rectangular Cross-Section. Revue Roumaine des Sciences Techniques. Serie Mecanique Appliquee. 27. 681-695.

https://www.researchgate.net/publication/25640479 6_Stability_Analysis_of_Box-

Shaped_Structures_of_Rectangular_Cross-Section

Zaki, N., 2021. Numerical parametric study on lateral torsional buckling of $\mathrm{T}$-shaped beams containing openings. Xi'an Jianzhu Keji Daxue Xuebao/Journal of Xi'an University of Architecture \& Technology, XIII.

Zhang, J., Ullah, S., Gao, Y., Avcar, M., \& Civalek, O. (2020). Analysis of orthotropic plates by the twodimensional generalized FIT method. Computers and Concrete, 26(5), 421-427. https://www.koreascience.or.kr/article/JAKO202033 064088382.jsp-

$\mathrm{kj}=\mathrm{SSMHB} 4 \& \mathrm{py}=2012 \& \mathrm{vnc}=\mathrm{v} 27 \mathrm{n} 6 \& \mathrm{sp}=588$

Zhou, L., Tang, J., Wang, W., Zhao, E., Ren, S., Zhang, Q., \& Liu, P. (2019). An accurate method for the calculation of ultimate load in lattice boom. Advances in Mechanical Engineering, 11, 168781401988677. https://doi.org/10.1177/1687814019886774

Zucco, G., Oliveri, V., Rouhi, M., Telford, R., Peeters, M. J. D., Clancy, G., McHale, C., O'Higgins, R. M., Young, T., \& Weaver, P. M. (2019). Static Test of a Variable Stiffness Thermoplastic Composite Wingbox under Shear, Bending and Torsion.. Aeronautical Journal, -New Series-. https://doi.org/10.1017/aer.2019.161 